\title{
Tunisia: Report on the Observance of Standards and Codes-Data Module; Response by the Authorities; and Detailed Assessments Using the Data Quality Assessment Framework
}

This Report on the Observance of Standards and Codes on Data Module for Tunisia was prepared by a staff team of the International Monetary Fund as background documentation for the periodic consultation with the member country. It is based on the information available at the time it was completed on July 27, 2006. The views expressed in this document are those of the staff team and do not necessarily reflect the views of the government of Tunisia or the Executive Board of the IMF.

The Response by the Authorities on this report, and the Detailed Assessments Using the Data Quality Assessment Framework (DQAF) are also included.

The policy of publication of staff reports and other documents by the IMF allows for the deletion of market-sensitive information.

To assist the IMF in evaluating the publication policy, reader comments are invited and may be sent by e-mail to publicationpolicy@imf.org.

$$
\begin{gathered}
\text { Copies of this report are available to the public from } \\
\text { International Monetary Fund • Publication Services } \\
70019^{\text {th }} \text { Street, N.W. • Washington, D.C. } 20431 \\
\text { Telephone: (202) 623-7430 • Telefax: (202) 623-7201 } \\
\text { E-mail: publications@imf.org • Internet: http://www.imf.org }
\end{gathered}
$$

Price: $\$ 15.00$ a copy

\section{International Monetary Fund Washington, D.C.}



INTERNATIONAL MONETARY FUND

TUNISIA

\section{Report on the Observance of Standards and Codes (ROSC)—Data Module}

Prepared by the Statistics Department

Approved by Robert W. Edwards and Mohsin S. Khan

July 27,2006

The Report on the Observance of Standards and Codes (ROSC) data module provides an assessment of Tunisia's macroeconomic statistics against the Special Data Dissemination Standard (SDDS) complemented by an assessment of data quality based on the IMF's Data Quality Assessment Framework (DQAF July 2003). The DQAF lays out internationally accepted practices in statistics, ranging from good governance in data producing agencies to practices specific to datasets.

The datasets covered in this report are national accounts, government finance, monetary, and balance of payments statistics. The agencies that compile the datasets assessed in this report are the National Statistics Institute (INS), the Ministry of Finance (MF), and the Central Bank of Tunisia (BCT).

The datasets to which this report pertains can be accessed in print and on the Internet:

INS: $\quad$ http://www.ins.nat.tn

BCT: $\quad \underline{\text { http://www.bct.gov.tn }}$

This report is based on information provided prior to and during a staff mission that took place during April 7-22, 2005, as well as on publicly available information. The mission team from the IMF Statistics Department comprised Messrs. Georgiou (Head), Abdallah, Galand, Khay, Ms. Matei (all STA), and Ms. Diaz-Zelaya (STA Administrative Assistant). 


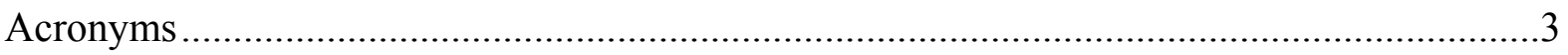

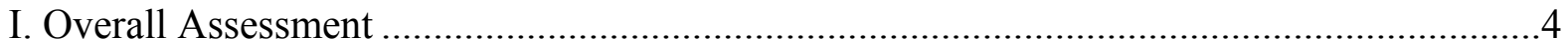

II. Assessment by Agency and Dataset............................................................................

III. Staff's Recommendations ........................................................................................ 18

Tables

1. Data Quality Assessment Framework July 2003-Summary Results............................10

2a. Assessment of Data Quality-Dimensions 0 and 1-National Statistics Institute..........11

2b. Assessment of Data Quality—Dimensions 0 and 1- Ministry of Finance .....................12

2c. Assessment of Data Quality—Dimensions 0 and 1 - Central Bank of Tunisia ...............13

3a. Assessment of Data Quality—Dimensions 2 to 5-National Accounts...........................14

3b. Assessment of Data Quality-Dimensions 2 to 5-Government Finance Statistics .......15

3c. Assessment of Data Quality-Dimensions 2 to 5-Monetary Statistics.........................16

3d. Assessment of Data Quality—Dimensions 2 to 5-Balance of Payments Statistics ......17

Appendix

I. Practices Compared to the SDDS Coverage, Periodicity, and Timeliness of Data ........22 


\section{ACRONYMS}

1968 SNA

1984 Guide

1993 SNA

BCT

BOP

BPM5

CNS

DGRE

DGGD

DQAF July 2003

DSBB

EPA

GDP

GFS

GFSM 1986

GFSM 2001

IIP

IMF

INS

ISWGNA

ITRS

JORT

MFSM

$\mathrm{MF}$

ODCs

QFSB

ROSC

SDDS

SNS

STA

VAT
System of National Accounts 1968

Draft Guide to Money and Banking Statistics in International

Financial Statistics (December 1984)

System of National Accounts 1993

Central Bank of Tunisia

Balance of Payments

Balance of Payments Statistics Manual, fifth edition

National Council on Statistics

General Directorate of Revenue and Budget

General Directorate of Debt Management

Data Quality Assessment Framework, July 2003 version

Dissemination Standards Bulletin Board

Public administrative units

Gross Domestic Product

Government Finance Statistics

A Manual on Government Finance Statistics, 1986

Government Finance Statistics Manual 2001

International Investment Position

International Monetary Fund

National Statistics Institute

Inter-Secretariat Working Group on National Accounts

International Transactions Reporting System

Journal Officiel de la République Tunisienne

Monetary and Financial Statistics Manual

Ministry of Finance

Other Depository Corporations

Quarterly Financial Statistics Bulletin (BCT)

Report on the Observance of Standards and Codes

Special Data Dissemination Standard

National Statistical System

IMF Statistics Department

Value Added Tax 


\section{Overall ASSESSMent}

1. The quality of macroeconomic statistics in Tunisia has improved over the past decade, and the statistics have been broadly adequate for macroeconomic analysis and policy design and monitoring. The Tunisian authorities have demonstrated their commitment to the quality of macroeconomic statistics by their subscription to the Special Data Dissemination Standard (SDDS) and the related significant steps they have taken, as well as their support to the preparation of this Report on the Observance of Standards and Codes (ROSC). The authorities are currently creating the conditions for accelerating the development of the financial system and moving towards full capital account convertibility. At the same time, they are focusing on managing the domestic macroeconomic environment with a view to achieving sustainable growth and employment gains. In this context, there is a need to pursue plans to further improve the quality of the country's statistics through, inter alia, a closer alignment with internationally accepted standards and good practices. Some of these plans have already been clearly articulated and are in the process of being implemented, while others need to be fleshed out in the period ahead. To achieve the above mentioned macroeconomic objectives, there is also a need to give greater weight to the accessibility of statistics.

2. Tunisia has a broadly effective legal and institutional framework, as well as a culture of good practices, that together support the quality of macroeconomic statistics. The staff resources available for statistical work in all areas are not fully adequate, and especially for government finance statistics (GFS). The work of all statistical agencies is based on professionalism, transparency, and adherence to ethical standards. Official statistics follow methodologies, which in most areas need to be updated. In particular, there is a need to complete the adoption of 1993 SNA for the national accounts, implement the plan to adopt the recommendations of the Monetary and Financial Statistics Manual (MFSM), and put forward a plan to adopt the methodology recommended in the Government Finance Statistics Manual 2001 (GFSM 2001). Tunisia's macroeconomic statistics are, to a large extent, reconcilable within each dataset and with other datasets. There are opportunities to improve the dissemination of statistics as well as information on methodology and assistance available to users in most assessed areas, and particularly in GFS.

3. Tunisia subscribed to the SDDS on June 20, 2001 and started posting its metadata on the Dissemination Standards Bulletin Board (DSBB) on the same date. Tunisia is in observance of the SDDS, meeting the specifications for coverage, periodicity, timeliness, as well as for the dissemination of advance release calendars. However, coverage of international reserves and foreign currency liquidity only partly meets SDDS requirements. Tunisia uses the flexibility options on the timeliness of the national accounts and on the periodicity and timeliness of employment and unemployment data. The metadata for these indicators do not specify any plans for improvement to meet the relevant SDDS requirements. While Tunisia has posted summary methodology pages for most data categories, preparatory work on several other data categories (employment, unemployment, interest rates, stock market share price index, exchange rate, and population) could be accelerated. Tunisia regularly updates its advance release calendar for all data categories, 
which is also posted on the DSBB. Appendix I provides an overview of Tunisia's dissemination practices compared to the SDDS.

4. Section II of this ROSC-Data Module provides a summary assessment by agency and dataset based on a four-part scale. This is followed by staff recommendations in Section III. Practices compared to the SDDS are summarized in Appendix I. The authorities' response to this report and a volume of detailed assessments are presented in separate documents.

5. In applying the IMF's Data Quality Assessment Framework (DQAF July 2003), the remainder of this section presents the mission's main conclusions. The presentation is done at the level of the DQAF's quality dimensions, by agency for the first two dimensions and by dataset for the remaining four.

\section{Prerequisites of Quality and Assurances of Integrity}

6. Tunisia's law on the National Statistical System (SNS) provides a proper environment for the production of official statistics at the national level, where the National Statistics Institute (INS) is the central body. The institutional coordination and planning of statistical activities is ensured by the National Council on Statistics (CNS), which is an advisory body whose membership comprises both producers and users of statistics. As the central executive body of the SNS, the INS ensures the technical coordination of statistical activities. There is an adequate practice of data exchange among the INS and the other government agencies. The law establishes the compulsory and confidential character of data reporting to the INS. Resources allocated to the INS for the conduct of surveys, as well as for equipment, are broadly sufficient, but staff resources are too limited. Users' feedback is sought by the INS in a wide variety of ways. The INS strives to improve the quality of its statistics and to meet international standards - all in the framework of its work program that is part of a five-year national statistical plan. Legal framework and actual practices support the independence of the INS in its work and the professionalism of its staff, who are subject to the statute of civil servants. However, the terms and conditions under which statistics are collected, processed, and disseminated, as well as the relevant metadata, are not as fully available to the domestic public as they could be.

7. Tunisia's legal framework clearly assigns the responsibility of collecting, processing, and disseminating GFS to the Ministry of Finance (MF). The MF compiles data on budget execution and debt in accordance with the Organic Budget Law. As mentioned above, there is firm legal basis for the coordination of agencies in the SNS by means of the CNS. Actual data-sharing and coordination between the MF and other agencies are satisfactory. The Directorate in charge of budget statistics is seriously understaffed but otherwise adequately equipped. The MF values the quality of its statistics, but improvements in GFS on the basis of consultation with users (including via MF's participation in the CNS) could be sought more actively. MF staff are professional and generally well-trained, and subject to the statute of civil servants. The MF does not adequately disseminate methodological information or publicize the terms and conditions under which GFS are produced and disseminated, hampered inter alia by personnel shortages and the absence of a MF website. 
8. The Central Bank of Tunisia (BCT) is responsible for the collection, processing, and dissemination of monetary and balance of payments statistics. As noted above, the law provides for the coordination of BCT with other agencies, and actual data-sharing between the agencies is satisfactory. The compulsory aspect of data reporting to the BCT is provided for in the legal framework. The relevance of BCT's statistics is safeguarded by consultations within the context of the CNS as well as with other data users. BCT closely monitors and assesses its own statistical work against standards. Staff - although well trained and professional - and computer software are not fully adequate. The central bank law contains provisions that ensure the overall independence of the BCT and thus of the statistical work of the institution. That work is found to follow strict technical criteria and to be free of any interference. Staff are subject to and aware of the staff code of conduct. Data are disseminated adequately to all interested parties through the BCT's web site and publications. However, the terms and conditions under which statistics are collected, processed, and disseminated, as well as some of the metadata, could be made more accessible to the public. Moreover, no advance notice of major changes in methodology, source data, and statistical technique is provided.

9. The methodological soundness of statistics in Tunisia is consistent in several areas with outdated international statistical standards. However, there is now a need to proceed quickly with the migration to the new standards. In the national accounts, work is well advanced to implement fully the $1993 S N A$, and it remains to finalize and schedule publication of the new series that have been compiled. Work has also begun in accordance with a plan to adopt the MFSM for compiling monetary statistics. As for the GFS, despite an expressed interest, Tunisia has not yet developed a transition plan to GFSM 2001. Balance of payments statistics (as provided in the DSBB) are already broadly consistent with the methodology of BPM5. However, the statistics of the data template on international reserves and international liquidity are not fully consistent with the requirements of the SDDS as they do not cover foreign currency deposits of resident banks with the BCT under "predetermined short-term net drains on foreign currency assets." In addition, the debt service of public companies is included under this heading, without this being specifically mentioned in the country notes, contrary to the recommendations of the International Reserves and Foreign Currency Liquidity Guidelines for a Data Template. With regard to national accounts statistics, the classification and valuation of currently published data series do not conform to international standards; however, new, still unpublished, statistics are consistent with international standards. Regarding GFS, coverage of published data outside those reported in the DSBB is limited to budgetary central government. The operations of the numerous public administrative units (such as schools) have only begun to be included in the budget. Moreover, GFS classification, while very close to GFSM 1986 standards, could be improved. The coverage and scope of balance of payments statistics is good, but classification of the important item of workers' remittances is inappropriate. There are also departures from the standard regarding recording on an accrual basis and, in national publications, regarding the breakdowns of the financial account. In monetary statistics, there are departures from the MFSM inter alia regarding disaggregation of credits by sector, valuation, and classification of assets and liabilities. For example, banks' credit to the rest of the domestic sector (other than central government and financial corporations) is not 
disaggregated into subsectors; monetary gold is not valued at market price, as recommended in the MFSM.

10. The accuracy and reliability of statistics in Tunisia are broadly adequate. In the national accounts, source data are sufficient to compile reliable annual estimates, but could be further diversified to improve indicator coverage for quarterly GDP estimates. Data sources for compiling GFS are adequately detailed and suitable for deriving the published aggregates. However the scope of data sources is rather narrow. In the context of current strict foreign exchange regulations, the data sources for balance of payments statistics are fully adequate. While very comprehensive in coverage and timely, source data for monetary statistics do not contain sufficient detail for classification of assets and liabilities as recommended in the MFSM. In all areas of statistics assessed, there is careful processing and validation of source data (following up actively with reporting units) as well as of intermediate data. An outdated base year (1990) is used for the current series and there is a need to refine the statistical techniques of the quarterly national accounts estimates. Adequate statistical techniques are used in all assessed sectors. Explicit studies of - the otherwise wellthought-out - revisions are not undertaken, but experience gained in revisions is used to inform subsequent work.

11. Serviceability of the assessed macroeconomic statistics is broadly satisfactory, as confirmed by the results of the user survey conducted in the context of this assessment. Data in all assessed areas are compiled and disseminated with the periodicity and timeliness prescribed by the SDDS with the exception of the national accounts data (whose timeliness lags behind the SDDS requirement by one month for the first quarter). Statistics are largely reconcilable within each dataset and over time, as well as with other datasets. However, the reconciliation of fiscal and monetary data cannot be readily confirmed using solely published information, as budget domestic financing is not presented by debt holder. Moreover, monetary statistics data on transactions between the BCT and deposit money banks, as well as among the latter, cannot be reconciled from published data as presentations are not consistently classified. In all assessed areas, there are established revision practices that agencies follow - albeit do not publicize - and preliminary and revised data are clearly identified in most publications, except in the monthly GFS printed publication.

12. There is room to improve accessibility to statistics. Adequate national accounts data and some brief methodological notes are disseminated, albeit with no analyses accompanying the data. Regularly updated metadata are provided on the DSBB, but no link is provided from the INS' website. National accounts statistics are released simultaneously to all users outside the government. Monthly GFS data are also disseminated without analysis or adequate publicizing of a preannounced release schedule, and their presentation could be improved. Moreover, the MF does not have a website. Methodological notes are only available on the DSBB website (in English). Monetary statistics and related methodological material are readily available to the public. However, information on how these statistics are compiled is not publicized. Accessibility of balance of payments statistics is also broadly adequate, but accessibility to metadata could be improved by posting them on the BCT website. Adequate assistance to users is provided for national accounts and monetary data. However much 
greater assistance can be provided to GFS users. It is also possible to further improve assistance to users of balance of payments statistics.

\section{ASSeSSment by AgenCy AND DAtaset}

13. Assessment of the quality of four macroeconomic datasets - national accounts, government finance, monetary, and balance of payments statistics - were conducted using the DQAF July 2003. In this section, the results are presented at the level of the DQAF elements and using a four-point rating scale (Table 1). Assessments of the prerequisites of data quality and the assurances of integrity (Dimensions " 0 " and " 1 " of the DQAF) are presented in Tables $2 \mathrm{a}-\mathrm{c}$. For each dataset, the assessment of methodological soundness, accuracy and reliability, serviceability, and accessibility (Dimensions " 2 " to " 5 " of the DQAF) are shown in Tables $3 \mathrm{a}-\mathrm{d}$.

14. To complement the Fund staff's assessment of the quality of macroeconomic statistics produced in Tunisia, an informal survey of key users of such statistics was conducted. The authorities sent questionnaires to 14 users; responses were received from 12 of them. Respondents included international and domestic banks, international and regional organizations, the financial media, think tanks, employer and producer associations, the trade unions, and some users of data in the public administration. Users were asked to evaluate the coverage, periodicity, timeliness, dissemination practices, accessibility, and overall quality of the official statistics assessed in this report.

15. Users overall expressed satisfaction with the quality of the statistics produced in Tunisia. The results of the survey indicated that a majority of users are satisfied with the coverage, periodicity, level of detail, methodological soundness, and timeliness of official statistics. On a five point scale (1 meaning poor and 5 excellent), respondents' average rating for the overall quality of the official statistics for all assessed sectors was a 3.8, with the lowest score (3.5) given to GFS and the highest (4.1) to monetary statistics. Most users regarded Tunisia's official macroeconomic statistics as being of better quality than the statistics of countries at similar levels of development in the region.

16. The main uses of official statistics are, in order of importance, for general economic background, analysis of current developments, analysis of trends, comparisons with developments in other countries, and economic research. The macroeconomic statistics most frequently used are the monetary and balance of payments statistics, closely followed by national accounts statistics. GFS are used less frequently. The main source of official statistics is, according to most users, official publications and press releases. However, similar numbers of users indicated they rely on publications of international organizations about Tunisia. Over 40 percent of users do not consult official descriptions of the sources and methods used to compile the official statistics.

17. Several comments and suggestions for improving official statistics were provided in the responses to the questionnaires. These concern mostly the national accounts (diversification of dissemination means for quarterly national accounts; dissemination of data 
with greater level of detail, including information on the informal sector). Some respondents also commented that the timeliness of some statistics (national accounts, GFS, and balance of payments) could be improved. 


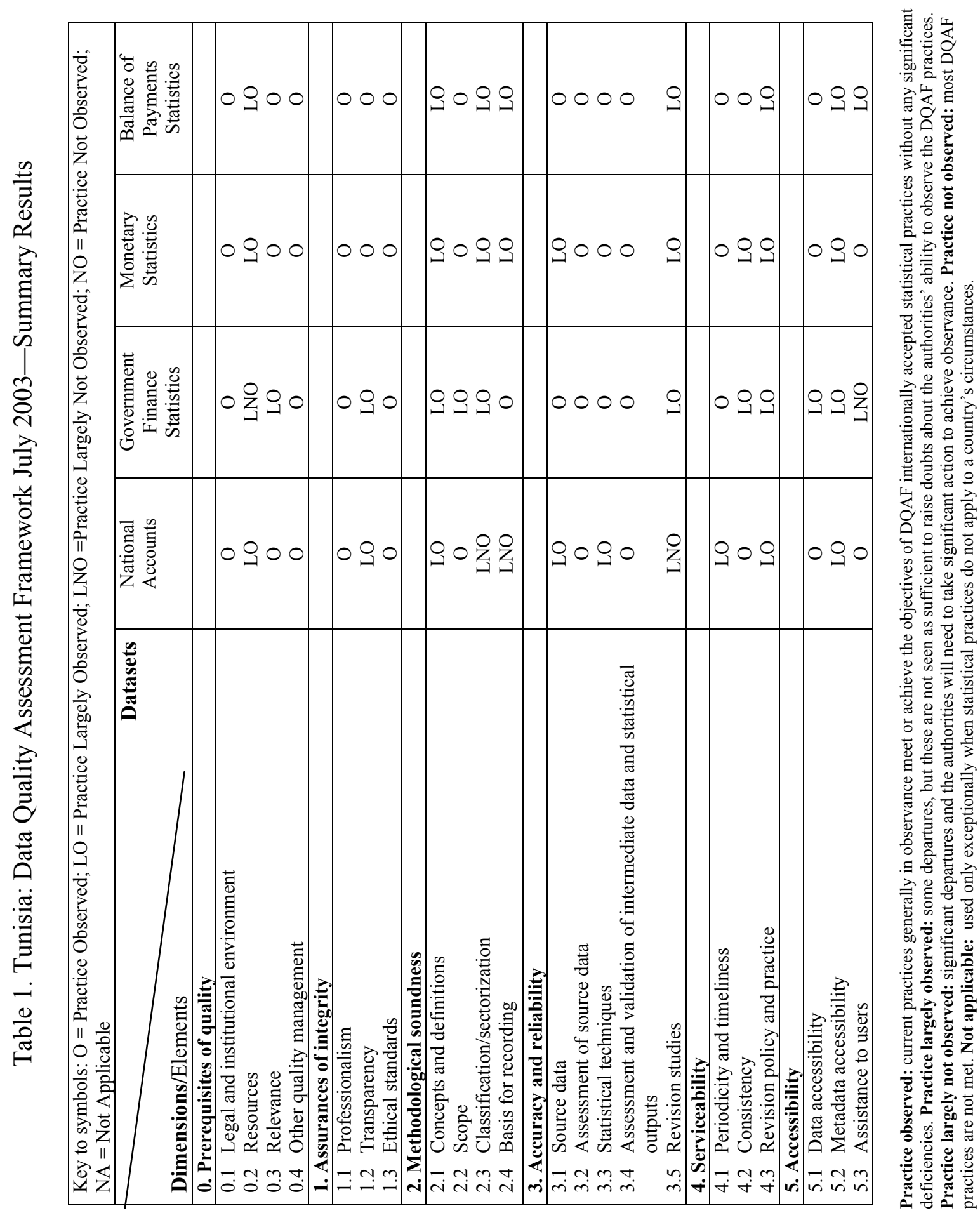




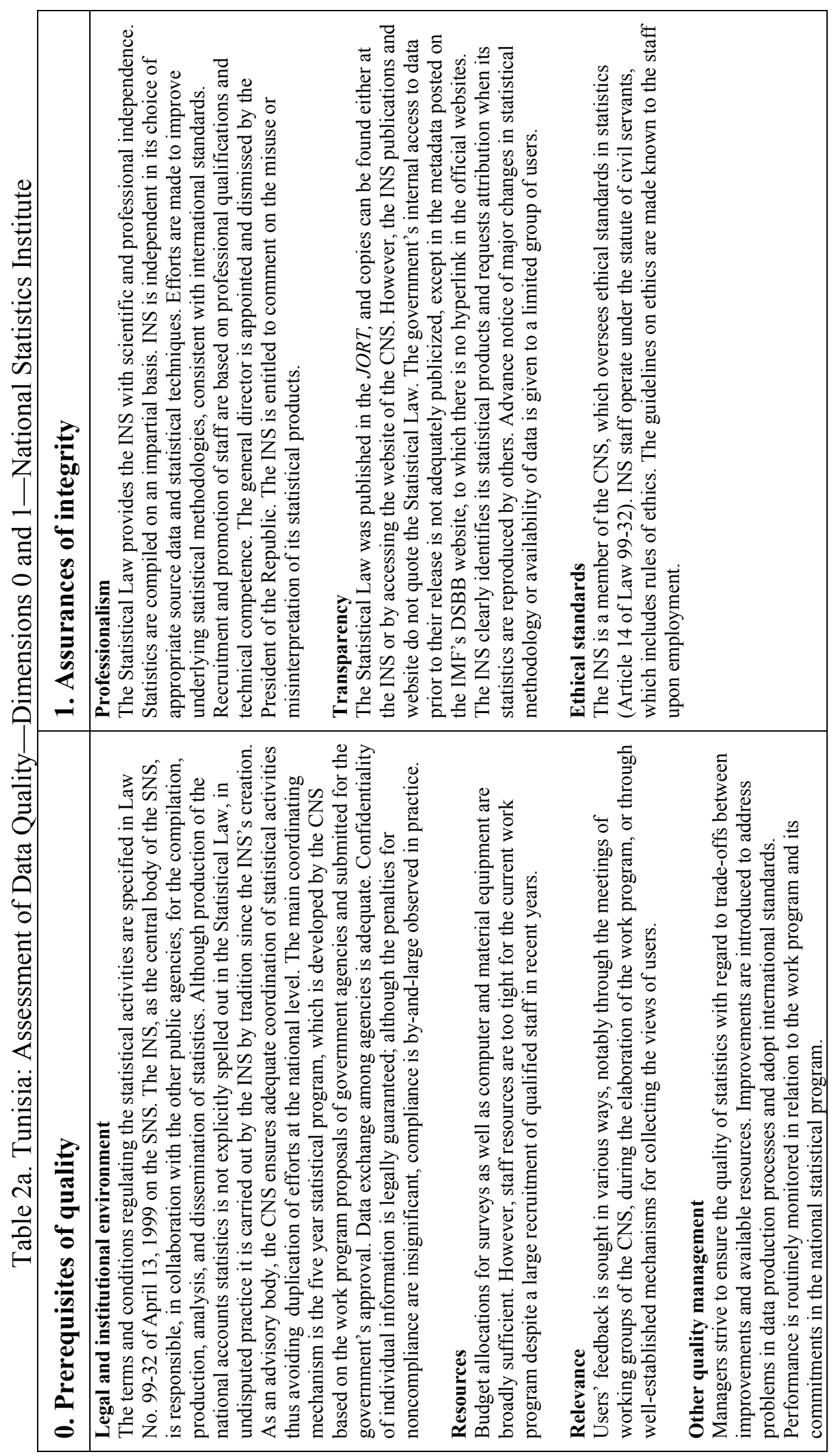




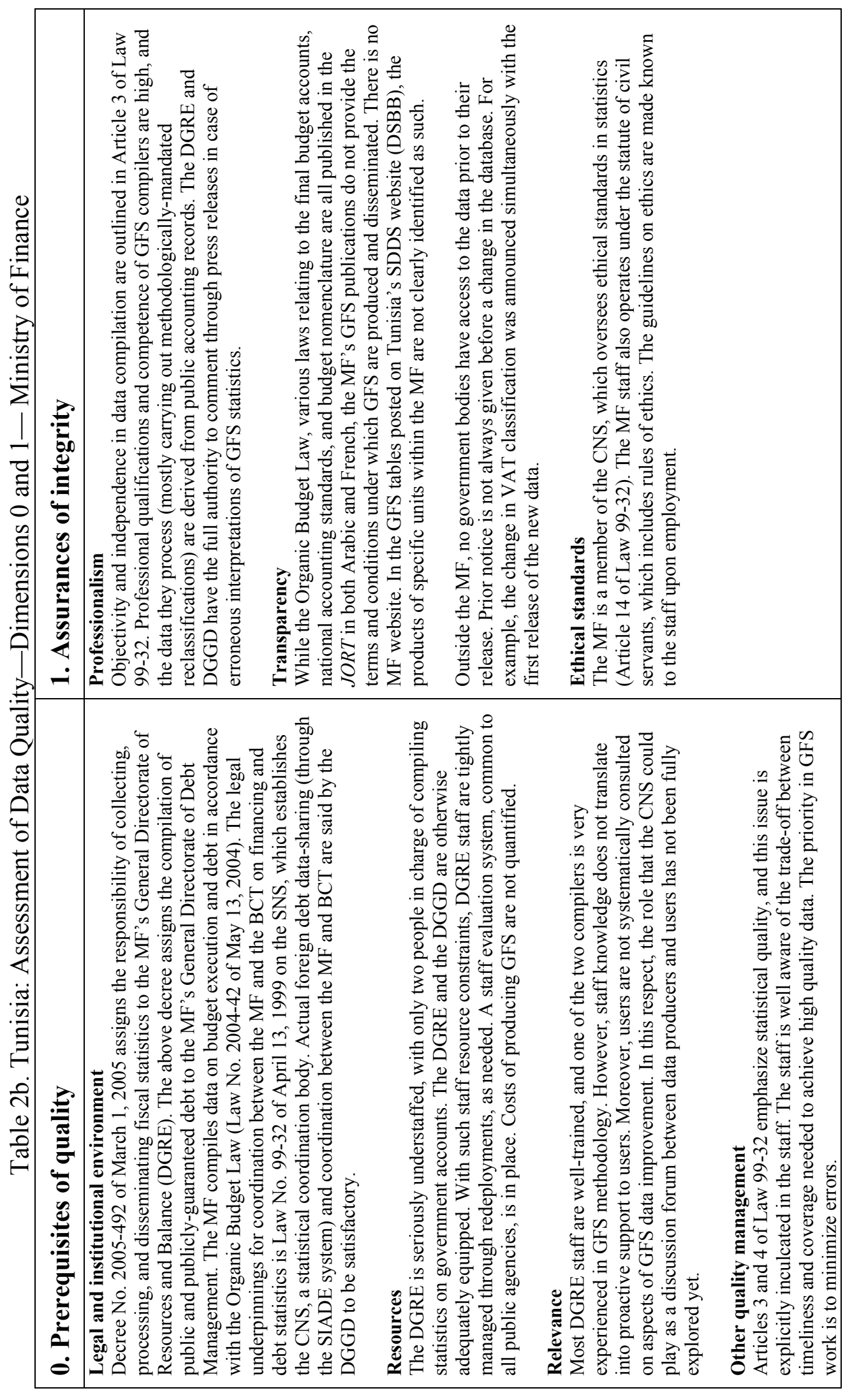




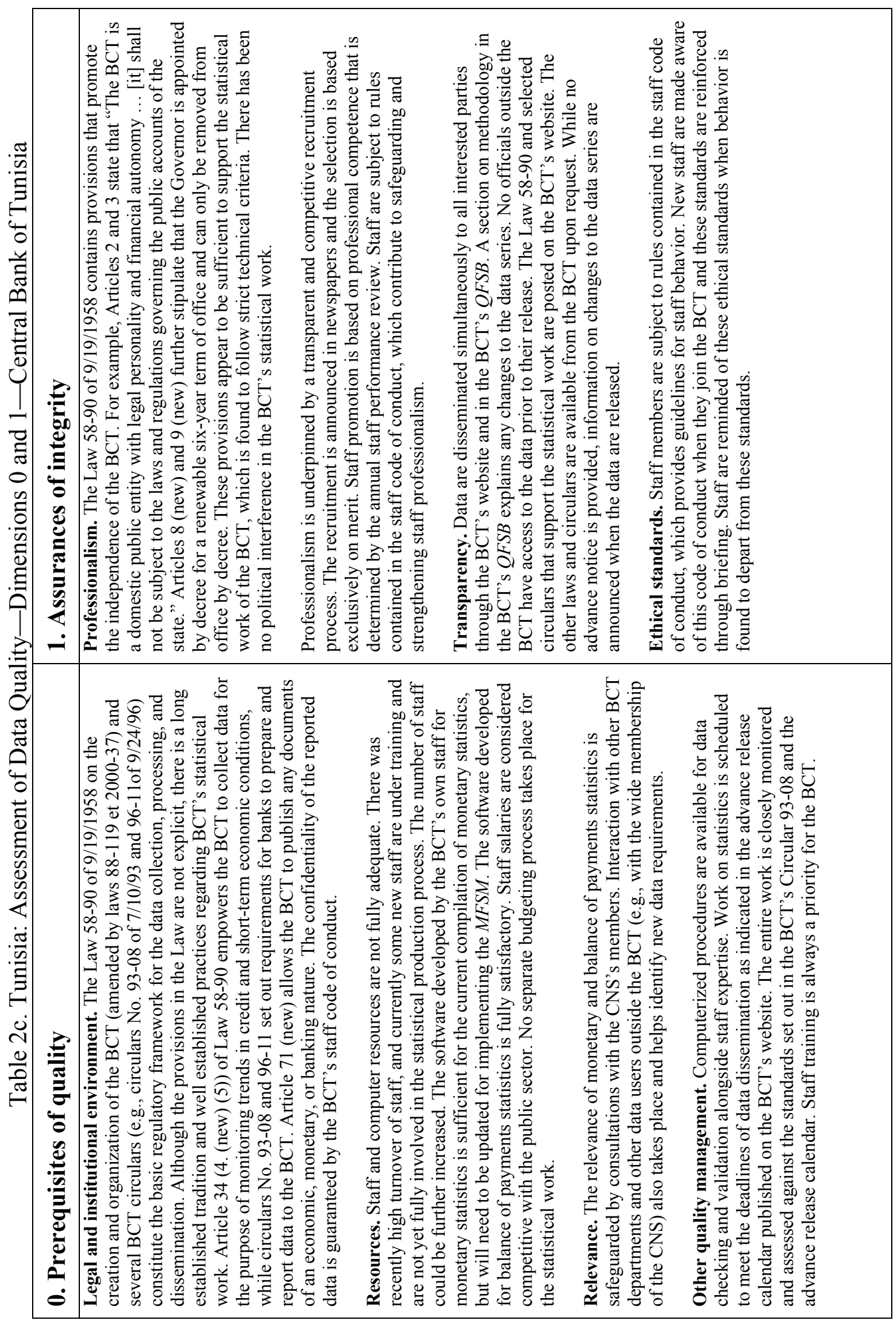




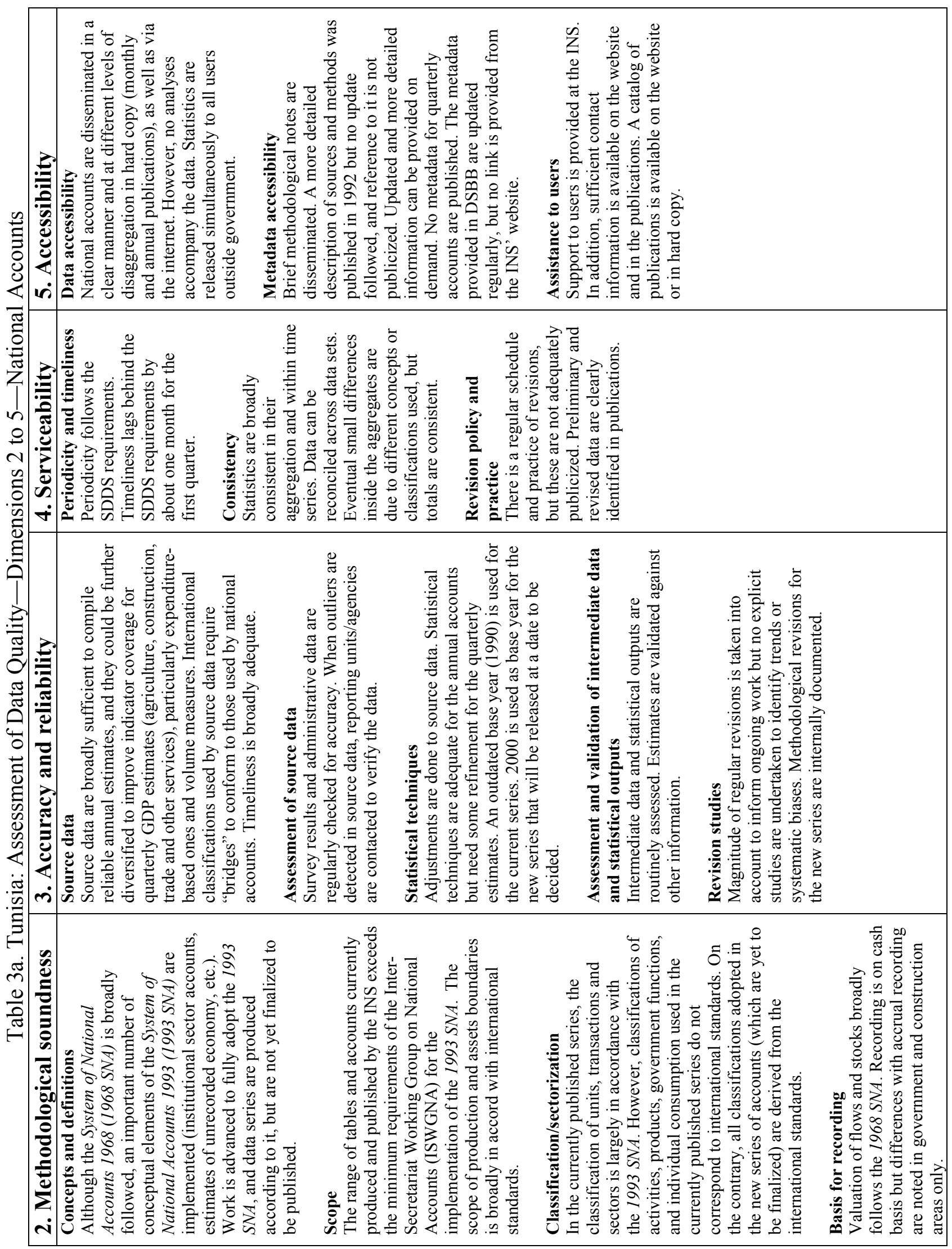




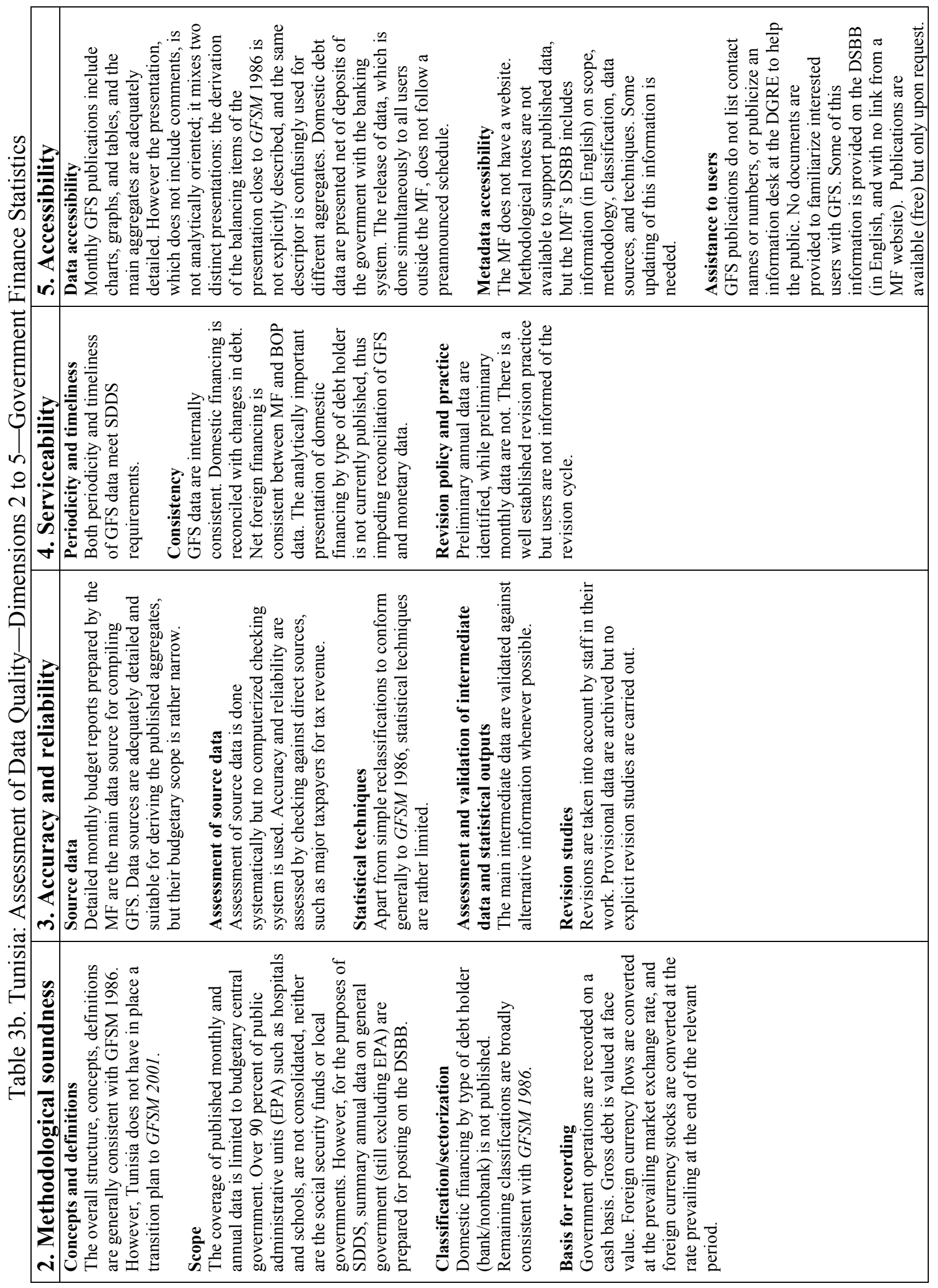




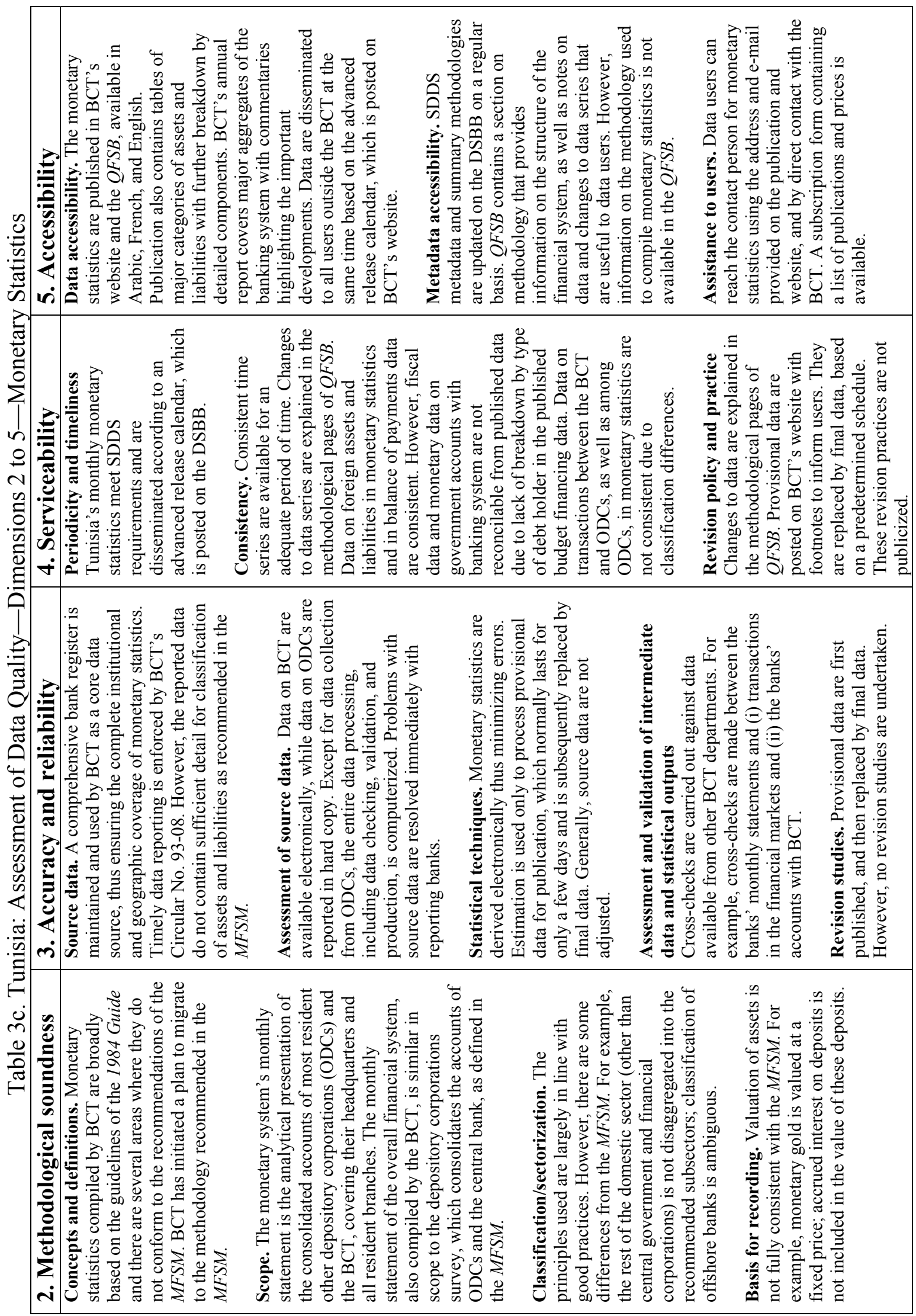




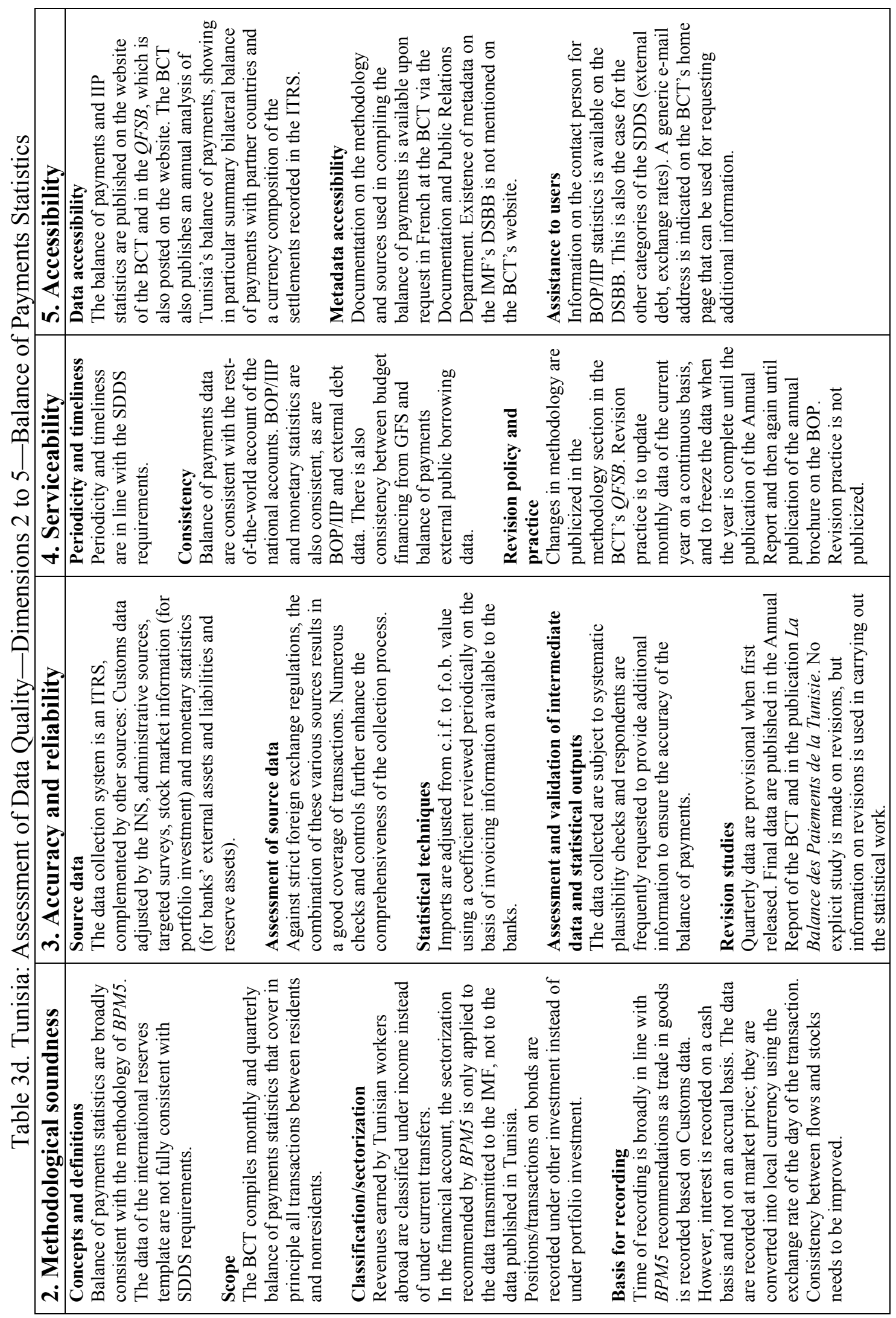




\section{STAFF's RECOMMENDATIONS}

18. Based on the review of Tunisia's statistical practices, discussions with the data producing agencies, and responses from data users (see Appendix III of the Detailed Assessments volume), the mission has a set of recommendations. They are designed to increase further Tunisia's adherence to internationally accepted statistical practices and would, in the mission's view, enhance the analytical usefulness of Tunisia's statistics. Some additional technical suggestions are included in the Detailed Assessments volume.

\section{Cross-cutting Recommendations}

- $\quad$ Pursue rigorously plans to further improve the quality of the country's official statistics by increasing the alignment of the current practices with internationally accepted standards and good practices.

- $\quad$ Promote in all data-producing agencies a culture of dissemination oriented toward the public at large.

- Dissemination of information on the conditions of statistical production, as well as of data, metadata, and contact information should be made fully and consistently for all assessed areas of statistics and through all available media.

- $\quad$ Provide more staff resources to statistical production in all the areas assessed in this report. This is particularly important in the area of GFS.

- $\quad$ Ensure that the adoption of international standards is translated into changes of domestically available data, beyond the data made available through the IMF's DSBB.

- Undertake revision studies and disseminate them as well as the revision policies and practices.

\section{National Accounts}

\section{High Priority}

- $\quad$ Complete work on the new series of annual accounts (starting with 1997), which is in line with the 1993 SNA and introduces a new base year, and disseminate it shortly. Revise backward the annual and quarterly account series to ensure consistency as far back as possible.

- Develop new infra-annual source data or improve existing ones that are particularly needed for quarterly accounts (e.g., agriculture, construction, and certain services); make use of all available administrative data (e.g., balance sheets submitted at the MF) as information becomes transmissible. 
- $\quad$ Prepare and disseminate "source and methods" documents that would include detailed methodological notes on the new series of annual and quarterly accounts; update these documents regularly.

\section{Other}

- $\quad$ Provide a link from the INS website to the metadata posted on the DSBB.

- Undertake basic analyses of data to accompany the dissemination of data.

\section{Government Finance Statistics}

\section{High priority}

- $\quad$ Adopt a migration plan to GFSM 2001. Start implementation of the plan by producing, concurrently with the current GFSM 1986-based GFS data, the same cash data based on the GFSM 2001 classification.

- $\quad$ Expand the coverage of government in published annual data to include all EPA, social security funds, and local governments. Ensure that the legal basis for the relevant reporting is in place.

- $\quad$ Adapt fully the current presentation of the monthly/annual data to the GFSM 1986 framework by performing the appropriate changes in descriptors and classifications.

- $\quad$ Publish a breakdown of domestic financing by type of debt holder (BCT, banking sector excluding BCT, and non-banking sector).

- Improve the accessibility of GFS data and methodology: identify all primary data sources in the main GFS tables, prepare methodological notes on GFS compilation, and include their summaries in monthly publications (and the upcoming website). Identify contact persons and their telephone, fax, and email in all publications and in the upcoming website.

\section{Other}

- $\quad$ Accelerate the introduction of the MF's own website; post on it all available detailed GFS data and expanded coverage data as they become available; provide a hyperlink to the DSBB.

- $\quad$ The MF should engage in dialogue with current and prospective GFS users through its participation in the CNS. 
- $\quad$ Streamline the presentation of tables in the monthly publication, with those following the GFSM 1986 at the beginning of the publication, and those following the Organic Law presentation at the end.

- Implement changes to the accounting system to move to double-entry accounting and identify and collect accrual data for the relevant main aggregates.

\section{Monetary Statistics}

\section{High priority}

- Develop and implement a timetable of actions to adopt the recommendations of the $M F S M$ in the following areas: (i) sectorization of the economy; (ii) classification of financial assets and liabilities (e.g., classification of domestic claims); (iii) valuation of financial assets and liabilities.

- Improve the report forms and the accompanying instructions (Circular 93-08) used to collect data for the compilation of monetary statistics with emphasis on the detailed breakdowns as recommended in the MFSM.

- $\quad$ Compile and disseminate the central bank survey, the other depository corporations survey, and the depository corporations survey according to the framework recommended in the MFSM.

- $\quad$ Review and improve the classification of data on interbank transactions in the compilation of monetary statistics to ensure consistency in these data.

\section{Balance of Payments Statistics}

\section{High priority}

- $\quad$ Reclassify workers' remittances from income to current transfers.

- Review the contents of the international reserves template to make it compliant with the SDDS's Guidelines for a data template.

- $\quad$ Move to the standard presentation of BPM5 for national publications of balance of payments and international investment position statistics and use the appropriate breakdowns in the financial account for instruments and sectors.

- Implement an annual collection of data on stocks of foreign direct investment and record reinvested earnings in the balance of payments.

- $\quad$ Post on the DSBB the summary methodology for exchange rates.

- $\quad$ Ensure consistency between flows and stocks for short-term trade credits. 


\section{Other}

- $\quad$ Study the possibility of recording interest on an accrual basis.

- $\quad$ Review the recording of technical assistants' remittances and of pensions.

- $\quad$ Provide a link to the DSBB website on the BCT's website page dedicated to external statistics.

- $\quad$ Add reference in publications to the legal framework within which the BCT compiles and disseminates balance of payments, international investment position, and external debt statistics. 
Table 1. Tunisia: Practices Compared to the SDDS Coverage, Periodicity, and Timeliness of Data

\begin{tabular}{|c|c|c|c|c|c|c|}
\hline \multirow{2}{*}{ SDDS Data Category } & \multirow{2}{*}{$\begin{array}{c}\text { Coverage } \\
\text { (Meets } \\
\text { SDDS) }\end{array}$} & \multicolumn{2}{|c|}{ Periodicity } & \multicolumn{2}{|c|}{ Timeliness } & \multirow{2}{*}{ Comments } \\
\hline & & SDDS & Tunisia & SDDS & Tunisia & \\
\hline \multicolumn{7}{|l|}{ Real Sector } \\
\hline National accounts & Yes & Q & $\mathrm{Q}$ & 1Q & $\begin{array}{l}\text { 1Q ( } 4 \mathrm{M} \text { for the } \\
\text { first quarter) }\end{array}$ & $\begin{array}{l}\text { Use flexibility } \\
\text { option }\end{array}$ \\
\hline Production index & Yes & $\mathrm{M}$ & $\mathrm{M}$ & $\begin{array}{c}6 \mathrm{~W}(1 \mathrm{M} \\
\text { encouraged })\end{array}$ & $6 \mathrm{w}$ & \\
\hline $\begin{array}{l}\text { Labor market: Employment } \\
\text { (Atvinna) }\end{array}$ & Yes & Q & $\mathrm{A}$ & $1 \mathrm{Q}$ & $7 \mathrm{M}$ & \multirow{2}{*}{$\begin{array}{l}\text { Use Periodicity } \\
\text { and timeliness } \\
\text { flexibility. } \\
\text { Missing SM } \\
\text { page for UEM }\end{array}$} \\
\hline $\begin{array}{l}\text { Labor market: Unemployment } \\
\text { (Registered unemployment) }\end{array}$ & Yes & Q & A & 1Q & $7 \mathrm{M}$ & \\
\hline Labor market: Wages/earnings & Yes & Q & $\mathrm{Q}$ & $1 \mathrm{Q}$ & $3 \mathrm{M}$ & $\begin{array}{l}\text { Missing SM } \\
\text { page. }\end{array}$ \\
\hline Price index: Consumer prices & Yes & $\mathrm{M}$ & $\mathrm{M}$ & $1 \mathrm{M}$ & $15 \mathrm{D}$ & \\
\hline Price index: Producer prices & Yes & $\mathrm{M}$ & $\mathrm{M}$ & $1 \mathrm{M}$ & $1 \mathrm{M}$ & \\
\hline \multicolumn{7}{|l|}{ Fiscal Sector } \\
\hline $\begin{array}{l}\text { General government or public sector } \\
\text { operations }\end{array}$ & Yes & $\mathrm{A}$ & A & $2 \mathrm{Q}$ & $6 \mathrm{M}$ & \\
\hline $\begin{array}{l}\text { Central government operations } \\
\text { (revenue and expenditure, capital } \\
\text { transactions, borrowing, and overall } \\
\text { cash balance) }\end{array}$ & Yes & $\mathrm{M}$ & M & $1 \mathrm{M}$ & $1 \mathrm{M}$ & \\
\hline Central government debt & Yes & $\mathrm{Q}$ & $\mathrm{Q}$ & $1 \mathrm{Q}$ & $2 \mathrm{M}$ & \\
\hline \multicolumn{7}{|l|}{ Financial Sector } \\
\hline $\begin{array}{l}\text { Analytical accounts of the banking } \\
\text { sector }\end{array}$ & Yes & $\mathrm{M}$ & $\mathrm{M}$ & $1 \mathrm{M}$ & $1 \mathrm{M}$ & \\
\hline $\begin{array}{l}\text { Analytical accounts of the central } \\
\text { bank }\end{array}$ & Yes & $\begin{array}{c}\mathrm{M}(\mathrm{W} \\
\text { recommended })\end{array}$ & $\mathrm{M}$ & $\begin{array}{c}2 \mathrm{~W}(1 \mathrm{~W} \\
\text { encouraged) }\end{array}$ & $2 \mathrm{~W}$ & \\
\hline Interest rates & Yes & $\mathrm{D}$ & $\begin{array}{c}\mathrm{D} \text { (all for } \\
\text { tenders rate and } \\
\text { the } 7 \text {-day } \\
\text { allowance } \\
\text { uptake rate) }\end{array}$ & & $\mathrm{D}$ & $\begin{array}{l}\text { Missing SM } \\
\text { page }\end{array}$ \\
\hline Stock market: Share price index & Yes & $\mathrm{D}$ & $\mathrm{D}$ & & $\mathrm{D}$ & $\begin{array}{l}\text { Missing SM } \\
\text { page }\end{array}$ \\
\hline \multicolumn{7}{|l|}{ External Sector } \\
\hline Balance of payments & Yes & $\mathrm{Q}$ & $\mathrm{Q}$ & $1 \mathrm{Q}$ & NLT 2M & \\
\hline $\begin{array}{l}\text { International reserves and foreign } \\
\text { currency liquidity }\end{array}$ & Partly 1/ & $\begin{array}{l}\mathrm{M}(\mathrm{W} \\
\text { recommended })\end{array}$ & M & $\begin{array}{l}1 \mathrm{~W} \text { for } \\
\text { official } \\
\text { reserve assets } \\
1 \mathrm{M}(1 \mathrm{~W} \\
\text { encouraged }) \\
\text { for the } \\
\text { reserves } \\
\text { template } \\
\end{array}$ & $\begin{array}{l}\text { 7D for } \\
\text { international } \\
\text { reserves and } \\
\text { the reserves } \\
\text { template data }\end{array}$ & \\
\hline Merchandise trade & Yes & $\mathrm{M}$ & $\mathrm{M}$ & $\begin{array}{l}8 \mathrm{~W}(4-6 \mathrm{~W} \\
\text { encouraged) }\end{array}$ & NLT 20D & \\
\hline International investment position & Yes & $\begin{array}{c}\mathrm{A}(\mathrm{Q} \\
\text { recommended })\end{array}$ & $\mathrm{A}$ & $\begin{array}{c}3 \mathrm{Q}(1 \mathrm{Q} \\
\text { encouraged) }\end{array}$ & $6 \mathrm{M}$ & \\
\hline External debt & Yes & Q & $\mathrm{Q}$ & 1Q & $3 \mathrm{M}$ & \\
\hline Exchange rates & Yes & $\mathrm{D}$ & $\mathrm{D}$ & $2 /$ & $\mathrm{D}$ & $\begin{array}{l}\text { Missing SM } \\
\text { page. }\end{array}$ \\
\hline \multicolumn{7}{|l|}{ Socio-demographic data } \\
\hline Population & Yes & A & $\mathrm{A}$ & $\ldots$ & $4 \mathrm{M}$ & $\begin{array}{l}\text { Missing SM } \\
\text { page. }\end{array}$ \\
\hline
\end{tabular}

Notes: for periodicity and timeliness: (D) daily; (WD) working days or business days; (W) weekly or with a lag of \#\# week(s) from the reference date; (M) monthly or with a lag of \#\# month(s); (Q) quarterly or with a lag of \#\# quarter(s); (SA) semiannual; (A) annual; (NLT) not later than; and (...) not applicable.

${ }^{1 /}$ Does not cover foreign currency deposits of resident banks with the BCT under "pre-determined short-term net drains on foreign currency assets," but covers debt service of public companies, without it being flagged.

${ }^{2 /}$ Given that the data are broadly disseminated by private means, the timeliness with which official data are disseminated is not time critical. 
INTERNATIONAL MONETARY FUND

TUNISIA

\title{
Report on the Observance of Standards and Codes (ROSC)_Data Module
}

\author{
Response by the Authorities
}

July 27, 2006

The following is the response by the authorities to the Report on the Observance of Standards and Codes (ROSC) - Data Module of the mission from the International Monetary Fund (IMF) of April 7-22, 2005. These official comments, which are confined to the government finance statistics, were provided by the Ministry of Finance and conveyed to the IMF by the Central Bank.

\section{IMF Remarks}

1. There are no formal reporting and coordination procedures for forwarding government finance statistics (GFS) between the Ministry of Finance (MF) and the Central Bank (BCT) (page 37 of the Detailed Assessments Using the Data Quality Assessment Framework (DQAF)).

\section{Human resources:}

Staffing for GFS compilation is insufficient, as those assigned to this area are often busy with other tasks (page 39 of the Detailed Assessments Using the DQAF).

\section{GFS production costs:}

GFS production costs are neither quantified nor valued on a regular basis, as there is no formal requirement to specify the time spent on each activity (page 39 of the Detailed Assessments Using the DQAF).

\section{Ministry of Finance Comments}

- The BCT, which is the coordinator of relations with the IMF, was given the task of publishing the GFS temporarily on its Web site, pending the creation of a dedicated Ministry of Finance GFS site. This clarification was given in the metadata pages related to the SDDS.

- The team responsible for the GFS was strengthened in 2005 (after the mission) through the recruitment of four senior officers (Statisticians and Information Analysts). 


\section{MF participation in the CNS:}

Advantage is not really taken of the MF's participation in the National Statistics Council

(CNS), which could be an ideal agency for reporting on user needs and engaging in discussions on those needs (page 39 of the Detailed Assessments Using the DQAF).

\section{Presentation of domestic financing:}

Domestic financing is presented by maturity rather than by creditor, which means that the government finance data and the monetary data cannot be reconciled. Similarly, the scope of the monthly data is limited to the budget (pages 40, 50, and 52 of the Detailed Assessments Using the DQAF).

\section{The Web site}

The MF does not have its own Web site (pages 41 and 55 of the Detailed Assessments Using the DQAF).
- MF representatives participate in roundtable conferences organized by the CNS and in the work of a technical committee responsible for, among other things, preparing and defining the economic and financial indicators.

- Given the deadlines required by the SDDS for dissemination of the central government's monthly GFS and the time necessary for collecting the data, it was agreed in 2001 to maintain the breakdown of domestic financing into short-term, medium-term, and longterm. However, the breakdown of domestic financing by debt holder (bank and nonbank) could be incorporated into the bulletin, depending on the availability of the information and the deadline for its dissemination.

- The monthly balances of the Social Security Funds are reported with a lag of at least a quarter, which means that they cannot be consolidated at the time of dissemination of the monthly GFS.

- In addition to the government's Web site (ministères.gov.tn), a Web site specifically dedicated to government finance statistics is being prepared. 


\section{Methodological note:}

The annual and monthly publications do not include details on whether or how users can obtain more information from the agency that produces the GFS (pages 42 and 55 of the Detailed Assessments Using the DQAF).

8. The two summary tables in the bulletin give the same headings (Revenue and Expenditure) to different concepts; the revenue in the second table includes borrowed resources, and the expenditure includes the amortization of principal (page 43 of the Detailed Assessments Using the DQAF).

\section{Migration to the 2001 GFSM:}

Tunisia has not yet formulated a plan for migrating to application of the principles in the 2001 GFSM (accrual basis instead of cash basis) (page 44 of the Detailed Assessments Using the DQAF).
- A comprehensive note to users has been inserted in the various publications. It gives:

- The definitions of the concepts used, - The methodology for compiling the data and information sources, - Persons to be contacted and their contact information, and

- The catalog of the various publications.

This same information will be available on the MF's Web site.

- This ambiguity has been eliminated, and a distinction established between total own revenue and total revenue, as well as between total expenditure excluding debt principal and total expenditure.

- Within the framework of the IMF technical assistance for adoption of the 2001 methodology, started in July 2004 and interrupted, the GFS were forwarded to the mission with a view to having them converted to follow the new presentation. The GFS for 2004 were presented in accordance with the classification in the 2001 GFSM but with cash-basis figures and using a conversion table.

- For the migration to accrual-basis accounting, a major reform of Government Accounting is needed, and we would like to seek technical assistance from the IMF for that purpose. 


\section{Data coverage:}

The monthly GFS do not cover the central government: the public administrative agencies (EPA), which total 2,125, are not consolidated in the data coverage. Similarly, the annual report does not include either the EPA, the social security agencies, or the local governments through consolidation; the accounts of the latter are presented separately in the report (page 44 of the Detailed Assessments Using the DQAF).

\section{Consistency of the data:}

*The GFS are consistent; the concepts, definitions, and classifications are the same for the annual and quarterly statistics, and the aggregates represent exactly the sum of their components. External financing represents the change in the stock of external debt (taking into account the exchange rate effect), and domestic financing represents the change in the stock of domestic debt (taking into account guarantee operations) (page 51 of the Detailed Assessments Using the DQAF).

*The GFS for the central government are consistent with the national accounts.

*The GFS are consistent with the balance of payments data (external debt drawings, repayments, and interest) (page 51 of the Detailed Assessments Using the DQAF).
- The operation to incorporate the EPA in the government budget has started, and the data for about 200 EPA are now covered by the GFS. Efforts are under way to speed up the process.

No comment.
- The GFS are forwarded to the INS to meet National Accounting needs. 
INTERNATIONAL MONETARY FUND

TUNISIA

Detailed Assessments Using the Data Quality Assessment Framework (DQAF)

Prepared by the Statistics Department

Approved by Robert W. Edwards and Mohsin S. Khan

July 27, 2006

This document contains a detailed assessment by dataset of the elements and indicators that underlie the data quality dimensions discussed in Tunisia's Report on the Observance of Standards and Codes (ROSC)—Data Module. It also includes as appendices the DQAF generic framework and the results of the users' survey. 


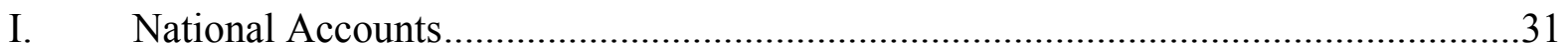

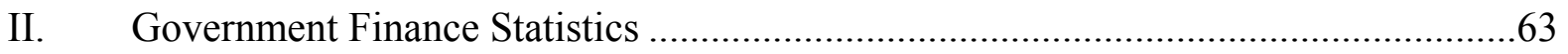

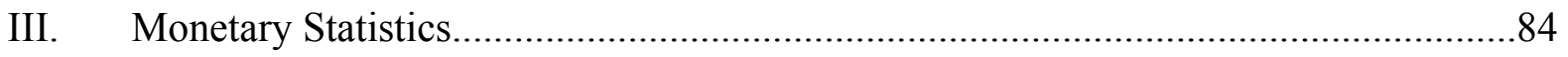

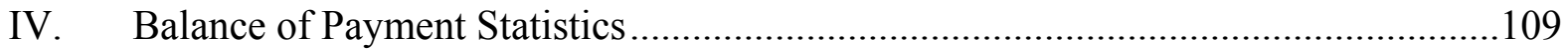

\section{Tables}

1. Tunisia: Data Quality Assessment Framework (July 2003): Summary of results for

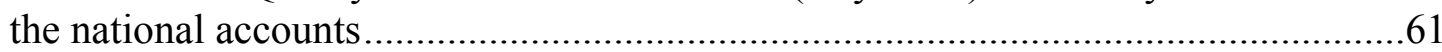

2. Tunisia: Data Quality Assessment Framework-Summary of results for Government

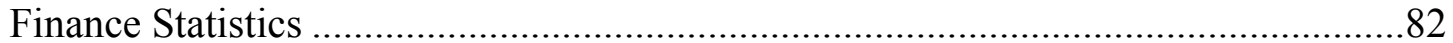

3. Tunisia: Data Quality Assessment Framework (July 2003): Summary of Results for Monetary Statistics................................................................................. 107

4. Tunisia: Data Quality Assessment Framework (July 2003): Summary of results for

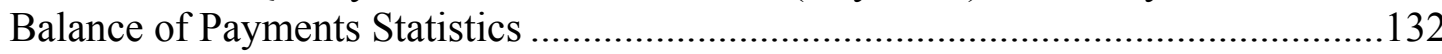

Appendices

I. Summary of the Special Data Dissemination Standard (SDDS) .............................134

II Detailed Results of Tunisia's User Survey .........................................................139

III. Questionnaire Results Analyzed by Type of User ...............................................140 
ACRONYMS

1968 SNA

1984 Guide

1993 SNA

ADB

AI

AMF

API

BCT

BOP

BPM5

BSD

CCP

CEP

CMF

CNS

COFOG

COICOP

CPI

CTP

DC

DGD

DGRE

DGGD

DITEG

DMBs

DQAF July 2003

DSBB

DSECN

ENAE

ENBC

EPA

FDI

FIPA

FTUSA

GDP

GFCF

GFS

GFSM 1986

GFSM 2001

HS

IATA
System of National Accounts 1968

Draft Guide to Money and Banking Statistics in International

Financial Statistics (December 1984)

System of National Accounts 1993

African Development Bank

Authorized Intermediaries

Arab Monetary Fund

Investment Promotion Agency

Central Bank of Tunisia

Balance of Payments

Balance of Payments Statistics Manual, fifth edition

Banking Supervision Department

Postal Check Center

Postal Savings Center

Financial Markets Board

National Council on Statistics

Classification of the Functions of Government

Classification of Individual Consumption by Purpose

Consumer Price Index

Tunisian Classification of Products

Depository Corporations

General Directorate of Customs

General Directorate of Revenue and Budget

General Directorate of Debt Management

Direct Investment Expert Group Meeting

Deposit Money Banks

Data Quality Assessment Framework, July 2003 version

Dissemination Standards Bulletin Board

Department of Economic Statistics and National Accounts

National Survey of Economic Activities

National Household Budget and Standard of Living Surveys

Public administrative unit

Foreign Direct Investment

Foreign Investment Promotion Agency

Tunisian Federation of Insurers

Gross Domestic Product

Gross Fixed Capital Formation

Government Finance Statistics

A Manual on Government Finance Statistics, 1986

Government Finance Statistics Manual 2001

Harmonized System of Commodity Description and Coding International Air Transport Association 


$\begin{array}{ll}\text { IIP } & \text { International Investment Position } \\ \text { IMA } & \text { Institute of the Arab World } \\ \text { IMF } & \text { International Monetary Fund } \\ \text { INS } & \text { National Institute of Statistics } \\ \text { IOT } & \text { Input-output table } \\ \text { IPI } & \text { Industrial Production Index } \\ \text { ISWGNA } & \text { Inter-Secretariat Working Group on National Accounts } \\ \text { ITRS } & \text { International Transactions Reporting System } \\ \text { JORT } & \text { Journal Officiel de la République Tunisienne } \\ \text { MA } & \text { Ministry of Agriculture } \\ \text { MDCI } & \text { Ministry of Development and International Cooperation } \\ \text { MFSM } & \text { Monetary and Financial Statistics Manual } \\ \text { MF } & \text { Ministry of Finance } \\ \text { MRD } & \text { Monetary Research Department } \\ \text { MT } & \text { Ministry of Transport } \\ \text { NAT } & \text { Tunisian Industrial Classification } \\ \text { NPISH } & \text { Non-Profit Institutions Serving Households } \\ \text { NSDP } & \text { National Summary Data Page } \\ \text { ODCs } & \text { Other Depository Corporations } \\ \text { QFSB } & \text { Quarterly Financial Statistics Bulletin (BCT) } \\ \text { RGPH } & \text { General Population and Housing Census } \\ \text { RNE } & \text { National Directory of Enterprises } \\ \text { ROSC } & \text { Report on the Observance of Standards and Codes } \\ \text { SDBP } & \text { Balance of Payments Subdirectorate } \\ \text { SDDS } & \text { Special Data Dissemination Standard } \\ \text { SDR } & \text { Special Drawing Rights } \\ \text { SNS } & \text { National Statistical System } \\ \text { SRFs } & \text { Special Report Forms } \\ \text { STA } & \text { IMF Statistics Department } \\ \text { SUT } & \text { Supply and use table } \\ \text { TGT } & \text { National Treasury of Tunisia } \\ \text { VAT } & \text { Value Added Tax } \\ & \end{array}$




\section{Detailed AsSessment USIng the Data Quality AsSessment Framework (DQAF)}

The following detailed information on indicators of statistical practices in the areas of the national accounts, prices, government finance, money and banking, and balance of payments statistics was gathered from publicly available documents and information provided by the officials. This information, which is organized along the lines of the generic DQAF (see Appendix II), was used to prepare the summary assessment of data quality elements, based on a four-part scale of observance, shown in Tunisia's Report on the Observance of Standards and Codes (ROSC)—Data Module.

\section{National Accounts}

\section{Prerequisites of quality}

\section{$0.1 \quad$ Legal and institutional environment}

\subsubsection{The responsibility for collecting, processing, and disseminating the statistics is clearly specified}

Pursuant to Law 99-32 of April 13, 1999 on the national statistics system, the mission of the National Statistics Institute (INS) is, "in coordination with other specialized public statistical units, to collect, process, analyze, and disseminate statistical data." The provisions of the Statistics Law provide strong support for the statistical work of the INS. Prior to 1999, the organization and coordination of statistical activity in Tunisia was less effective.

The INS, as the central executive body of Tunisia's National Statistics System (SNS), also serves as the permanent secretariat of the National Council on Statistics (CNS), and is responsible for the technical coordination of statistical activities. In addition to the CNS and the INS, the SNS includes other specialized public statistical units as well as statistical training institutions.

The CNS is responsible for institutional coordination of the statistical work of the SNS, as well as proposing a national statistical program based on the statistical program proposals put forward by public statistics units and agencies. Although the INS is capable of compiling statistics in all fields, statistical production in Tunisia is decentralized. Each administrative ministry has specific statistical responsibilities within the context of the SNS.

Pursuant to the Statistics Law, a series of decrees was issued, most notably Decree 99-2797 of December 13, 1999 defining the composition, organization, and operation of the National Council on Statistics; Decree 99-2798 of December 13, 1999 establishing the procedures and conditions for payment of the fee users are charged for statistical information; and Decree 99-2799 of December 13, 1999 setting out the conditions and procedures for conducting statistical censuses and surveys.

Responsibility for national accounts compilation, although not specifically mentioned in the Statistics Law, rests with the INS, both by mandate and by tradition since the creation of a 
national accounts unit within the $\mathrm{INS}^{1}$ in 1977 . The work is organized with a view to the accomplishment of these duties. The compilation of the accounts by the INS actually began in 1983, although the work was initiated in 1977.

\subsubsection{Data sharing and coordination among data-producing agencies are adequate.}

The CNS coordinates statistical activity and is responsible for formulating the national statistical program to be proposed to the government. The program covers the term of the development plan (five years) and is based on the statistical programs submitted by the public agencies that make up the SNS. In addition, the Law stipulates that the CNS is responsible for (a) ensuring observance of the ethical rules of the profession, (b) expressing an opinion on the policy for the development of statistical information, (c) ensuring dialogue between the producers and the users of statistical information in order to meet the country's needs, and (d) granting approval for statistical surveys and censuses organized by the public agencies of the SNS so as to prevent duplication of effort. ${ }^{2}$ The INS serves as the secretariat of the CNS and also manages its operating budget.

The operations of the CNS are consistent with the duties assigned to it by law. The Council meets four times a year, with working groups meeting more often, as required. The CNS established a record of SNS statistical activities in 1999, which is kept up to date based on the reports submitted by the public agencies that carry out those operations. As is true of other government agencies, every major operation undertaken by the INS is part of the fiveyear SNS work plan approved in the context of CNS operations.

The law provides for the creation of specialized committees within the CNS, responsible for monitoring issues related to its activities and responsibilities, as well as sectoral working groups whose reports are to be submitted to the council for study. At present, there are six working groups that meet fairly often (once or twice a month). The INS, represented by the Director of the Economic Statistics and National Accounts Department is an active participant in the activities of the group responsible for sectoral economic statistics. Participation in working meetings and other seminars on various economic and social topics is an effective way for INS to keep abreast of the progress of the activities of other public agencies and establishing productive contacts to facilitate the communication of statistical data.

The public agencies are willing to share information. In general, the General Directorate of Customs (DGD), the INS, and the Central Bank of Tunisia (BCT) collaborate effectively in the dissemination of external trade data.

\footnotetext{
${ }^{1}$ The INS was created in 1969 (Article 21 of Budget Law 64 of December 31, 1969). Its organization was defined by Decrees 70-63 and 70-64 of February 25, 1970.

${ }^{2}$ In practice, however, the CNS, as a consultative body, expresses an opinion only on the approval for these surveys, with the final decision resting with the ministries (Ministry of Development and International Cooperation (MDCI) for the INS surveys) responsible for carrying out these operations.
} 
With a view to harmonizing concepts, classifications, and methods, a major effort is underway in Tunisia to adopt new classifications ${ }^{3}$ and methods used internationally. This affects numerous public agencies, particularly the INS, where the work of implementing the 1993 SNA is well advanced. As expected, the transition to the new concepts in the various public agencies is progressing unevenly. For example, compilation of the current series of accounts (according to $1968 S N A$ ) requires a bridge table from the new classification of activities used in the enterprise bookkeeping, as well as the new (unpublished) series of accounts (compiled according to $1993 S N A$ ), to the old classification. Consequently, the INS' delay in implementing the $1993 S N A$ is largely explained by the fact that it relies on the work of other public agencies, particularly the overseeing ministry, to avoid breaks in the data series ${ }^{4}$ used for macroeconomic analyses.

\subsubsection{Individual reporters' data are to be kept confidential and used for statistical purposes only.}

Statistical secrecy is considered one of the core principles governing the activities of the SNS. The Statistics Law guarantees the protection of individual data. Article 5 of the Law states that statistical secrecy means that the individual data contained in statistical survey questionnaires cannot be disclosed by the recipient agencies for a period of sixty years. Individual data of an economic or financial nature cannot be used for any reason related to a tax, economic, or social welfare investigation. In no case may individual data be used for other than statistical purposes.

In its statistical surveys, the INS informs respondents of their rights and obligations regarding the communication of data by making reference in the questionnaires to the legal provisions on (a) statistical secrecy (Article 5), (b) the obligation to respond promptly and accurately to statistical survey questionnaires (Article 6), and (c) penalties for refusal to respond or for providing incomplete or incorrect responses (Article 26).

Article 28 of the Statistics Law refers to the provisions in Article 254 of the Criminal Code on the violation of statistical secrecy by the employees of public agencies. According to the legislation in force, employees with access to confidential data are subject to professional secrecy. Article 25 of the Statistics Law states that employees of the ministries responsible for compiling statistics, including those of the INS, are required to take an oath before the president of the tribunal de première instance of Tunis. In practice, only the director general and department heads are sworn in connection with the drafting of reports on violations of

\footnotetext{
${ }^{3}$ The 1996 decree of the minister of industry orders adoption of the Tunisian Industrial Classification (NAT) by all concerned institutions. The INS used it for the first time in the 1997 survey of enterprises and is working toward its implementation in the national accounts.

${ }^{4}$ As the adoption of the 1993 SNA will necessitate changes in GDP and the indicators used for various ratios, resulting in a different coverage as compared to the GDP forecasts of the MDCI, the new series of accounts cannot be produced by the end of the current five-year national plan (20022006).
} 
the Statistics Law. However, INS employees are subject to the statute of civil servants, which includes the code of ethics..$^{5}$ The guidelines on ethics are made known to the staff upon employment.

The INS has developed special aggregation rules to prevent the disclosure of individual data. Under these rules, the responsible personnel examine the data to be disseminated to prevent any indirect disclosure of confidential data and compile data aggregates for publication that include at least three enterprises. Any individual data communicated to various institutions for research purposes are presented in such a way so as to be anonymous.

Access to individual data is restricted to INS employees who need them to perform their duties. A number of steps have also been taken to secure the database (use of passwords, restricted access according to the users of data, proper data storage, etc.). An ongoing project with the World Bank is aimed at setting up a data center at the INS, including procedures for restricted data access.

\subsubsection{Statistical reporting is ensured through legal mandate and/or measures to encourage response.}

According to the Statistics Law (Articles 6 and 26), individuals and legal entities must respond promptly and truthfully to statistical survey questionnaires. Anyone who refuses to respond to the statistical survey questionnaires mentioned in Article 6 of the Law or who provides incomplete or incorrect responses will be fined. However, the amounts of the fines provided for by the Law (D 100 to D 500 for enterprises and D 10 to D 50 for households) are insignificant; consequently, the INS strives to win the goodwill and cooperation of respondents.

The INS is aware of the workload that the obligation to provide statistical information places on respondents. In most cases, the INS field staff helps respondents fill out the questionnaires. Thought is given by the INS on how to increase respondent awareness while also taking into account existing resource constraints. For example, for the surveys to be launched this year, the INS plans to prepare a brochure containing the most important aggregates calculated on the basis of a panel of enterprises, which will be distributed to respondent enterprises. The INS is also planning to adapt the questions to the terminology of the enterprise chart of accounts, to facilitate completion of the questionnaire and, more generally, to respond to various user needs, especially those of the government.

\footnotetext{
${ }^{5}$ Law 83-112 of December 12, 1983 establishing the general regulation applicable to employees of the central government, local governments, and government administrative agencies.
} 


\section{$0.2 \quad$ Resources}

\subsubsection{Staff, facilities, computing resources, and financing are commensurate with statistical programs.}

The INS has about 400 permanent employees, including 160 senior staff. In addition, temporary employees (approximately 500) are hired for fixed periods to assist with statistical surveys. To better respond to current and future needs, the INS hopes to increase staffing in the long- run, but this will depend on the availability of budget resources. In any case, the environment in Tunisia is favorable to the production of statistics, the importance of which is recognized and supported at the highest level of government.

The Department of Economic Statistics and National Accounts (DSCN) currently has 35 employees, including 25 trained statisticians. The remaining 10 are professional staff and secretaries. Its mission is to compile the national accounts and conduct enterprise surveys. There are three directorates: (1) the Enterprise Survey Directorate; (2) the Statistics and Sectoral Accounts Directorate; and (3) the Directorate of National Accounts Summaries. The latter two directorates have about twenty professionals who prepare the annual and quarterly accounts. This level of staffing seems insufficient, given the current workload necessitated by the transition to the 1993 SNA and the change of base year.

The staff is well trained in the area of national accounts. Most professionals were trained either in France or in Morocco at the National Institute of Statistics and Applied Economics (the former United Nations school), or at the recently created Advanced School of Statistics and Information Analysis in Tunis. ${ }^{6}$ A large number of professionals were recruited recently to make up for the loss of senior staff due to retirement, ${ }^{7}$ which explains the relatively young age of the staff of the INS. The internal training of new professionals is not rigorously planned. Staff members attend as many international courses, seminars, and workshops on the national accounts methodology as they can.

The promotion and advancement incentives are the same as those offered in the civil service. However, for senior staff, the gap between private and public sector wages is generally not significant. In addition, the INS sometimes uses preferential promotion as a means of encouraging and retaining competent professionals.

Available IT resources are adequate. Each person has a computer, which is connected to the internal network. Much of the IT equipment was acquired recently for the 2004 General Population and Housing Census (RGPH). The software used for the establishment and analysis of statistical series is generally well-suited to the performance of both existing and new tasks. ACCESS software is used to manage the INS database, and each office has access to the working files, depending on their tasks. IT resources are adequately protected

\footnotetext{
${ }^{6}$ By Decree 2001-1912 of August 14, 2001.

${ }^{7}$ The recruitment of professionals was suspended for a long time.
} 
(antivirus programs, backup copies, etc.). Survey data are entered into the system in the regional offices and stored in the INS Central Office.

The INS operating budget is prepared annually and submitted for approval to the overseeing ministry MDCI. Financial resources are distributed by operation. Funding is considered adequate for surveys but inadequate for other activities. Physical facilities, such as offices, office equipment, and transportation arrangements are generally adequate to perform required tasks.

\subsubsection{Measures to ensure efficient use of resources are implemented.}

The INS prepares its annual budget on the basis of various statistical operations programmed. For each operation, projected expenses are broken down by category of operation and the costs are carefully monitored. For example, all expenditure related to statistical surveys is included in the line item for surveys.

The work of implementing the 1968 SNA at the INS was accomplished with technical assistance provided by the National Institute of Statistics and Economic Research (INSEE) of France over the course of several years. For the development of quarterly accounts, the INS received technical assistance from the IMF. Major efforts are underway at the INS to complete the transition to the $1993 S N A$, and the first series of accounts (1997-2001) is nearly ready (except for the summary tables).

\subsection{Relevance}

\subsubsection{The relevance and practical utility of existing statistics in meeting users' needs are monitored.}

The INS regularly attends CNS working group meetings as well as meetings of international organizations. For example, during the mission a seminar on the analysis of statistical data for development was held by the CNS and the INS with support from Consortium Paris 21. The seminar brought together a large number of producers and users of statistical data from the Maghreb countries and included a number of speeches by representatives of international organizations. The subject matter of the seminar underscored the necessity of strengthening statistical analysis.

The working groups created within the CNS monitor and assess the various statistical programs of the public agencies involved, as well as the statistical operations included in those programs and the resulting outputs. The working groups propose action programs and publications to the CNS with a view to identifying new needs and better responding to user requests. The composition of the CNS (half the members are representatives of various sectors) adequately represents the broadly defined categories of users. 
The relevance and practical utility of the existing statistics in meeting user needs, particularly public agencies, are monitored by the working groups. Moreover, users are consulted indirectly, either during the preparation of surveys (by circulating a draft questionnaire) or after the statistics are compiled (by asking for feedback on the quality of statistics consulted, via a form to be completed at the point of provision of information requested). For example, after receiving repeated requests for certain external trade data, the INS developed a database application that can be consulted at the disseminating department. A project is also underway with the World Bank to establish a system to make individual data anonymous, the objective being to respond better to growing user needs for more detailed information.

\subsection{Other quality management}

\subsubsection{Processes are in place to focus on quality.}

The INS promotes data quality in its work. The Institute's mandate requires it to produce the most reliable statistics possible. Procedures are in place to assess the quality of statistics, particularly in the context of collecting statistics. The DSCN plays an important role in the detection of quality-related problems. The quality of the data is checked at every stage of national accounts compilation, including through checking the work done at different levels of the staff hierarchy: comparison of various data sources, contribution of basic indicators to quarterly GDP growth, etc. The various working groups created within the CNS hold periodic meetings in which the importance of the various quality aspects is stressed. However, formal quality control methods, such as the total quality or ISO 9000 concept, are not implemented. Moreover, because of the way that the SNS is organized, the responsibility of the INS is interpreted narrowly - as a producer of statistical data, it being understood that analyses and interpretations are the responsibility of other agencies such as the Institute of Quantitative Economics. At present, there is no culture that promotes data analysis in each producing unit or the establishment of research units, although the staff responsible for producing statistics are in a good position to perform an initial analysis.

\subsubsection{Processes are in place to monitor the quality of the statistical program.}

The CNS examines the statistical programs of public agencies from the standpoint of their purpose, their place in the information mechanism, and their degree of priority. Thus, every survey selected meets a general information need, is not a duplication of effort, and is consistent with the objectives defined for the area under study. Moreover, the requirement that every questionnaire bear the approval of the MDCI, based on the opinion of the CNS, provides assurance that the questionnaire satisfies the needs of the statistical program. Finally, during the meetings within the CNS on the work program, the quality of the data produced is implicitly examined and efforts are made to identify measures to improve quality. 


\subsubsection{Processes are in place to deal with quality considerations in planning the statistical program.}

In addition to what was mentioned in the previous point (0.4.2), the INS checks the progress of its statistical program at various stages. In its meetings to prepare the program for a given year, a diagnostic analysis is performed of the work accomplished (in terms of value and opportunity cost) by area and by operation during the preceding year, and needs are expressed in close correlation with the availability of budget resources and the possibilities of improving the coverage and reliability of statistics. The INS thus recognizes that there are choices to be made between the various dimensions of data quality (for example, between timeliness on the one hand, and accuracy/reliability on the other), and that the improvement of data quality is essential in the definition of its work programs.

\section{Assurances of integrity}

\subsection{Professionalism}

\subsubsection{Statistics are produced on an impartial basis}

The Statistics Law guarantees the impartiality of the INS. Article 3 of the Statistics Law stipulates that the units of the National Statistics System enjoy professional independence and carry out their tasks in accordance with the concepts, methodological rules and techniques commonly accepted in the field. Practice is consistent with the legislation, and the national accounts statistics are compiled on a completely impartial basis by the DSCN of the INS. The INS asserts that it is not subject to any outside interference or pressure in the process of compiling and disseminating the national accounts.

The INS Director General is appointed by presidential order. The other officials of the institute (directors of divisions) are appointed by the director general based on the criterion of professional qualification and in agreement with the minister of the overseeing ministry (MDCI) pursuant to the laws and regulations governing the management of the INS as a nonadministrative government agency.

The tradition and culture of the INS promote professionalism. The integrity of the statistics also depends on the professionalism of the INS staff. Indeed, professional qualifications play a determining role in recruitment and internal promotion. Most professional positions are filled on a competitive basis by graduates of renowned statistics schools in France or Morocco, or the University of Tunis. Grade promotions are also made on a competitive basis.

The DSCN seeks to promote professionalism by encouraging participation in seminars and meetings with other professional groups, such as sectoral meetings to monitor the country's five-year development plan. Additional training courses are also given for certain selected employees. However, it is only occasionally that a staff member publishes an article in a scientific journal. Staff members sometimes give speeches to an audience (working groups, technical centers) and they also teach statistics courses. 


\subsubsection{Choices of sources and statistical techniques as well as decisions about dissemination are informed solely by statistical considerations.}

The choice of databases (for example, among surveys and between surveys and administrative sources) and statistical techniques (for example, processing and validation techniques) are determined solely by statistical considerations. The most comprehensive statistical sources are preferred.

The decision to disseminate data is based on statistical considerations and takes into account needs expressed by a large category of users.

\subsubsection{The appropriate statistical entity is entitled to comment on erroneous interpretation and misuse of statistics.}

The INS has the right to comment on any misuse of statistics by providing explanations (to the press, for example). A daily press review in the library department provides an opportunity to examine all references to INS data. However, such public comment occurs only on very rare occasions (see also 1.2.1).

Unfortunately, the statistics disseminated by the INS are not accompanied by any commentary that would decrease the probability of erroneous interpretation.

\subsection{Transparency}

\subsubsection{The terms and conditions under which statistics are collected, processed, and disseminated are available to the public.}

The terms and conditions governing the collection, processing, and dissemination of statistics by the INS are set out in the legislation, which is available to the public either at the $\mathrm{INS}^{8}$ or on the CNS website. In addition, the questionnaires used in the INS statistical surveys contain references to the observance of statistical secrecy, the obligation to respond, and penalties for noncompliance with the Statistics Law. However, neither the INS publications nor the website mention these legal provisions. The INS's mandate as the primary producer of statistics, although generally known to the public, is not broadly publicized. Moreover, regular press conferences on the occasion of the release of part-year data are organized exclusively by the overseeing ministry (MDCI).

${ }^{8}$ Copy of the Journal Officiel containing the legislation published in French and in Arabic. 


\subsubsection{Internal governmental access to statistics prior to their release is publicly identified.}

A summary of national accounts statistical data is forwarded to the office of the overseeing ministry one month before they are released, for budget-related work. Except for the IMF's DSBB, to which there is no hyperlink from the INS website, the public is not informed of this prior access to the data before their release.

\subsubsection{Products of statistical agencies/units are clearly identified as such.}

The data disseminated are clearly identified as products of the INS. In the case of joint publications, the portion attributable to the INS as producer of the data is identified. This same procedure is followed when the INS publishes data series from other institutions (for example, the BCT).

\subsubsection{Advance notice is given of major changes in methodology, source data, and statistical techniques.}

When major changes are made in methodology, source data, and statistical techniques, technical discussions and presentations are organized in the context of the working groups in the CNS, but no prior notice is given to the wider public. This could be handled in a more formal context or indicated in current publications or in the press. Generally, the INS avoids committing itself to the release of new data by a given deadline if there are any doubts about the reliability of the data and before obtaining the agreement of other SNS agencies. A discussion will be held on organizing a presentation to give advance notice of the transition to the 1993 SNA.

\subsection{Ethical standards}

\subsubsection{Guidelines for staff behavior are in place and are well known to the staff.}

The Statistics Law, which incorporates most of the core statistical principles of the United Nations, is one of the documents covered in the competitive examination for employment in the government. INS personnel are subject to the statute of civil service, which includes the code of ethics to be followed in the event of a potential conflict of interest. ${ }^{9}$ The guidelines on ethics are made known to the staff upon employment. In addition, the survey questionnaires mention statistical secrecy, and staff working with individual data are made aware of this fact and are sensitive to it. The tradition and reputation of INS managers with regard to the observance of ethical standards ensure the independence of the INS from political interference. At the national level, there is an ethics committee at the CNS, responsible for examining ethical principles and standards and finding ways of putting them into practice.

\footnotetext{
${ }^{9}$ Law 83-112 of December 12, 1983 setting out the general regulation applicable to staff of the central government, local governments, and government agencies.
} 


\section{Methodological soundness}

Methodological soundness is assessed for currently published data against the recommendations of the System of National Accounts 1993 (1993 SNA). Improvements that are introduced to the new (unpublished) series do not form part of the assessment, but are listed for information.

\subsection{Concepts and definitions}

\subsubsection{The overall structure in terms of concepts and definitions follows internationally accepted standards, guidelines, or good practices.}

The annual and quarterly national accounts statistics currently published generally follow the standards and recommendations of the System of National Accounts 1968 (1968 SNA), although they also contain a considerable number of elements from the $1993 \mathrm{SNA}$. The work of adopting the $1993 S N A$ on a parallel basis is well advanced (see also 0.2.2).

\section{$2.2 \quad$ Scope}

\subsubsection{The scope is broadly consistent with internationally accepted standards, guidelines,} or good practices.

The scope of published accounts is broadly consistent with internationally accepted standards. The national accounts have been compiled regularly since 1983 and the quarterly accounts since 1997. Since the outset, the national accounts have incorporated numerous innovative elements that were adopted later on by the new system (1993 SNA) as recommended by the INSEE experts, and the INS regularly produces a wide range of tables and accounts that exceed the minimum requirements of the Intersecretariat Working Group on National Accounts (ISWGNA).

The system of published accounts includes the following:

Annual:

- $\quad$ Value added and GDP at current prices, previous year prices, and base year prices (1990) for 115 industries (grouped into 20 for publication purposes);

- $\quad$ Expenditure approach GDP at current prices, previous year prices, and base year prices (1990);

- A breakdown of value added in a generation of income account (compensation of employees, operation surplus, taxes and subsidies) at current prices by industry; 
- The series of accounts for the institutional sectors ${ }^{10}$ (including financial accounts), as well as accounts for the rest of the world according to the $1968 \mathrm{SNA}$;

- $\quad$ An annual input-output table (IOT) for 115 industries (115 industries and 400 products for the supply and use tables-SUT); and

- An annual fiscal operations table (TOF) and an annual integrated economic accounts table (TEE).

In 1997, Tunisia began the production of quarterly value added and GDP aggregates at current and constant prices $(1990=100)$ for 20 industries, including both unadjusted and seasonally adjusted data (only the adjusted series are published). Work is underway to prepare the quarterly accounts using the expenditure approach. The initial exercises led to a quarterly presentation of the published 2004 annual accounts. The INS plans to make up for the delay in implementing the production approach and to disseminate those figures toward the end of 2005.

The definition of the component units of the economy in the published accounts is largely consistent with the 1993 SNA. The economic territory encompasses territorial enclaves located in the rest of the world, bonded warehouses or factories operated by offshore enterprises under customs control, and wage-earners who work part of the year in another country.

The production boundary and the asset boundary in the published accounts are consistent with the 1968 SNA criteria. However, several new elements of the 1993 SNA have already been introduced, such as: production for own account of goods for own final consumption or for fixed capital formation for own account, mineral exploration, as well as work-in-progress estimates for certain activities (e.g., agriculture). Estimates have also been made for the underground economy. Further improvements have been made in the production and asset boundaries in the new (unpublished) series of accounts, based on the $1993 \mathrm{SNA}$, which will be released at a date to be determined.

\subsection{Classification/sectorization}

\subsubsection{Classification/sectorization systems used are broadly consistent with internationally accepted standards, guidelines, or good practices.}

The classification systems used are not entirely consistent with internationally accepted standards. The current series of accounts is still based on an outdated classification of industries and products that differs in some respects from the ISIC. ${ }^{11}$ However, the new (still

\footnotetext{
${ }^{10}$ The household sector, including nonprofit institutions serving households (NPISH).

${ }^{11}$ International Standard Industrial Classification of All Economic Activities.
} 
unpublished) series of accounts uses the $\mathrm{NAT}^{12}$ and the CTP ${ }^{13}$ which have also been adopted by other government agencies that report data. This complicates the task of producing the current series of accounts, as it requires the use of a bridge table between the two classifications. The $\mathrm{COICOP}^{14}$ and the $\mathrm{COFOG}^{15}$ have also been incorporated into this new series.

Regarding sectorization in the published series, institutional units are classified by institutional sector in accordance with the 1993 SNA, with the exception of the NPISH sector, which is not differentiated from households. The classification of transactions and other flows is largely consistent with the 1993 SNA.

\subsection{Basis for recording}

\subsubsection{Market prices are used to value flows and stocks.}

For the currently published series, the valuation rules followed for recording flows and stocks are generally consistent with the 1968 SNA criteria. However, the new series (not yet published) follows the 1993 SNA rules for valuing flows and stocks.

- In the currently published series, market output is valued at the ex-factory gate price, including all indirect taxes (VAT inclusive); output for own use is generally valued at equivalent market prices; and non-market output based on production costs. By contrast, in the new (unpublished) series, market output is valued at the base price, in accordance with the $1993 S N A$;

- $\quad$ VAT is broken down (deductible or nondeductible) by use only in the new (unpublished) series;

- In the currently published series, consumption of fixed capital is globally distributed at the national level and is not included in the value of government output (according to the $1968 S N A$ ); this latter point contributes to the difference in GDP between the currently published and the new (unpublished) series;

- $\quad$ Imports are valued at CIF prices (but FOB in the new series); exports are valued FOB;

- $\quad$ Transactions in foreign currency are converted using the mid-point exchange rate prevailing in the market at the moment they take place.

\footnotetext{
12 Tunisian Industrial Classification. This classification is an adaptation of ISIC Rev. 3 to Tunisia's specific circumstances, but without affecting international comparability.

${ }^{13}$ Tunisian Classification of Products.

${ }^{14}$ Classification of Individual Consumption by Purpose.

${ }^{15}$ Classification of the Functions of Government.
} 


\subsubsection{Recording is done on an accrual basis.}

Transactions and flows in the currently published series are recorded on a cash basis. According to the study conducted by the INS for the new series of accounts, there is not much difference between the time when transactions occur and when they are recorded, except with regard to construction and the government's transactions (approximately one month, especially for the recording of taxes).

\subsubsection{Grossing/netting procedures are broadly consistent with internationally accepted standards, guidelines, or good practices.}

Transactions between establishments within the same enterprise are recorded on a gross basis.

\section{Accuracy and reliability}

\subsection{Source data}

\subsubsection{Source data are collected from comprehensive data collection programs that take into account country-specific conditions.}

The data collection program is broadly sufficient to compile reliable annual estimates. The need to construct a sampling base arose at the start of the work of compiling national accounts in accordance with the $1968 S N A$. Thus, the first national directory of enterprises (RNE) was compiled in 1981-1982 by the INS, based on the results of the 1981 survey of public and private enterprises. The current RNE was prepared in 1997 on the basis of tax data from the Directorate General of Tax Audits (based on requests for authorization to operate) and social security data from the Caisse nationale de la sécurité sociale using the new industrial classification (NAT). This RNE comprises approximately 400,000 units. For each legally established unit, the RNE includes the name, main office address and list of establishments, legal status, number of employees, etc. The directory is updated annually, based on the results of annual surveys and other available sources. However, keeping track of small enterprises (pertaining to the household sector) is more difficult, particularly when enterprises go out of business. A broader, but also more costly operation such as an economic census could be carried out to update the RNE and thus improve the sampling base for enterprise surveys.

The INS survey program, much of which is also part of the five-year economic and social development plan, includes:

National Survey of Economic Activities (ENAE), conducted annually and covering economic units employing more than six paid workers in the industrial, mining, energy, construction, trade, and other services sectors, as well as major agricultural enterprises. The sample was drawn from the RNE. The sampling plan is stratified as follows: comprehensive for all public enterprises regardless of size as well as for private enterprises with at least 50 paid 
employees, and covering a sample of enterprises having between 6-50 paid employees. The overall coverage, as a percentage of the value added/turnover of the industry, is at least 60 percent and the response rate is around 66 percent. The survey allows for the collection of a set of data by product and activity, for use in calculating the national accounts aggregates. It is used for the compilation of the semifinal and final accounts.

Survey of the microenterprise sector, conducted every five years (the most recent surveys were conducted in 1997 and 2002). The RNE serves as the base for sampling and extrapolation and is used to measure the share of the informal sector in GDP. For the 1997 survey, the sample drawn from the RNE was made up of nonagricultural enterprises with fewer than 6 paid employees. The data collected were used to estimate production and employment indicators. The nonresponse rate of over 40 percent is attributable in large part to the weak coverage of these units in the sampling base. ${ }^{16}$

Monthly survey for compiling the industrial production index (IPI) uses a smaller sample of representative enterprises covering the manufacturing, mining, and energy sectors. These data are used to compile both the annual and the quarterly accounts.

Investment survey: (i) semiannual survey to obtain information on investment projects, and (ii) annual survey to collect information on investment returns.

National household budget and standard of living surveys (ENBC) are conducted every five years. The most recent survey, conducted between April 2000 and March 2001, used a sample of more than 12,000 households representative of the entire national territory and all socioeconomic groups. The sample was based on the appropriate principles (stratified random sample, reasonableness tests, substitution in case of nonresponse). The sample base was the $1994 \mathrm{RGPH}$, updated with the results of the 1999 national population and employment survey. The survey provides information on the level of several categories of household consumption expenditure, production for own account, employment, etc., and is considered a good source for national accounts compilation.

The employment survey is conducted annually and was launched in recent years; it provides additional data for compilation of the accounts.

The annual rental survey (since 1997) aims to collect information to estimate real and imputed rents.

The $R G P H$ are conducted every 10 years. The last RGPH occurred in 2004; all the data have been recorded and the preliminary results were published recently.

${ }^{16}$ Due to difficulties in updating the RNE with regard to the small enterprises, the survey sample may include units that had ceased their activity. 
INS ad hoc surveys: a 2001/2002 survey on nonprofit associations was carried out to distinguish the NPISH sector from the household sector in the new series compilation.

In addition to statistical sources, national accounts compilation relies on a number of administrative sources, such as:

Data on the external trade in goods are transmitted monthly by the DGD. They are compiled, validated, and adjusted in terms of value and quantity by the INS, which is recognized as the official source for external trade data. Customs data are weaker with regard to their level of detail. Based on the information provided (quantities and values), the INS constructs unit value indices for exports and imports.

The data on general government come from the Ministry of Finance (MF) and include the general government budget: budgetary revenue and expenditure, accounting records of government administrative agencies and local governments, and special Treasury accounts. The revenue and expenditure accounts of the social security agencies are provided in the form of balance sheets and attached accounts. Although the coverage and level of detail of these data are good, their transmission is sometimes delayed for reasons related to printing and dissemination rather than their production.

To assist in the compilation of the accounts of finance and insurance companies, data on banks and other financial institutions from the BCT, accounting records on the activity of insurance companies provided by the Tunisian Federation of Insurers (FTUSA), and reports from insurance companies are used. In addition, stock exchange bulletins and monetary statistics are consulted in order to compile the financial account and prepare the financial operations tables.

Other sources that contribute to national accounts compilation include: tax data (taxes, VAT, etc.), price statistics (monthly consumer price index-CPI), monthly index of industrial sales prices-IPVI, agricultural data (balances by product, in value and quantity) provided by the Ministry of Agriculture (MA), various indicators of transport activity (balance sheets of enterprises that did not respond to the surveys, number of taxis, etc.) from the Ministry of Transport, indicators provided by the Office of Tourism (for example, number of overnight stays), information on housing construction (building permits), etc. 


\section{Main sources for annual estimates}

\begin{tabular}{|c|c|c|}
\hline \multicolumn{3}{|c|}{ Production approach } \\
\hline Industry & Main source data & Quality of coverage \\
\hline $\begin{array}{l}\text { Agricultural products and } \\
\text { fisheries }\end{array}$ & $\begin{array}{l}\text { MA (complete data on agricultural and } \\
\text { fisheries products) }\end{array}$ & Good \\
\hline $\begin{array}{l}\text { Manufacturing industries } \\
\text { (including repairs) }\end{array}$ & $\begin{array}{l}\text { National Survey of Economic Activities } \\
\text { (ENAE) (annual) }\end{array}$ & Good \\
\hline Minerals and ores & $E N A E$ & Good \\
\hline Oil and gas & $E N A E$ & Good \\
\hline Electricity & $E N A E$ & Good \\
\hline Water & $E N A E$ & Good \\
\hline Construction & $\begin{array}{l}\text { ENAE } \\
\text { Estimates based on building } \\
\text { permitsGeneral government budget }\end{array}$ & Satisfactory/Poor \\
\hline Trade & $\begin{array}{l}\text { ENAE } \\
\text { Estimates based on SUT }\end{array}$ & Poor \\
\hline $\begin{array}{l}\text { Transport and } \\
\text { telecommunications }\end{array}$ & $E N A E$ & $\begin{array}{l}\text { Good / } \\
\text { Poor for land transport }\end{array}$ \\
\hline Hotels and restaurants & $\begin{array}{l}\text { ENAE } \\
\text { National Office of Tourism }\end{array}$ & $\begin{array}{l}\text { Good/ } \\
\text { Poor for } \\
\text { cafés-restaurants }\end{array}$ \\
\hline $\begin{array}{l}\text { Financial and insurance } \\
\text { services }\end{array}$ & $\begin{array}{l}\text { ENAE } \\
B C T \\
\text { FTUSA }\end{array}$ & Good \\
\hline Other market services & $\begin{array}{l}\text { ENAE } \\
\text { Other data (ad-hoc enquiries, employment } \\
\text { data, etc.) }\end{array}$ & Poor \\
\hline General government & $M F$ & Good \\
\hline Tourism and other travel & $B C T$ & Good \\
\hline
\end{tabular}

\section{Expenditure approach}

\begin{tabular}{|l|l|l|}
\hline Expenditure category & Main source data & Quality of coverage \\
\hline Household final consumption & ENBC (every five years) & Good \\
\hline $\begin{array}{l}\text { General government final } \\
\text { consumption }\end{array}$ & $\begin{array}{l}\text { Estimate based on documents provided by } \\
\text { the MF }\end{array}$ & Good \\
\hline Gross fixed capital formation & $\begin{array}{l}\text { ENAE } \\
\text { Housing estimates } \\
\text { Investment survey }\end{array}$ & Satisfactory \\
\hline Change in inventories & $\begin{array}{l}\text { ENAE } \\
\text { Estimates of inventories of certain } \\
\text { agricultural products provided by MA }\end{array}$ & Poor \\
\hline $\begin{array}{l}\text { Imports and exports of goods } \\
\text { and services }\end{array}$ & $\begin{array}{l}\text { BGD (balance of payments) } \\
\text { BCT }\end{array}$ & Good \\
\hline
\end{tabular}


For the quarterly accounts, subannual surveys are conducted to collect data on the volume and prices of mining, energy, and manufacturing activities. The other quarterly data come from administrative sources.

Quarterly GDP data are calculated using econometric methods (benchmarking), which are based on annual ratios between the aggregate (production or value added by industry or subsector) and the indicator(s) selected (in general, the production of the same sector or subsector), the trend of which is assumed to be similar. The following table contains all the indicators used to estimate quarterly GDP. It illustrates the weakness of sources for the quarterly estimates of construction, agriculture, and services in general for which there are no sources or the quarterly indicator chosen does not ensure a proper representativity.

Main sources for quarterly estimates

\begin{tabular}{|c|c|}
\hline Industry & Indicator(s) \\
\hline Agriculture and fisheries & $\begin{array}{l}\text { No quarterly source for some agricultural production. } \\
\text { Use of extrapolation made for the annual account } \\
\text { (particularly grains) } \\
\text { Part-year indicators for tree farming, market gardening, } \\
\text { fisheries, and poultry farming) }\end{array}$ \\
\hline Industries & IPI at level 50 of the industrial classification \\
\hline Construction and public works & Local sale of cement and related products \\
\hline Transport & $\begin{array}{l}\text { Statistics on freight shipments by rail, air, or sea, as well } \\
\text { as data on passenger travel }\end{array}$ \\
\hline Telecommunications & $\begin{array}{l}\text { No quarterly source. Use of extrapolation made for the } \\
\text { annual production }\end{array}$ \\
\hline Hotels, cafés, and restaurants & $\begin{array}{l}\text { Number of overnight hotel stays (for the production of } \\
\text { hotels) } \\
\text { No quarterly source for the production of cafés and } \\
\text { restaurants. Use of extrapolation made for the annual } \\
\text { production }\end{array}$ \\
\hline Other nonfinancial market services & $\begin{array}{l}\text { No quarterly source. Use of extrapolation made for the } \\
\text { annual account }\end{array}$ \\
\hline Financial and insurance institutions & $\begin{array}{l}\text { No quarterly source. Use of extrapolation made for the } \\
\text { annual account }\end{array}$ \\
\hline Non-market services & $\begin{array}{l}\text { No quarterly source. Use of extrapolation made for the } \\
\text { annual account }\end{array}$ \\
\hline
\end{tabular}


The sources for compiling quarterly accounts using the expenditure approach are still being developed. To improve these estimates, more direct indicators should be developed, especially for final consumption and gross fixed capital formation (GFCF).

\subsubsection{Source data reasonably approximate the definitions, scope, classifications, valuation, and time of recording required.}

Most of the source data satisfy the requirements of national accounts compilation, and the coverage of industries is adequate. Because national accountants participate in the establishment of technical files for the INS surveys, the definitions and concepts used can be easily adapted for national accounts purposes.

However, some discrepancies concerning sources can be mentioned. The most significant concerns the old classifications used in the currently published series of national accounts, which differ from those used in business accounting and in the statistical surveys, so that additional bridging is necessary. This problem does not arise for the new (unpublished) series based on the $1993 S N A$, as the classifications are consistent both with business accounting and with the administrative statistics produced by other public agencies.

Another difference of the currently published series vis-à-vis the national accounts standards concerns the time of recording (recording of government transactions on a cash basis), which particularly affects certain categories of government data. However, the results of the recent study on differences in the time of recording and their impact on the national accounts indicate insignificant differences for government transactions, and pertain to the adjustment of taxes (approximately one month).

\subsubsection{Source data are timely.}

In general, source data are available within acceptable time periods. However, there are some delays in disseminating the balance of payments and government statistics, which makes it difficult to produce and disseminate the quarterly accounts on a timely basis. The time required to disseminate the balance of payments should also be reduced to help in the more timely compilation of the preliminary annual accounts.

\subsection{Assessment of source data}

3.2.1 Source data-including censuses, sample surveys, and administrative records-are routinely assessed, e.g., for coverage, sample error, response error, and nonsampling error; the results of the assessments are monitored and made available to guide statistical processes.

For surveys, the INS has data on sampling errors. The non-response rate is taken into account in adjusting the extrapolation coefficients. The source data are first checked (manual coding check, software consistency tests, etc.) in the regional offices following collection. Outliers 
are identified and corrected, and suspect values are confirmed or corrected, sometimes by checking back with respondents.

The accuracy of administrative data, such as budget data and external trade statistics, is also checked regularly, and explanations are requested when there are questions. In any case, staff responsible for sector compilation collect data on any change in the economy well before the accounts are compiled for a given year, in order to provide a better explanation of atypical changes.

The source data are analyzed in order to correct as many errors as possible. The analysis includes checking temporal consistency as well as consistency with other related data sources. In particular, the source data are checked in relation to the national accounts definitions, their valuation principles, reference periods, and proper classifications.

\subsection{Statistical techniques}

\subsubsection{Data compilation employs sound statistical techniques to deal with data sources.}

Survey data are processed electronically to detect errors (coding, revision, etc.) (see also 3.2.1.). Recorded data are adjusted only when required. When enterprises with a major share of a given industry fail to respond, they are contacted several times to ensure their cooperation.

The use of old benchmark data (1983) is limited mostly to the calculation of technical coefficients for the intermediate consumption of certain products (less than 20 percent). Additional data sources are sought to check the accuracy of the data. Adjustments to improve data coverage are made to the extent possible by cross-checking data from different sources.

\subsubsection{Other statistical procedures (e.g., data adjustments and transformations, and statistical analysis) employ sound statistical techniques.}

Methods of adjusting data sources are developed to improve data coverage and conformity with international standards. For example, to incorporate the unobserved economy in the currently published GDP, the INS uses an estimation method based on cross checking data from various sources, experience in the subject, and a good knowledge of the sector in question. For example, for small units in the food processing, textile, and services (especially trade) sector, which are not included in the directory of enterprises (a category more difficult to update), the INS adds specific percentages per industry in calculating output by industry. Compensations in kind are also estimated and added to specific industries (transport and electricity). The share of the activities of the unobserved economy amounts to 7 to 10 percent of GDP. 
Production approach

Compilation of the annual accounts is based largely on the results of the ENAE and on an annual input-output table covering 115 industries by 115 products, and 115 industries by 400 products for the SUTs. For publication purposes, the data are aggregated at the level of 20 sectors of activity. Detailed data are available for those who request them.

To estimate the value added, the use of fixed ratios more than five years old is limited (less than 20 percent). The work is done in stages, starting with the basic structure of the IOT for 1983 (reference year), followed by sectoral analysis to correct certain positions by replacing the technical coefficients derived from the 1983 IOT with the current data (more than 20 percent of replacements). For the rest, value added is calculated using the 1983 technical coefficients within the SUT framework. In the next stage, a comparison is made for each sector between the resulting IOT and the data obtained from the production accounts by sector, priority being given to the accounts by sector (which means that the detailed production estimates of the current sources are reliable). At the end of the iterations, the use of fixed ratios is reduced to less than 20 percent. For the new (unpublished) series, the technical coefficients have been calculated using a new benchmark year, which is 1997.

Specific issues:

Owner-occupied dwellings: Housing output is valued on the basis of the rent paid for similar accommodation. For the current series, the extrapolations are based on the results of the rental survey of 1983, whereas the new series uses the results of the 1997 rental survey. The main reason for this is the need to avoid a sudden break in the current series, as the difference between the results of the two surveys is significant. ${ }^{17}$

Work in progress: In the two series, livestock reared for purposes of food, construction, and the output of large equipment are considered work in progress. Growing crops, standing timber, and stocks of fish are not considered work in progress.

Construction: The INS follows the recommendations of the 1993 SNA and estimates the value of housing construction projects using the housing (or buildings, as applicable) equivalents method. This method consists of spreading the value of constructed buildings (individual or collective) over time using the semiannual completion grids (over an average period of 3 years), based on building permit (area) data. The results are adjusted with margins for unauthorized/uncompleted construction to take account of the actual situation in Tunisia. The current grids date back to 1983. The estimates obtained with this approach are then compared with the results of the RGPH before they are considered reliable.

${ }^{17}$ It constitutes a large portion of the difference between the two GDP figures for 1997. 
Inventory valuation is not adjusted to eliminate holding gains or losses. The figures recorded in the accounting documents of enterprises are used to calculate output or intermediate consumption. An exercise to estimate the holding gains or losses on inventories was carried out for the new (unpublished) series, but the information proved insufficient to yield good results.

Consumption of fixed capital is estimated at an aggregated level using the perpetual inventory method for the new (unpublished) series only.

Trade: In general, the value of trade sector output is estimated by comparing the extrapolations obtained using the 1983, 1984, and 1985 results (ENAE) with those obtained by applying trade margin rates to domestic production plus imports by product. ${ }^{18}$ Because the comparisons in recent years revealed significant differences between the estimates resulting from the two methods, the latter method was chosen.

Basis for recording: See 2.4.2.

Volume estimates: Volume measurements are obtained in the context of the SUTs by product using the double deflation method. Thus, the volume measurement of each component of the supply and use of a product is obtained either by deflating with a price index or by extrapolating using the IPI. The results are aggregated by activity to obtain value added as a residual (by subtracting the volume of intermediate consumption from the volume of output). Although the technique is appropriate, the small range of price indices (CPI, IPVI, and unit value indices for external trade) sometimes causes problems, particularly for services. To calculate the volume of trade margins, the INS uses volume change indicators (growth rate) according to uses (intermediate consumption, final consumption, GFCF, exports), which is consistent with the accepted standards. Conversely, the volume of taxes/subsidies on products, to the extent that they are differentiated (in the new series of accounts), is obtained by deflating the current value (the change in the tax rate is used as the price indicator). However, the base year (1990) is not changed every five years at a maximum, as is generally recommended.

Expenditure approach

Estimates of GDP expenditure components are obtained in the context of the SUT by product or, in most cases, inventories are obtained as a residual. In general, expenditure estimates are calculated at a fairly detailed level to match the IOTs.

Household final consumption expenditure is estimated at the fairly detailed level for SUT purposes, using the COICOP. Adjustments are made to match the presentation of the currently published series of accounts, but since the new (unpublished) series uses the same classification as in the source data, there are no adjustment problems for the new series. A

${ }^{18}$ Assuming they are entirely consumed within the same period. 
number of minor household final consumption positions are obtained as residuals in the SUT context.

Government final consumption expenditure is presented at a sufficiently detailed level and excludes incidental sales. It should be noted that the new (unpublished) series uses the COFOG for these calculations.

Gross fixed capital formation GFCF is calculated by sector of activity and by type of assets. The annual data collected through the ENAE allow for a breakdown into five categories: land, buildings, technical installations, industrial equipment and tools, transport equipment, and other tangible fixed assets. A study on GFCF was conducted in the context of the transition to the new SNA. The results were incorporated into the calculation of GFCF in the new series.

In most cases, the estimate of changes in inventories is obtained as a residual in the context of the SUT, at the product and activity level (with the exception of grain inventories, for which the data are collected directly and provided by the MA).

The consumption of nonresidents is excluded from household final consumption expenditure and included in exports. The consumption of Tunisian residents abroad is included in household final consumption expenditure and in imports.

NPISH final consumption, which is not calculated, is included with household final consumption in the current series.

Imports and exports of goods and services are determined on the basis of data from customs (imports and exports of goods) and the BCT (balance of payments).

In the total estimates of each category of expenditure, the use of fixed ratios more than five years old is less than 20 percent.

Volume estimates: Insofar as possible, dedicated price indices or deflators are used to deflate GDP components at a fairly detailed level, in order to correctly reflect trends. The implicit household consumption deflator moves similarly with the CPI. Government final consumption expenditure is calculated by deflating production costs. In particular, the wage bill ( 80 percent) is deflated using an index of wages ${ }^{19}$ in the civil service. The volume of changes in inventories is calculated as a residual.

Although at times the use of more specific deflators could enhance the reliability of the results, the techniques used by the INS to compile the national accounts are generally sound. One strong point is the work at a highly detailed level in the SUT context.

${ }^{19}$ Government wages are raised every year in accordance with a three-year agreement. 
Specific quarterly compilation techniques

The approach to compiling the quarterly accounts comprises three stages.

The first stage consists of seasonally adjusting the quarterly indicators. SAS software is used for the operations. The second stage consists of "benchmarking" the seasonally adjusted indicator using the annual data, i.e., finding a mathematical relationship between the value shown by the indicator and the values taken as correct in the annual estimates. Although the mathematical relationship provides a quarterly series over the period covered by the indicator, the annual sum is not equal, over the estimation period, to the annual series: it differs by the residuals of the regression. The third stage in preparing quarterly estimates consists of distribution of discrepancies between the annual and the quarterly accounts (benchmarking to annual data) when the new annual accounts data become available. In general, the techniques used by the INS to prepare quarterly estimates are consistent with international practices. Some weaknesses are noted with regard to the quarterly indicators selected to monitor developments in various industries. For some sectors, the coverage is less complete (agriculture and construction) or insufficiently representative (different trend of the quarterly indicator and the annual data, particularly for certain services) (see also 3.1.1).

\subsection{Assessment and validation of intermediate data and statistical outputs}

\subsubsection{Intermediate results are validated against other information where applicable.}

The data from the main sources used to compile the national accounts statistics are checked whenever possible against other sources. For example, (a) in the case of taxes, survey results are checked against government data; (b) for interest, BCT data are used to check the survey data.

\subsubsection{Statistical discrepancies in intermediate data are assessed and investigated.}

Detailed SUTs, including a sectoral analysis of products, are prepared with a view to identifying and eliminating discrepancies. In general, the best source is selected after analysis.

\subsubsection{Statistical discrepancies and other potential indicators of problems in statistical outputs are investigated}

The discrepancy between the GDP figures obtained using the two approaches (production and expenditure) is insignificant in the final version of the accounts. It is reconciled during the summarization process and the figures are published without discrepancies. 


\subsection{Revision studies}

\subsubsection{Studies and analyses of revisions are carried out routinely and used internally to inform statistical processes (see also 4.3.3)}

The annual national accounts are compiled in preliminary, semifinal and final versions. The initial national accounts estimates are revised with supplementary information according to a clearly-defined internal schedule. Apart from simple comments on the scope of these revisions, no assessment of scale is performed to detect biases, data fluctuations, long-term trends, etc.

Information on the quality of sources is obtained when the various versions of the national accounts are prepared, so that appropriate choices can be made among them when compiling the summary accounts, but these choices are not documented.

The transition to the new method of compiling the accounts (1993 SNA) led to an analysis of the differences in concept, methods, and calculation that contribute to the discrepancies observed between the current GDP series and the new series. These studies should be made available to the public.

\section{Serviceability}

\subsection{Periodicity and timeliness}

\subsubsection{Periodicity follows dissemination standards}

The periodicity of the annual and quarterly GDP estimates is consistent with SDDS requirements.

\subsubsection{Timeliness follows dissemination standards}

The normal lag for the dissemination of quarterly national accounts estimates is consistent with SDDS requirements, except for the first quarter, in which case the lag is a little more than a quarter. ${ }^{20}$ The lag for the dissemination of the annual aggregates is 12 months following the end of the reference year. However, the MDCI prepares the initial version of the accounts (preliminary accounts) well ahead (around six months) for purposes of the government's budget, thus complying with the SDDS recommendations.

\footnotetext{
${ }^{20}$ Tunisia exercised a flexibility option for this requirement to subscribe to the SDDS.
} 


\subsection{Consistency}

\subsubsection{Statistics are consistent within the dataset}

The annual national accounts statistics are, by design, inherently consistent. In particular, there is no statistical discrepancy regarding GDP among the various approaches. ${ }^{21}$ Although the estimation of the main aggregates is made independently in the national accounts, the fact that they are consistent in the IOT and the integrated economic accounts table leads to a single estimate, as a result of a series of iterations.

Estimates of GDP at current prices, volume measurements, and deflators (implicit) are consistent in the formula "value = volume times price."

The quarterly GDP estimates are generally consistent with the annual estimates. The concepts, definitions, and classifications governing preparation of the quarterly estimates are identical to those used to calculate the annual estimates. However, the methods used for the annual accounts are different from those used for the quarterly accounts; the latter are based specifically on an econometric approach. The discrepancies are more apparent at the sectoral level (manufacturing, construction, etc.) than at the level of the economy as a whole. The benchmarking of the annual series occurs during the annual revision of the semifinal accounts. Discrepancies are eliminated in a benchmarking procedure based on minimizing the discrepancies (in a least squares approach).

\subsubsection{Statistics are consistent or reconcilable over a reasonable period of time}

The INS publishes consistent time series with a 1990 price base and using the framework of the benchmark year 1983. For the quarterly accounts, the series go back only to 1997, with base 1990. At present, to avoid discrepancies with the series of preliminary accounts compiled by the MDCI for the economic budget, the policy is not to change the methodology before the start of the new five-year economic development plan. Consequently, the new series of accounts now being prepared, ${ }^{22}$ which conforms to the concepts and definitions of the 1993 SNA and the new base 2000, will be adopted at a later date. The INS plans to reconstruct the retrospective series by going as far back in time as possible (at least to 1996).

An analysis of changes and discrepancies in GDP and its main components between the two series is being prepared.

The INS has a document containing retrospective national accounts data (since 1961). ${ }^{23}$ This document, which is a rich source of information for research, could be disseminated in a special publication or made available to the public in some other way.

${ }^{21}$ The production approach and the expenditure approach are reconciled in the preparation process.

${ }^{22}$ The work is nearly completed for the 1997-2001 period.

${ }^{23}$ A GDP series since 1961 but which is not linked to the current methodology. 


\subsubsection{Statistics are consistent or reconcilable with those obtained through other data sources and/or statistical frameworks}

The national accounts statistics are broadly consistent with the balance of payments statistics and the government finance statistics, as they are based largely on the same sources. Regarding the consistency of the external account with the balance of payments, apart from conceptual variations, there are some differences specifically related to the different treatment of current and capital transfers, owing to the different classifications, but these are reconcilable.

\subsection{Revision policy and practice}

\subsubsection{Revisions follow a regular and transparent schedule}

Revisions follow a predefined schedule, which has been in place for a number of years, but this fact is not known by many users.

During a given year $n$, the compilation of the different versions of the annual national accounts by the INS is carried out as follows:

- Preliminary accounts for year $n-1$;

- Semifinal accounts for year $n-2$; and

- Final accounts for year $n-3$.

The preliminary annual accounts for year $n$ are published toward the end of the following year and the final accounts at the end of the third year (see also 4.1.2). The initial estimates (preliminary accounts) of the annual national accounts are revised when more detailed data become available, particularly from the ENAE, administrative data, etc.

The quarterly accounts are constantly revised. First, the two-year revisions ${ }^{24}$ of the annual accounts are incorporated. In addition, any changes in the annual accounts due to the transition to a new base or the implementation of a new methodology (e.g., $1993 \mathrm{SNA}$ ) are incorporated into the quarterly accounts shortly afterwards. Thus, the changes generated by the introduction of the new series of annual accounts will be reflected in the quarterly accounts after the release of the new annual series.

\subsubsection{Preliminary and/or revised data are clearly identified}

Publications clearly identify the preliminary and semifinal accounts. The revised data are disseminated at the same level of detail as the original data.

${ }^{24}$ Semifinal and final accounts. 


\subsubsection{Studies and analyses of revisions are made public (see also 3.5.1)}

No explanation of annual revisions is provided in the publication of the statistical series. At present, the publications do not give the reasons for revisions except in the case of major changes.

\section{Accessibility}

\subsection{Data accessibility}

\subsubsection{Statistics are presented in a way that facilitates proper interpretation and meaningful comparisons (layout and clarity of text, tables, and charts)}

The national accounts statistics are disseminated in the form of tables accompanied by a summary of methodological notes, but without any commentary or chart to facilitate analysis.

The main national accounts publication is the document entitled Les comptes de la nation, in which the national accounts estimates are disseminated at a fairly detailed level and cover five years. The annual accounts (an abridged version) are included in the Annuaire statistique (Statistical Yearbook) of the INS and in the brochure Tunisie en chiffres (Tunisia in Figures), as well as by other institutions (the Bulletin économique of the MDCI and the Rapport of the $\mathrm{BCT}$ ). Finally, the national accounts tables are available to the general public on the INS website. The INS plans to include a CD-ROM in the national accounts publication containing a short series of accounts, as covered in the hard copy publications. However, the INS could choose to prepare a CD-ROM containing the main long series of the annual accounts and the series of quarterly accounts, in PDF and Excel format, as well as a set of methodological notes.

There is no publication devoted exclusively to the quarterly accounts. A seasonally adjusted version of the quarterly accounts is disseminated on the Internet in the form of tables covering up to eight quarters, without any accompanying commentary or charts.

\subsubsection{Dissemination media and format are adequate}

The national accounts are disseminated on a variety of media. The main results (GDP aggregates) are initially released in the form of a press release issued by the overseeing ministry, followed by publication on the Internet before appearing in the dedicated publication.

The following are available upon request: recently disseminated data and older (back to 1983) or more detailed time series on diskette or by e-mail. This service is free of charge, but this is not clearly indicated. Nevertheless, the INS receives a large number of data requests from the public. 


\subsubsection{Statistics are released on a preannounced schedule}

The release schedule for the annual accounts series is not preannounced. However, owing to the regularity of publication of the annual accounts, major users are aware of the approximate release dates for new data. The INS website includes a release calendar for the quarterly accounts, based on the SDDS presentation, which indicates when the quarterly GDP data will be posted next.

\subsubsection{Statistics are made available to all users at the same time}

The statistical series are made available simultaneously to all users outside government.

\subsubsection{Statistics not routinely disseminated are made available upon request}

Unpublished (but not confidential) data are provided free of charge upon request. However, the availability of unpublished statistics and the terms governing access to them could be publicized more widely (on the Internet, for example).

\subsection{Metadata accessibility}

5.2.1 Documentation on concepts, scope, classifications, basis of recording, data sources, and statistical techniques is available, and differences from internationally accepted standards, guidelines, or good practices are annotated

Summary documentation accompanies the annual accounts publications and is also available on the website. Except for the metadata posted on the IMF's DSBB (in English), which are updated regularly, no methodological note on the quarterly accounts is published. Moreover, no link to the DSBB appears on the INS website. Documentation in the form of basic notes is only available internally.

Detailed methodological documentation on the production of the currently published national accounts series was included in a publication (Système de comptabilité nationale tunisien) in March 1992, but the fact that it is available to the public is not well known and there have been no updates.

\subsubsection{Levels of detail are adapted to the needs of the intended audience}

Users can access different levels of detail, depending on their needs (see also 5.1.1 and 5.2.1). 


\subsection{Assistance to users}

\subsubsection{Contact points for each subject field are publicized}

Publications and the Internet site generally refer only to the INS, without mentioning the individual or department responsible for producing the data or a contact person within that department. However, the INS has a publications department that provides prompt assistance to users. E-mail technical requests concerning the national accounts are forwarded to the DSECN specialists.

The publications department keeps a file of requests received. Regardless of what information they may be seeking, users who visit the INS are asked to fill out an information request form in order to evaluate the assistance provided to them and to keep a record of such requests. The file of requests could be analyzed regularly to better discern the public's needs.

\subsubsection{Catalogs of publications, documents, and other services, including information on any charges, are widely available}

A catalog of publications is available and is updated every year. The price of statistical products and services is clearly indicated in the catalog, which is also available on the Internet. The dissemination department offers assistance to facilitate orders. 


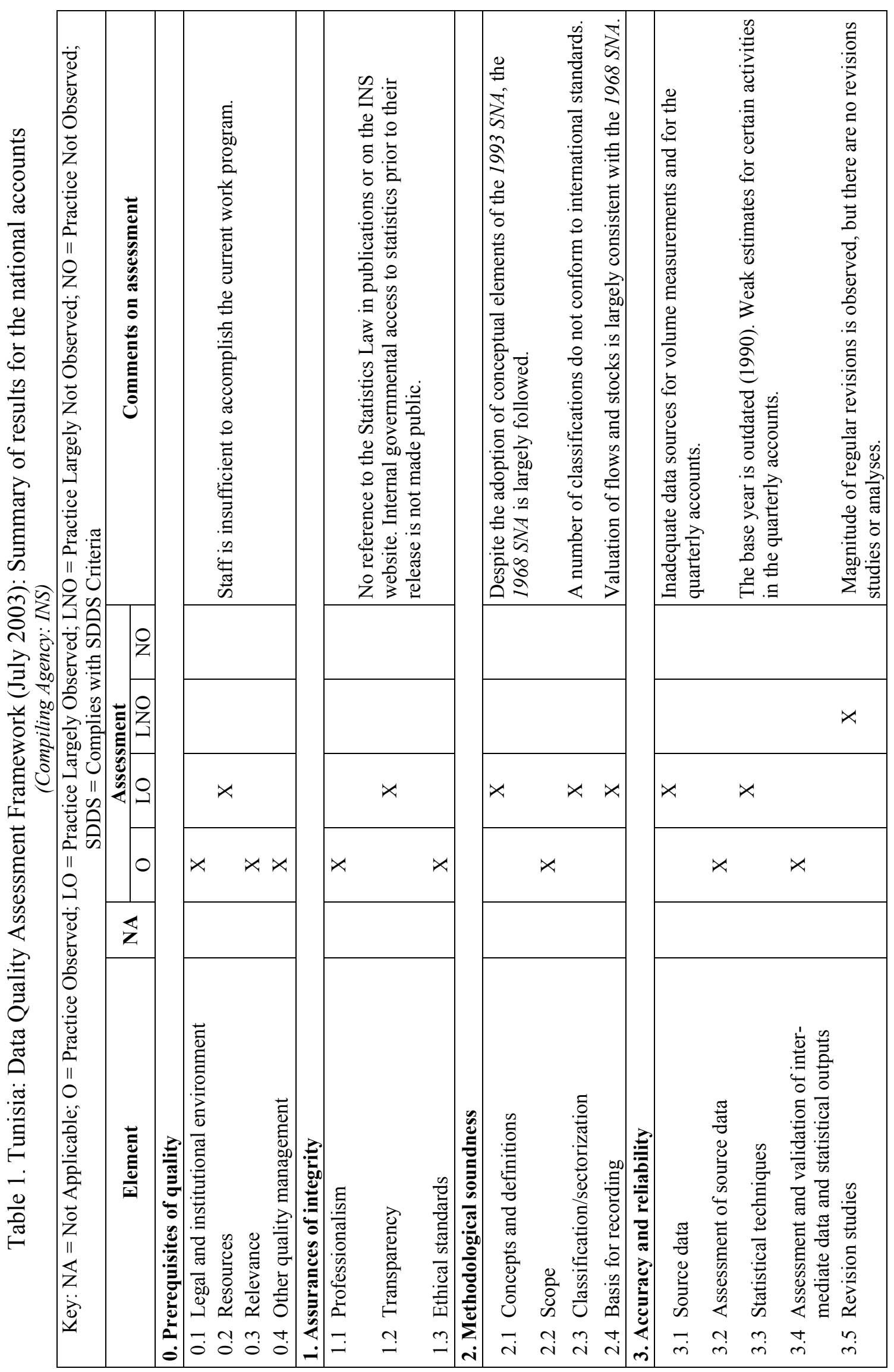




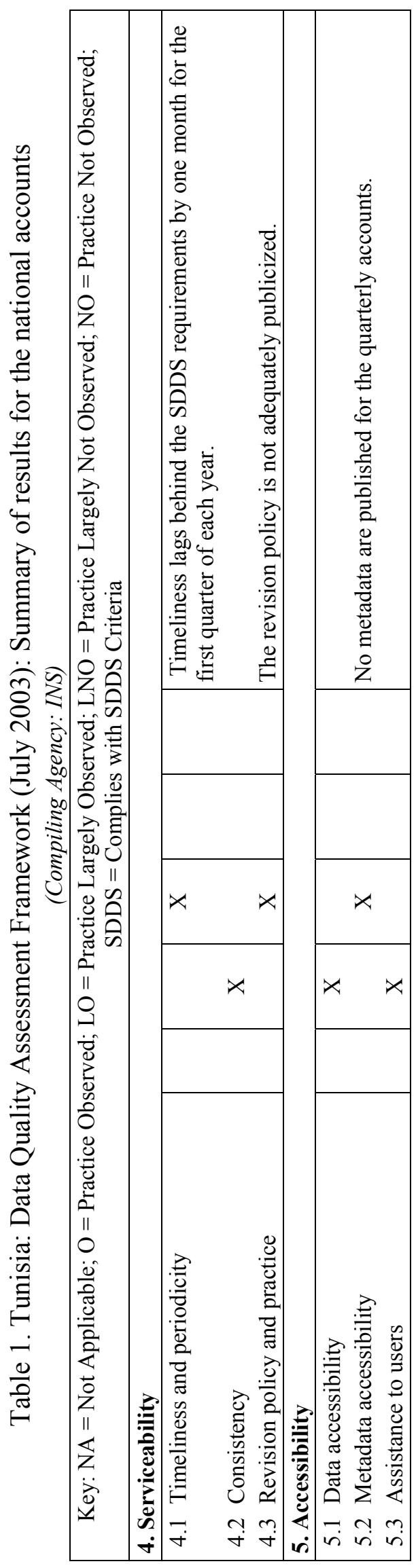




\section{GOVERNMENT FinANCE STATISTICS}

\section{Prerequisites of quality}

\subsection{Legal and institutional environment}

\subsubsection{The responsibility for collecting, processing, and disseminating GFS is clearly specified.}

Article 13 bis of Decree No. 2005-492 of March 1, 2005, amending and supplementing Decree No. 91-556 of April 23, 1991 on the organization of the Ministry of Finance (MF), assigns to the General Directorate of Resources and Balances (DGRE) of the MF responsibility for "preparation and dissemination of public finance statistics." More precisely, the office of statistics collection and classification of the statistics and publications sub-directorate of the Directorate of Studies, itself one of the three Directorates within the DGRE, is responsible for "preparing and disseminating public finance statistics."

With respect to public debt, the General Directorate of Debt Management (DGGD) of the Ministry of Finance (MF) is responsible for preparation and distribution of GFS relating to public debt. Decree No. 2005-492 of March 1, 2005 defines "the management, analysis, and preparation of forecasts on public debt" as duties of the DGGD. The decree only mentions the "monitoring of statistics on external public debt" with no explicit reference to domestic debt statistics, but actual practice also includes the monitoring of such statistics.

The obligation of State accountants (and municipal collectors) to provide the MF with a statement of their budgetary, off-budget, and cash flow receipts and expenditures operations on a monthly basis is governed by Articles 198 and 278 of the Public Accounting Code (Law 73-81 of December 31, 1973, published in Arabic and French in the JORT (Official Gazette of the Republic of Tunisia).

\subsubsection{Data sharing and coordination among data-producing agencies are adequate.}

Coordination within the agencies responsible for producing statistics in general is governed by Law 99-32 of April 13, 1999 on the National Statistical System (SNS), which establishes a National Council on Statistics (CNS). Pursuant to its statute, the CNS is in charge of coordinating statistical work and ensuring cooperation between data producers and data users. With respect to the MF, coordination with the BCT (Central Bank of Tunisia) takes the form of sharing the SIADE information system for data on external government financing and debt, and an informal but effective cooperation with respect to domestic government financing and debt. Other than the above-mentioned law, there are no formal arrangements between the MF and the BCT with respect to the compilation of GFS. Instead, there is an informal cooperation that the MF considers satisfactory. With respect to dissemination of GFS, in the absence of a MF website, GFS data are temporarily posted on the CBT website. 
Data on revenues are centralized directly by the Directorate General of Public Accounting (DGCP) based on RAFIK (taxes) and SINDA (customs) applications software and reported to the DGRE within an average of 10 to 20 days after the end of the month. Monthly expenditures are obtained automatically through the financial information management system used for budgeting and accounting requirements (ADEB). The DGGD obtains data on external financing (drawings, payments, and interest) directly from the computerized external debt management system (SIADE), as noted above. The DGGD and the BCT hold meetings to further improve the reliability of SIADE and eventually expand it to cover domestic public debt.

In addition, the DGRE and DGGD report GFS data to the INS (National Statistics Institute) for preparation of the national accounts. However, the scope of the data reported to the INS by the MF is very narrow (budget) and the INS turns to other sources (public administrative units (EPAs), social security funds, local governments) to complete the general government accounts.

Given the fact that the DGRE and the DGGD both produce GFS data and contribute to the formulation and monitoring of budget policy, there is a close link between the preparation of the GFS and their use in the formulation of budget policy.

\subsubsection{Individual reporters' data are to be kept confidential and used for statistical purposes only.}

The principle of data confidentiality does not generally apply to governmental sector units. Rather it covers data collected from state-owned companies, in the case where the GFS cover the entire public sector, which is not currently the case in Tunisia.

\subsubsection{Statistical reporting is ensured through legal mandate and/or measures to encourage response.}

The MF is legally authorized (under Decree 99-32) to access data from all budget agencies before they are verified and/or published. However, the MF needs special legislative and/or administrative powers to access the data of non-budgetary agencies like the EPAs, social security funds, and local governments. It currently accesses these data for compiling summary annual general government data for SDDS requirements on an informal basis.

\subsection{Resources}

0.2.1 Staff, facilities, computing resources, and financing are commensurate with statistical programs.

The DGRE has four employees and the DGGD has 20 employees. Only two of the DGRE's employees and two of the DGGD's employees work directly on preparing the GFS. Staff members in charge of the GFS include people who have been in their positions for several years as well as recent graduates. The qualifications of staff in the general directorates 
involved in producing the GFS are appropriate, and their skills are generally kept up to date. DGRE staff resources for producing the GFS seem particularly inadequate because those who work directly on the GFS are often involved in other unrelated tasks for a significant portion of their working hours. Moreover, it should be noted that several vacant positions within the DGRE also lead to increased work pressures on current personnel, and employees are routinely called upon to help in the work of directorates other than the one in which they formally belong. Finally, the employees who have received training in GFSM 2001 are not always involved in preparing the GFS, and thus run the risk of gradually losing their knowledge in this area. Officials have indicated that there are plans to reinforce the staffing of DGRE in the coming months. For its part, the DGGD says it has no lack of staff.

Allocated computing resources to DGRE and the DGGD appear to be sufficient.

\subsubsection{Measures to ensure efficient use of resources are implemented.}

DGRE management ensures that resources are used effectively by redeploying staff from one unit to the other in response to changing needs. Staff performance is also evaluated annually. However, the costs of producing the GFS are not quantified or evaluated on a regular basis, as there is no formal requirement to charge the time for such activity. Only a standard job description sheet outlines procedures and working methods.

\subsection{Relevance}

\subsubsection{The relevance and practical utility of existing statistics in meeting users' needs are monitored.}

The GFS data produced by the DGRE and the DGGD are continuously updated for methodological soundness on the basis of information received through the regular participation of the staff in meetings and statistical seminars at the invitation of international and regional organizations such as the IMF, IMA, and ADB. These two directorates provide all the details that are needed at the request of users who visit the MF, and keep a list of information requested. However, other than the informal collaboration with the BCT and INS as GFS users, there is currently no regular process (for example, based on consultative committees of users or task forces) to effectively consult with the principal data users (universities, the press, or other private sector representatives), examine the utility of existing statistics (level of detail, periodicity, timeliness), or define new data requirements. The MF participates in roundtables organized by the CNS, and in the work of a technical committee in charge of identifying economic and financial indicators. However, the participation of the MF on the CNS, which might be the ideal body for communicating users' needs and for engaging in dialogue on this subject, could be better utilized for that purpose. 


\subsection{Other quality management}

\subsubsection{Processes are in place to focus on quality.}

The importance assigned to data quality and transparency is reflected in Articles 3 and 4, respectively, of Statistics Law 99-32 on the SNS. DGRE and DGGD staff are made particularly aware of the importance of data reliability and accuracy in preserving the credibility of Tunisia's GFS and of the MF. Staff training in general and the professional memorandum sent to new employees in particular insist on the importance of quality and give the staff a good understanding of how to guarantee it.

\subsubsection{Processes are in place to monitor the quality of the statistical program.}

Systematic reviews to check the monthly GFS are conducted before their release. DGRE and DGGD employees systematically perform crosschecks and reclassifications to improve data quality. There is an explicit priority in GFS work to minimize errors.

\subsubsection{Processes are in place to deal with quality considerations in planning the statistical program}

The DGRE and the DGGD are well aware of the trade-offs necessary among the various dimensions of quality, given staffing limitations. Specifically, the staff is aware of the tradeoff between timeliness and coverage needed to achieve high quality data. Thus, in order to ensure more rapid distribution of monthly data on domestic financing, the data are presented by maturity rather than by type of debt holder. Similarly, to meet SDDS requirements the scope of the monthly data is limited to the budget, while the annual GFS for the SDDS cover general government. There is room, nonetheless, for a more systematic dialogue with users on the dimensions of quality and for reflecting the conclusions into the statistical program.

\section{Assurances of integrity}

\subsection{Professionalism}

\subsubsection{Statistics are produced on an impartial basis.}

Impartiality in the compilation of GFS data is clearly specified by Article 3 of Law 99-32 on the SNS. Article 3 states that "The structures of the SNS enjoy scientific independence ... They collect, process, store, and disseminate (data) in accordance with standards and requirements for producing quality data that are entirely impartial and objective." Moreover, the preparation of the GFS is based on source data derived in large part from the information maintained by public accountants (but also from payment authorizing officers and financial controllers) in the course of their work, with the strict standards that this implies. 
The DGRE is well aware of the need to reprocess statistics in order to move from a budgetary presentation to an economic presentation, and says it is entirely free, if necessary, to discard the source data reported if they are considered incorrect or unreliable. This is sometimes the case with the identification and elimination of intra-sectoral transactions when consolidating the operations of social security funds and local governments with budget operations.

Professional qualifications are a determining criterion for recruitment and promotion within the DGRE. The number of years of university training and the degree earned play an important role in recruitment. Professional experience is also important: the director in charge of preparing the GFS according to GFSM 86 from the organic budget presentation has very significant technical experience and high-level training in this area.

Most DGRE employees, including the main person in charge of preparing the GFS, as well as some of those with the DGGD, have participated in IMF seminars on GFSM 1986, GFSM 2001, financial programming, as well as in other courses and workshops offered by regional and international organizations to expand their knowledge of statistical practices.

Research and analysis are encouraged to the extent that they are subordinated to the tasks to be completed. Given current constraints on staff resources, the time that can be devoted to research is rather limited. In the recent past, only one MF employee has been able to publish (a textbook on public finances).

\subsubsection{Choices of sources and statistical techniques as well as decisions about dissemination are informed solely by statistical considerations.}

The choice of sources is dictated by the accounting data. For the GFS on the DSBB, dissemination dates are dictated by the SDDS dissemination schedules.

\subsubsection{The appropriate statistical entity is entitled to comment on erroneous interpretation and misuse of statistics.}

The DGRE and the DGGD are authorized to comment publicly and in a timely fashion, usually in the press, on erroneous interpretations or misuse of statistics in the press and elsewhere, although this situation has never arisen. They may also provide explanatory and informative documents (particularly to the press) to prevent erroneous interpretations.

\section{$1.2 \quad$ Transparency}

\subsubsection{The terms and conditions under which statistics are collected, processed, and disseminated are available to the public.}

Decree No. 2005-490 of March 1, 2005 organizing the MF is available to the public, as are Organic Law No. 2004-42 of May 13, 2004, final budget laws, and various pieces of legislation organizing government accounts and budget nomenclature. These documents are 
available on request from the MF and are also published in the JORT, and posted on the government's Internet site, as the MF does not have its own site.

Apart from a reference to the Organic Law in the monthly report on public finances, information on the conditions governing GFS dissemination and the role of the MF is available only upon request. Such information is also mentioned in the context of the SDDS data and metadata on the IMF's Internet site (Dissemination Standards Bulletin BoardDSBB), which is in English only.

The monthly and annual statistical publications (Public Finances) identify data sources (The Directorate of Studies and Analyses of the DGRE) without, however, including more details on how users could obtain further information from the agency producing the GFS. On the other hand, the DSBB provides information on how to contact the DGRE. The authorities have indicated that a methodological note describing the data compilation procedures as well as information on contact persons will be included in the various monthly (Bulletin) and annual (Annual Report) publications in the future.

\subsubsection{Internal governmental access to statistics prior to their release is publicly identified.}

Other than the DSBB notice on the subject (in English), the public is not officially informed who among the MF staff has access to the data, and at what stage, prior to their release. As GFS are used in economic policy analysis, and considering that the DGRE and DGGD both produce data and contribute to economic decision-making, their staffs participate in economic and financial policy meetings and have preferential access to these data before they are released to users or published. This access seems to be public knowledge. There are no rules governing this preferential access in the context of procedures for approving publication of the GFS.

\subsubsection{Products of statistical agencies/units are clearly identified as such.}

GFS data are clearly identified as products of the Directorate of Studies and Analyses of the DGRE and public debt data are identified as products of the DGGD. However, there is no indication as to which units, including data source units, have actually contributed to the preparation of the GFS. Moreover, the DGRE and the DGGD do not require those who use or reproduce their statistics to acknowledge their sources.

\subsubsection{Advance notice is given of major changes in methodology, source data, and statistical techniques.}

Major changes in methodology are always accompanied at the same time, rather than preceded, by a notice to the public and to users outside the MF. Thus, when VAT proceeds were reclassified from import revenues (customs) to VAT revenues, a note to the public accompanied the first appearance of the data in the new format. 


\subsection{Ethical standards}

\subsubsection{Guidelines for staff behavior are in place and are well known to the staff.}

Article 14 of Law 99-32 of April 13, 1999 on the national statistics system created the CNS, which "monitors compliance with professional ethical standards and the principles of statistical activity." Pursuant to Decree No. 2002-2925 of November 4, 2002, the Director of the Economic Situation and Economic and Financial Analyses at the MF is one of the 28 members of the CNS. Article 25 of Law 99-32 stipulates that "Violations of the provisions of this law and all applicable legislation are recorded by officers of the judicial police and sworn and authorized officials reporting to the Ministry (of Finance) Reports are drawn up on these violations and brought before the Minister (of Finance) who sends them to the Office of the Public Prosecutor. The Ministry (of Finance) officials are required to take the following oath: "I swear in the name of Allah the all powerful to perform my duties selflessly and honestly and to adhere to professional secrecy." The oath is taken before the president of the court of first instance in Tunis. A report is drawn up as a result.

The DGRE and the DGGD also operate under general administrative legislation relating in particular to professional error and ethics in the civil service (civil service employee statute). The guidelines on ethics are made known to the staff upon employment. In addition, the producers of GFS and public debt statistics rely more generally on accounting records, the preparation of which is governed by strict standards, in view of the specific statute for DGCP (Directorate General of Public Accounting) employees within the civil service.

\section{Methodological soundness}

Methodological soundness is assessed against the principles stated in the Government Finance Statistics Manual (GFSM 1986).

\subsection{Concepts and definitions}

\subsubsection{The overall structure in terms of concepts and definitions follows internationally accepted standards, guidelines, or good practices.}

The DGRE produces GFS according to both the concepts and definitions of the Organic Budget Law (No. 2004-42 of May 13, 2004) and GFSM 1986, and disseminates them to a group of users (public sector, banks, embassies, universities, research institutes) through its monthly and annual publications. The organic budget presentation (Government Budget by Operation) appears on page 1 of the monthly report, while a data presentation that follows closely the GFSM 1986 framework appears on page 2. This dual presentation, which is used as the basis for fiscal policy analyses and economic decision-making, is accompanied by numerous charts and tables detailing the various aggregates. However, it runs the risk of confusing readers as the same headings and descriptors (revenues, expenditures) represent either source and use concepts on page 1 ("revenues" include borrowed funds, and "expenses" include amortization) or GFSM 1986 concepts on page 2. Also, this last 
presentation, while following broadly the definitions and concepts of GFSM 1986, does not provide a breakdown of financing by type of debt holder, which makes it difficult to reconcile data on domestic bank financing from the MF with net credit to government from the BCT's monetary survey.

With a view to meeting SDDS requirements, the DGRE produces, based on the organic presentation, a monthly submission (covering the budget) as well as an annual submission (covering the budget, social security funds, and local governments); these strictly follow the GFSM 1986 concepts. The submissions are sent by fax to the BCT (one and six months, respectively, after the end of the period covered in the monthly and annual data) and posted on its site with a direct link to the IMF's DSBB. Similarly, annual GFS data for central government (including social security funds) and local governments (with the necessary reclassifications to ensure their consistency with the GFSM 1986) are sent to STA for publication in the GFS Yearbook.

Public debt data seem to follow the concepts of GFSM 1986, with external and internal debt differentiated according to the concept of residence of the Balance of Payments Manual (BPM5). The DGGD publishes data quarterly as well as annually in a Report on Public Debt, covering direct government debt (based on a narrow budget coverage) as well as guaranteed debt.

Tunisia has not yet developed a plan for the transition to application of the methodology of the GFSM 2001. Like all countries that prepare their GFS according to GFSM 1986, it would benefit from having such a plan. The short GFS mission of July 2004 suggested certain transition phases. The authorities indicated that in the context of that last mission, GFS data were reported to the IMF mission with a view to converting them to the new presentation. However, according to the authorities, technical assistance will be needed for the next phase, which is the transition to recording on an accrual basis.

\section{$2.2 \quad$ Scope}

\subsubsection{The scope is broadly consistent with internationally accepted standards, guidelines, or good practices.}

The monthly GFS only cover the budgetary central government. Government administrative agencies (EPAs), which under the 2005 Budget Law number about 2125, are for the most part not included in the scope of the GFS data. The Budget Directorate completed the incorporation of only 200 EPAs in the 2005 budget, and the process of incorporating most of them will take some time. Although for most of them (hospital centers, high schools, universities) their own resources may not be significant in comparison with the transfers they receive from the budget, the total may turn out to be substantial given their large number. The authorities indicated that efforts are being made to accelerate the process of integrating the EPAs in the government's budget. 
The annual GFS data (published in the Annual Report on Public Finances) have the same very limited coverage as the monthly data. They do not include the EPAs (most of them), social security funds, and local governments. However, local governments' annual accounts are presented separately in that report. Finally, we note that the data are available on all cash transactions that fall within the scope of the GFS.

\subsection{Classification/sectorization}

\subsubsection{Classification/sectorization systems used are broadly consistent with internationally} accepted standards, guidelines, or good practices.

The monthly and annual GFS reports include two different presentations:

(1) The first is quite close to that of the GFSM 1986, with only minor classification differences at the level of revenues from privatizations and repayments on on-lent loans

(2) The second follows the organic budget presentation, under a "source and use of funds" concept that is markedly different from the GFSM 1986.

The tables refer to the first presentation. They are:

(a) Summary table of principal components (revenues and grants, expenditures, deficit)

(b) Two detailed tables of revenues (tax and non-tax) and grants (Table A of the GFSM 1986)

(c) Classification of the functions of government (Table B of the GFSM 1986)

(d) Economic classification of government expenditure and lending minus repayments (table C of the GFSM 1986)

(e) Financing by type of debt instrument (Table E of the GFSM 1986).

The principal differences between the first presentation and the GFSM 1986 tables are:

(1) The summary table does not include financing;

(2) Financing is not presented by type of debt holder (BCT, banks other than the BCT, and non-banks) as in Table D of the GFSM 1986;

(3) In each table, the classifications of revenues, grants, expenditures, and financing do not follow the structure of the presentation of the GFSM 1986.

The authorities indicated that the organic presentation has never generated any comments from the Tunisian public. However, they also indicated that adaptation to the GFSM 1986 methodology will be soon incorporated in the monthly bulletin. 
The data on gross debt of budgetary central government are classified on the basis of residence (resident or non-resident) of the parties to the operations, but without a detailed breakdown by type of debt holder. Regarding the absence of a breakdown of domestic financing by type of debt holder, the authorities indicated that the current presentation by instrument was agreed upon in 2001 so that the monthly GFS could be released in the timeframe required by the SDDS. However, the publication of the domestic financing breakdown by type of debt holder (bank and non-bank) could be incorporated in the bulletin if data are available within the time frame that allows the authorities to fulfill the timeliness requirements for dissemination/publication.

\subsection{Basis for recording}

\subsubsection{Market prices are used to value flows and stocks.}

In accordance with the GFSM 1986 methodology, flows and stocks are valued at the prices paid rather than on the basis of market prices. Flows are valued on a cash basis or its equivalent. Gross public debt is valued at face value, i.e., the amount that the government is obligated to pay when the debt matures. Flows in foreign currency are converted to Tunisian dinars using the mid point between the buying and selling market rates on the date of recording, and the stock of debt in foreign currency is converted by the BCT at the exchange rate at the end of the period under consideration.

\subsubsection{Recording is done on an accrual basis.}

As Tunisia has not yet implemented the GFSM 2001 methodology, operations are recorded on a cash basis (cash received for revenues, disbursements for expenditures). ${ }^{25}$ Although certain source data, such as those of the social security funds, are recorded on an accrual basis, their accounts are adjusted to a cash basis before being sent to the DGRE.

\subsubsection{Grossing/netting procedures are broadly consistent with internationally accepted standards, guidelines, or good practices.}

All transactions are recorded on a gross basis, with the exception of Treasury loans minus repayments, which is appropriate. The only exception is the treatment of on-lent loans: their repayments are recorded on a gross basis (in revenues) rather than a net basis (loans minus repayments). The data on financing are recorded on a net basis, as they should be. Transactions to correct revenues and expenditures (tax reimbursements, for example) are deducted from the amounts in question, in accordance with the GFSM 1986 methodology.

Public debt is presented net of the balance in the Treasury's account at the BCT.

${ }^{25}$ For annual data, provisional expenditures data based on payment orders are produced until the end of the complementary period (20 days). 


\section{Accuracy and reliability}

\subsection{Source data}

\subsubsection{Source data are obtained from comprehensive data collection programs that take into account country-specific conditions.}

The sources of data on the budgetary government subsector are complete and allow for the preparation of GFS for this subsector. The source data on government operations are directly captured by various computerized information systems: SINDA for customs revenues, RAFIK for tax revenues, ADEB for expenditures, and SIADE for public debt. The centralizing accountant, who is also the Treasurer, centralizes the data on revenues; the data are made available to the DGRE by the National Treasury of Tunisia (TGT). With respect to expenditures, in addition to the amount of budget appropriations, the integrated expenditure circuit allows the user to know, in real time, commitments, payment orders, and amounts paid. The DGRE accesses the expenditure data directly through ADEB. However, in the case of direct payments for externally financed projects, the information collected by SIADE is more complete, given delays in recording direct payment data in ADEB.

The DGGD uses the "public debt" sub-program of SIADE, which interfaces with the BCT, the paying agent, to produce data on external government debt, debt of enterprises and banks guaranteed by the government, as well as government loans to enterprises and banks. The DGGD monitors the issue and repayment of Treasury bonds, and the government's handling of non-performing public debts with banks and more generally the handling of debts guaranteed by the state. Thanks to the STICODEVAM clearing house, the DGGD says it can produce data on domestic bank (BCT and others) financing and non-bank financing, respectively.

A comprehensive register of individual public sector units is available in the JORT. It is regularly updated as some units are eliminated and others are created and listed in the Budget Law (December 31). It includes not only units covered by the GFS data scope (the budget and cost-sharing contributions (fonds de concours)) but also the EPAs, of which there are 2125 (2005 Budget Law).

The bridge table from the Treasury codes, in which the computerized source data are classified, to the codes for the organic presentation of the GFS, as in the monthly and annual data published by the MF, is directly built on an Excel sheet: detailed tables of revenues (Table A) and expenditures (Table B) are obtained directly in Excel by grouping source data according to their codes as they appear in the first column of the tables. The migration from this organic presentation to the GFSM 1986 presentation for the requirements of SDDS dissemination on the DSBB, as well as for transmission to the STA for publication in the Public Finance Yearbook, is done by deriving and reclassifying various aggregates (revenues, expenditures and net loans, financing and debt) in accordance with the GFSM 1986. 
Data sources are reviewed regularly to ensure the integrity of the data collection system. Thus, the data on tax revenues for large companies (Pétrolière Steg, Telecom) obtained from the Treasury are reconciled with the tax returns filed by these same companies.

The DGRE does not consult the agencies that provide data with respect to updating the chart of accounts or for other changes of this nature, since these basic updates are already present in the budget law, which incorporates all changes that occur during the year.

3.1.2 Source data reasonably approximate the definitions, scope, classifications, valuation, and time of recording required.

The source data used to prepare the GFS are on a cash basis (revenues and expenditures) and are very detailed. Thus, they permit classification according to the breakdown required by the GFSM 1986. However, the scope of these data is limited to the budget.

\subsubsection{Source data are timely.}

\section{Expenditures}

Expenditures are obtained in real time by the ADEB system, with the exception of "direct payments" on projects, where there are delays in the clearance of payments from the donor to the public enterprise or the administration. In the latter case, the data are then extracted from the SIADE system, which turns out to be more reliable. Cross-checks are performed between ADEB and SIADE at year-end.

\section{Revenues}

Monthly budget revenues are centralized by the Treasury and made available to the DGRE within 10 to 20 days after the end of the month. This period allows the DGRE to perform usage checks, and to reclassify the data according to GFSM 1986 before sending them by fax to the BCT on the twenty-ninth day of the next month for posting to the DSBB in accordance with the deadlines of the SDDS. It should be noted that before the tenth of each month the DGCP produces a provisional statement based on more aggregate data (particularly tax revenues and some nontax revenues).

\section{Financing and debt}

The data on external financing and external debt are captured in real time by the computerized SIADE system. Drawings and repayments on Treasury bonds are collected by the STICODEVAM, which sends them to the DGGD. 


\subsection{Assessment of source data}

3.2.1 Source data-including censuses, sample surveys and administrative records-are routinely assessed, e.g., for coverage, sample error, response error, and other nonsampling error; the results of the assessments are monitored and guide statistical processes.

The procedures for assessing source data are not computerized. Although in principle the capture of revenues is done by computer according to the codes, errors in the allocation of revenues can occur and are corrected at the DGRE level.

The accuracy of source data is also checked by the DGRE by means of cross-checks: thus, tax revenues obtained by the Treasury through the RAFIK system are compared with the tax returns of large enterprises (petroleum companies, Telecom, etc.). Discrepancies between the data as well as out-of-trend values are discussed with the reporting units and documented.

Data consistency over time is also checked to detect cases where information is incorrectly reported. For all questions relating to the accuracy of source data, the DGRE relies on direct communication with the reporting agencies.

\subsection{Statistical techniques}

\subsubsection{Data compilation employs sound statistical techniques to deal with data sources.}

The procedures for compiling data minimize processing errors due to coding, editing, and tabulation errors. Preliminary monthly data are eventually replaced by final (checked) data no later than by the end of the month following their publication. However, compilers attempt to achieve an appropriate balance between accuracy and timeliness.

\subsubsection{Other statistical procedures (e.g., data adjustments and transformations, and statistical analysis) employ sound statistical techniques.}

Other than simple reclassifications, there are no statistical techniques in the compilation of the GFS. An Excel sheet bridge table allows the migration of source data to the organic presentation, which is disseminated to a small group of users and published. A presentation in accordance with GFSM 1986 is obtained with a few simple reclassifications of revenues and payments on on-lent loans.

\subsection{Assessment and validation of intermediate data and statistical outputs.}

\subsubsection{Intermediate results are validated against other information where applicable.}

The detailed data obtained from the DGCP on tax revenues are checked against direct company returns before being consolidated to produce the aggregate data. 


\subsubsection{Statistical discrepancies in intermediate data are assessed and investigated.}

Discrepancies (compared to returns) in intermediate data noted in tax revenues are investigated with the companies involved in order to determine the sources of error and quickly correct them.

\subsubsection{Statistical discrepancies and other potential indicators of problems in statistical outputs are investigated.}

The integration of stocks and flows presents no discrepancies at the level of external debt given that the MF and the $\mathrm{BCT}$ share the same source of computerized data. As to domestic debt, data on issuances and repayments of Treasury bonds are gathered by the DGGD (through its agent, the STICODEVAM) and sent by fax to the BCT. The balances of government accounts at the BCT are reported by the BCT. In the absence of regularly available data on the bank and non-bank breakdown of domestic financing, the data from the $\mathrm{BCT}$ and the MF are not systematically compared. In addition, for investment expenditures in "direct payments" (i.e., direct payments by the donor that are not initially recorded by ADEB), bilateral comparisons are made between ADEB and SIADE at year-end, surveys are conducted regularly with donors, and discrepancies are thoroughly analyzed.

\subsection{Revision studies}

\subsubsection{Studies and analyses of revisions are carried out routinely and used internally to inform statistical processes (see also 4.3.3).}

Statistics are routinely archived. However, no revision studies have been conducted to date. At the same time, revisions are taken into account by staff in their work.

\section{Serviceability}

\subsection{Periodicity and timeliness}

\subsubsection{Periodicity follows dissemination standards.}

The periodicity of the GFS on general government operations (budget, social security funds, and local governments) is annual. The periodicity of GFS on central government operations (budgetary only) is monthly. The periodicity of statistics on the debt of budgetary central government is quarterly. Therefore the periodicity of all relevant GFS is consistent with the requirements of the SDDS.

\subsubsection{Timeliness follows dissemination standards.}

The GFS on general government operations (budget, social security funds, and local governments) are disseminated one quarter after the reference period. The GFS on central government operations (budgetary only) are disseminated at the end of the month following 
the reference period. Quarterly statistics on central government debt are disseminated at the end of the quarter following the reference period. Therefore the timeliness of all relevant GFS is consistent with the SDDS.

\subsection{Consistency}

\subsubsection{Statistics are consistent within the dataset.}

The GFS are internally consistent: (1) concepts, definitions, and classification are the same for both annual and quarterly statistics; (2) the sum of quarterly statistics is equal to the annual statistics; (3) aggregates are equal to the sum of their parts; (4) the balance is equal to minus financing; (5) total expenditures in the table by economic type is equal to expenditures in the table by function.

Finally, external financing matches the change in external debt (after taking exchange rate variations into account), and domestic financing matches the change in domestic debt. The mission performed a full consistency check on annual data for 2003 and 2004 to ensure that domestic financing corresponded to the change in the stock of domestic debt, after taking into account government assumption/guarantee operations, the impact of which on the stock of debt is not reflected in actual financing.

\subsubsection{Statistics are consistent or reconcilable over a reasonable period of time.}

Time series covering 1986-2004 are available. These series are reconstructed backwards when data or methodology change. Thus, when the VAT on imports was reclassified from "customs proceeds" to "internal taxes: VAT," the series were completely reconstructed in historical terms.

Any significant development in the data relative to trends is explained in the commentary to the "Annual Report" and the "Plan Follow-up." On the other hand, monthly reports do not contain commentary.

\subsubsection{Statistics are consistent or reconcilable with those obtained through other data sources and/or statistical frameworks.}

The national accounts data are drawn, for budgetary central government, directly from the GFS data of the DGRE and the DGGD, and are thus fully consistent with them in terms of the coverage of budgetary central government.

Similarly, the data on government financial transactions with non-residents are consistent with the balance of payments data. For example, the mission verified that for 2003 the data on net external financing of the budget and external interest due coincide exactly with the balance of payments data. In addition, the data on the stock of external debt are identical in the GFS and the external debt statistics given that they share the same data source, the computerized SIADE system. 
On the subject of transactions with non-residents, it should be noted that non-residents have recently been authorized to hold Treasury bonds up to a limit of 5 percent of the total bond stock. The STICODEVAM is responsible for monitoring the data for this directive.

Banking sector transactions are not identified separately in GFS domestic financing, which makes it difficult from the outset to analyze the consistency of net bank domestic financing in the GFS and net government claims with the banking systems. The only presentation available for domestic financing is by debt instrument (such as issue and repayment of shortterm treasury bonds). In addition, given that these securities can be traded on the secondary market, it is not possible to determine what sector holds them based on issues. The mission examined the consistency of these two data sources for 2003 and 2004 based on supplementary data provided by the authorities and concluded that they are broadly consistent.

As for the lack of a breakdown of domestic financing by debt holder, the authorities indicated that the current presentation by instrument was agreed upon in 2001 to allow for the dissemination of the monthly GFS within the timeframes required by the SDDS. However, the publication and breakdown of internal financing by debt holder (bank and non-bank) could be incorporated in the bulletin if data are available within the time frame that allows the authorities to fulfill the timeliness requirements for dissemination/publication.

\subsection{Revision policy and practice}

\subsubsection{Revisions follow a regular and transparent schedule.}

The SDDS dissemination schedule follows a predictable timetable dictated by the monthly data revision cycle: these data are published one month after the reference month, and the final data are introduced the following month. However, the provisional data are not identified as such, there is no documentation detailing revision policy or practice, and the public is not explicitly informed of the revision cycle. Provisional annual data are clearly identified as such. Estimated data used are replaced as soon as the revised or final data become available.

\subsubsection{Preliminary and/or revised data are clearly identified.}

The annual and monthly reports on the GFS clearly indicate on their cover pages that the data are provisional. However, at the detailed series level, preliminary monthly data are not indicated as such.

Similarly, one month after the appearance of the provisional monthly data, the definitive monthly data for the reference month are published, but without any mention of the fact that these data have been revised and are now final. The annual data on public debt that appear in the "Provisional Results of Government Budget Execution," which cover at least two years, are not identified as provisional or final. 
The authorities emphasized that the preliminary or revised nature of the information will be noted in the budget execution bulletin in the near future.

\subsubsection{Studies and analyses of revisions are made public}

No study of revisions is done (see 3.5.1).

\section{Accessibility}

\subsection{Data accessibility}

\subsubsection{Statistics are presented in a way that facilitates proper interpretation and meaningful comparisons (layout and clarity of text, tables, and charts).}

The statistics on government operations are provided effectively in accordance with the GFSM 1986 tables (revenues and grants, expenditures and lending minus repayments by economic type, expenditures by function, and financing (by instrument only)). Additional series, charts, tables, chronological development of detailed series are provided to respond to users' needs by offering them several levels of detail. However, data coverage is limited: budget and Treasury accounts for monthly data; and in addition social security funds and local government accounts for annual data. Unlike the annual reports, the monthly reports contain no commentary or analysis. However, the authorities indicated that a summary analysis would soon be introduced in the monthly bulletin.

The data on the stock of debt are broken down into domestic and external debt based on the criterion of residence. External and domestic debt service is broken down by interest and principal. External debt is broken down by foreign currency as well as by type of donor. The data on domestic debt are broken down by instrument but not by type of debt holder (BCT, other banks, non-banking sector), which does not facilitate their use for purposes of economic analysis. In addition, the stock of domestic debt is presented net of Treasury deposits with the banking system (Treasury's current account and public accountants' account).

\subsubsection{Dissemination media and format are adequate.}

The DGRE disseminates the monthly or annual GFS (Provisional Results of Budget Execution) with limited coverage (the budget and Treasury accounts) to a small group of about 60 users (public sector, banks, embassies, universities, research institutes). Other users can obtain the data on request or subscribe to the distribution list. The MF also publishes the same annual data in the Annual Report on Public Finances in French and Arabic; this report contains analyses and commentary and is available on request and disseminated to ministries, university institutions, and research centers, in addition to an annual report on follow-up to the budget law. 
The annual GFS data for central government (including the social security funds) and local governments are also reprocessed to ensure their consistency with GFSM 1986 and sent to STA for publication in the GFS Yearbook. Finally, the BCT publishes the annual GFS on the budget in its annual report, which also appears on its Internet site.

In addition, very summary data on central government agencies (monthly data covering the budget and the Treasury accounts) and general government agencies (annual data covering the budget, Treasury accounts, the social security funds, and local governments) are sent by fax to the BCT and posted on its website with a direct link to the IMF's DSBB, consistent with the terms of the SDDS.

Each year, the DGGD publishes a Report on Public Debt that includes direct government debt (with narrow budget coverage) as well as guaranteed debt. This report is sent to the Court of Auditors. It may be consulted by the public at the MF library but is not disseminated outside the Ministry. The quarterly data on public debt are disseminated through the BCT posting on the IMF's DSBB, with a two-month delay. Finally, current GFS data and the oldest time series are available on request from the DGRE.

\subsubsection{Statistics are released on a preannounced schedule.}

Statistics are released on a timely basis but without any reference to a pre-established schedule. The authorities indicated that a data release schedule will soon be incorporated in the monthly bulletin.

\subsubsection{Statistics are made available to all users at the same time.}

The small group of users is informed of the publication of the GFS data, which are released to them all at the same time.

\subsubsection{Statistics not routinely disseminated are made available upon request.}

Besides systematically disseminated data, the DGRE and the DGGD provide statistics of general interest as requested by interested parties. Aggregate data tabulated on request may be provided based on specific needs. However, the conditions governing access to these statistics are not made public.

\subsection{Metadata accessibility}

5.2.1 Documentation on concepts, scope, classifications, basis of recording, data sources, and statistical techniques is available, and differences from internationally accepted standards, guidelines, or good practices are annotated.

There is no regularly published document containing comprehensive descriptions of data sources and methods. SDDS metadata and methodology notes are not updated at regular intervals. Thus, the indication that "there are no extrabudgetary units" should be corrected 
since more than 90 percent of the EPAs are still not included in the scope of the GFS data. Similarly, the reference to the "release schedule posted on the Internet site of the Ministry of Finance at the following address: http://www.fin.gov.tn," should be eliminated since this site is not operational. The authorities indicated that a methodological note explaining the data compilation method as well as information on contact persons will in the near future be incorporated in the various monthly (Bulletin) and annual (Annual Report) publications.

Finally, the SDDS metadata are not easily accessed by local Tunisian users. In effect, the MF does not have its own Internet site, the data and metadata are in English, and their availability is not mentioned anywhere in MF publications.

\subsubsection{Levels of detail are adapted to the needs of the intended audience.}

Information adapted to the needs of users is provided when the user goes to the MF units involved, but there is no brochure available with general or specialized information on the GFS and how to access the GFS data.

\subsection{Assistance to users}

\subsubsection{Contact points for each subject field are publicized.}

The users of statistics receive complete assistance upon request (through visits or by telephone). However, there is no statistical publication providing the information needed (address, telephone, fax, e-mail) to obtain more information. On the other hand, the MF metadata on the IMF's DSBB indicate the information (telephone, fax) for the Director General of the DGRE. There is no general brochure describing the GFS and making potential users (market analysts, university students, researchers) aware of their importance and possible use in their research. Access points where clients may obtain statistical information are not specified. The authorities indicated that a methodological note explaining the data compilation method as well as information on contact persons will in the near future be incorporated in the various monthly (Bulletin) and annual (Annual Report) publications.

\subsubsection{Catalogs of publications, documents, and other services, including information on any charges, are widely available.}

The publications of the MF are free of charge and available through the MF library. The authorities indicated that a catalog of publications available to users will be published on the MF website that is now being created. 


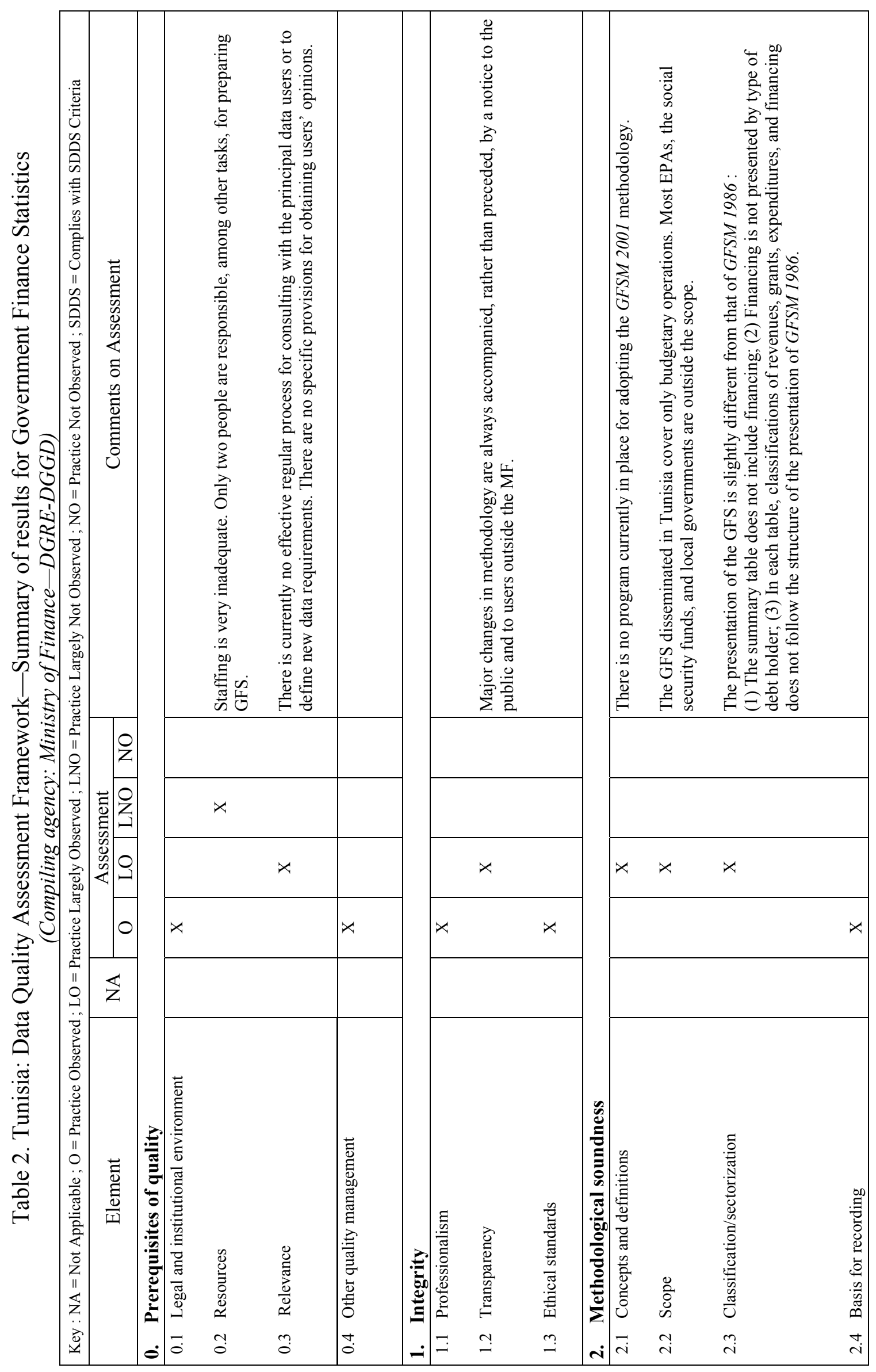




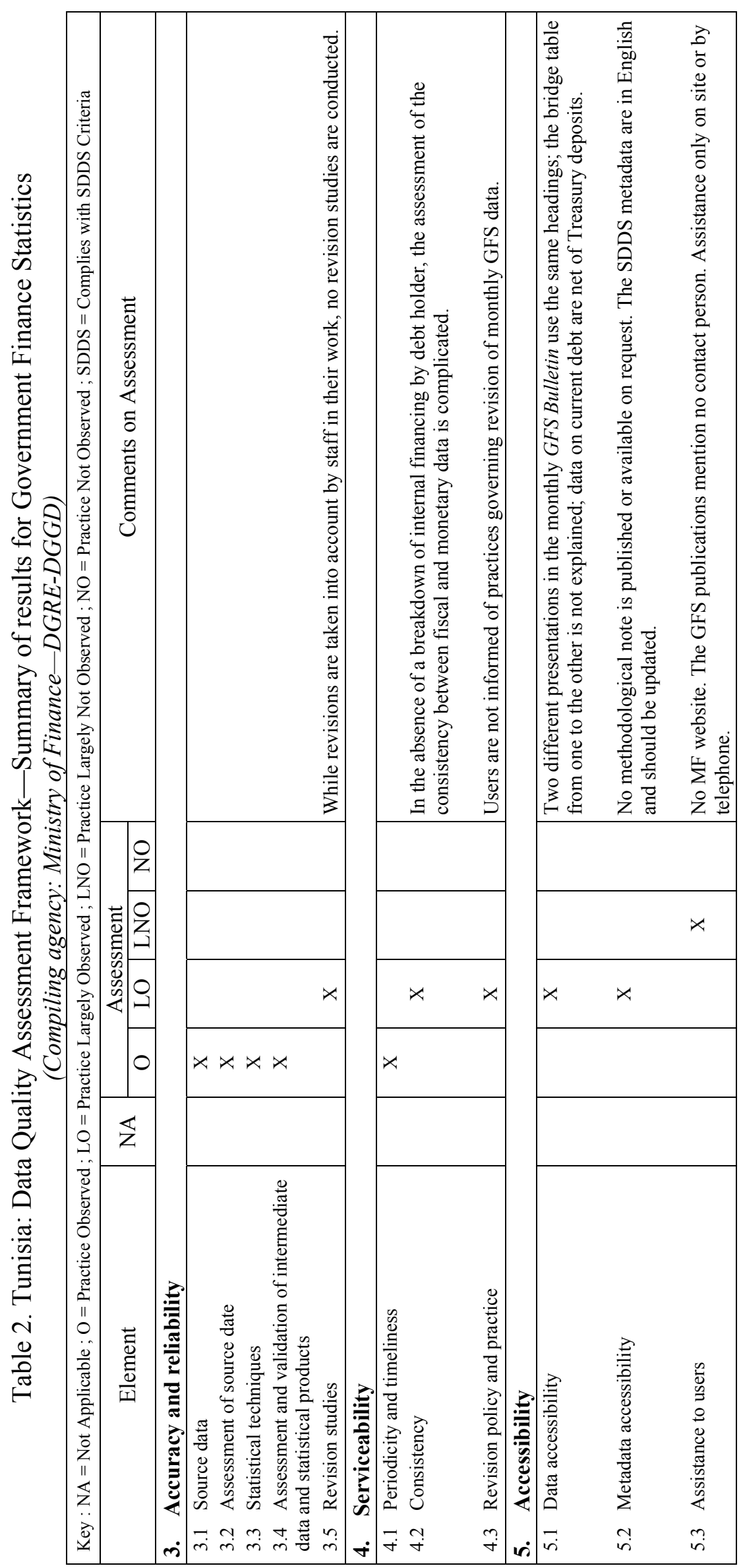




\section{Monetary STATISTICS}

\section{Prerequisites of quality}

\subsection{Legal and institutional environment}

\subsubsection{The responsibility for collecting, processing, and disseminating the statistics is clearly specified}

Monetary statistics are collected, compiled, and disseminated by the Monetary Research Department (MRD) of the Central Bank of Tunisia (BCT). No other agencies are involved in the BCT's work on monetary statistics. Data on the BCT are obtained directly from the BCT's Accounting Department through a computerized system. Data on the other components of the banking system are obtained from the BCT's Banking Supervision Department (BSD), which is responsible for collecting and processing data from other depository corporations (ODCs) ${ }^{26}$ through a monthly reporting system. Data on the Postal Check Center and the Postal Savings Center are obtained from the National Post Office. Data on cash balance of the Treasury are transmitted from the Ministry of Finance. Data flows between the BCT's departments are fully computerized. The monetary statistics are disseminated to the public through the BCT's publications and website.

Law 58-90 of 9/19/1958 on the creation and organization of the Central Bank of Tunisia (amended by Laws 88-119 and 2000-37) and the BCT's circular 93-08 of 7/30/93 constitute the basic regulatory framework for the BCT to collect, produce, and disseminate monetary statistics. Although the legal framework does not explicitly refer to BCT's work on monetary statistics, there is a long established tradition and well established practices regarding BCT's work in this area. As regards the data collection, article 34 of the Law 58-90 states that "the Central Bank may also request that banks and financial institutions provide it with such statistics and information as it may consider necessary to monitor trends in credit and shortterm economic conditions." Article 71 (new) allows the BCT to publish any documents, periodicals, reports, or papers having an economic, monetary, or banking focus."

The BCT's data collection is underpinned by the circular 93-08, which sets out the detailed requirements for banks and other financial institutions to prepare and submit the periodical statements and accounting records to the BCT. Article 17 of the circular states that "Banks

\footnotetext{
${ }^{26}$ In the Monetary and Financial Statistics Manual, the ODCs subsector consists of all resident financial corporations (except the central bank) and quasi-corporations mainly engaged in financial intermediation; their liabilities consist of deposits or financial instruments that are included in the national definition of broad money. In Tunisia, the ODCs subsector should include all financial institutions, except the BCT, that comprise Tunisia's overall financial system. The depository corporations subsector should consist of the BCT and ODCs.
} 
and financial corporations operating in Tunisia must transmit to the Central Bank of Tunisia periodical records (monthly, quarterly) indicating, during the course of the year, their statements of assets and liabilities providing various information required both for supervision of adherence to regulations and to inform the monetary authorities." In addition, according to articles 1 and 4, the circular requires that banks and financial corporations design their accounting systems in accordance with the general Tunisian chart of accounts as well as the specific rules laid out in this circular and that the data reflect accurately and completely the positions on the last working day of the period to which they refer, covering the activities of the head office and all branches of the reporting bank. Also, article 32 of the Law No. 2001-65 of July 10, 2001 governing credit institutions lays out the requirements, including types of information, for banks and other financial institutions to report data to the BCT.

Besides, Law 99-32 of April 13, 1999 on the National Statistical System (SNS) "defines the basic principles of statistical activity, the structure of the National Statistical System, its mission, and the role of each of its components." Article 12 of the law states "The National Statistical System is made up of the units and agencies in charge of collecting, processing, storing, analyzing, and disseminating the official statistics, and of coordinating statistical activity. The National Statistical System comprises the National Council on Statistics (CNS), the National Statistics Institute (INS), other specialized public statistics units, and the statistical training institutions." The Director General of Research of the BCT is an officio member of the National Council on Statistics.

In the context of the legal framework described above, the collection, compilation, and dissemination of monetary statistics is well established and effective. In general, there have been no notable problems in collecting data from banks and other financial institutions and the data are processed and disseminated according to an advanced release calendar.

\subsubsection{Data sharing and coordination among data-producing agencies are adequate}

The $\mathrm{BCT}$ is the sole institution responsible for compiling and disseminating monetary statistics to both domestic and foreign users, including international organizations. It collects all the requisite source data for these purposes directly from ODCs without support from other data producing agencies. A formal reporting system is in place, where banks and other financial institutions are required to prepare and report data to the $\mathrm{BCT}$ on a regular monthly basis according the BCT's Circular 93-08.

The BCT is one of 36 members of the CNS, which comprises representatives from the public sector, private sector, and academia. The CNS's General Assembly meets four times a year, while its ad-hoc committees and working groups on specific areas of statistics are set up and meet more frequently to address issues pertaining to the statistical methodology and to exchange views on the developments in the area of statistics. Participation in these meetings provides opportunities for the BCT to share experience with other data producing agencies, such as the INS and the Ministry of Finance (MF), and to understand the needs of the data users in both the public and private sectors. 


\subsubsection{Individual reporters' data are to be kept confidential and used for statistical purposes only}

There are no written internal rules for staff compiling monetary statistics to guarantee the confidentiality of data. However, staff members are informed of the importance of this confidentiality and would face disciplinary sanctions if they breached the confidentiality of data. In addition, the staff compiling monetary statistics, like other BCT staff, are subject to the provisions of BCT's staff's statute, which states that, among other things, "staff must, at work as well as in their private lives, avoid anything that could compromise their independence with respect to third party institutions or the dignity of the bank" (Article 3 (4)). Only staff who are responsible for compiling monetary statistics have access to the database, which is also protected by passwords. In practice, only aggregated data (of three or more reporting entities) can be made available to the public - so that the identification of data on individual transactions and reporting institutions can be prevented. Normally, only data published by the BCT are available to be used by the data users for research and analytical purposes. Information on the respondents' rights and obligations and the purpose of the data collection is not provided on the report form, but banks and other financial institutions are informed that the information they provide will be used for the purpose of banking supervision and monetary statistics compilation. In the BCT, confidential documents are destroyed by shredding them at a designated place.

As regards individual data, articles 4 and 5 of the Decree 99-2797 of December 13, 1999 on the composition and organization of the CNS clearly stipulate that individual data are to be kept confidential and used for statistical purposes only. In addition, Law 2004-63 of July 27,2004 provides for the protection of data of personal nature.

\subsubsection{Statistical reporting is ensured through legal mandate and/or measures to encourage response}

The BCT's legal authority to collect the source data for compiling monetary statistics emanates from Law 58-90 of 9/19/1958 on the creation and organization of the Central Bank of Tunisia. The data collection is supported by BCT's circular 93-08 of 7/30/93, which sets out the detailed requirements for banks and other financial institutions to prepare and submit the periodical statements of their assets and liabilities to the BCT (see Section 0.1.1 above). To encourage response, article 49 of the Law No. 200165 of July 10, 2001 governing credit institutions states that "any dissimulation of information or deliberate communication of false information can be punished by a fine to the amount prescribed under Article 42 of the present law. Any delay in the communication of documents, information, clarifications and justifications under Article 32 of the present law is subject to fine, from the moment notification is made by the Central Bank, which is of 100 dinars per day of delay and is collected according to the provisions of Article 42."

In practice, there are no notable problems in collecting data from banks and other financial institutions as their data compilation is computerized and the counterparts in the banking sector understand the importance of monetary statistics and are, therefore, willing to make 
every effort to produce and provide data to the BCT. Normally, the reporting banks and other financial institutions contact the BSD if they need technical support to complete the report form according to BCT's circular 93-08.

\section{$0.2 \quad$ Resources}

\subsubsection{Staff, facilities, computing resources, and financing are commensurate with statistical programs}

The MRD is made up of two divisions - (1) the Statistics and Monetary Analysis Division and (2) the Monetary Policy and Programming Division. The Statistics and Monetary Analysis Division is responsible for the collection, compilation, and dissemination of monetary statistics. It has six staff members, including the manager. All staff had on-the-job training, and three of them participated in training courses on monetary statistics organized by the International Monetary Fund (IMF). The Statistics and Monetary Analysis Division obtains data on the BCT directly from the BCT's database and data on ODCs from the BSD. Data checking and validation are carried out by the BSD, which has to notify the MRD after data have been checked and deemed ready for use to compile monetary statistics.

Overall, the number of staff allotted for the compilation of monetary statistics is not fully adequate as they also have to work on monetary analysis and other related assignments. The Statistics and Monetary Analysis Division experienced a high turnover of staff recently and, as a result, some staff are still under training and lack the full skills to perform the required tasks. However, a core staff is maintained and new staff are highly qualified and are expected to be able to get fully involved in compilation work quickly. The MRD puts great emphasis on on-the-job training as well as on attending training courses outside the BCT. Salaries of BCT staff are considered competitive with the public sector in the country.

Hardware has improved in recent years and is now considered adequate as almost all staff have their own computer. Software utilized for compiling monetary statistics was developed within the BCT with support from BCT's Information Systems Department. The current software is sufficient for the current compilation of monetary statistics, but will need to be updated for implementing the MFSM. Protection is provided for computer resources via the implementation of a daily back-up system, which is carried out and maintained in premises located far from BCT's building. Physical facilities and other resources are adequate to perform the required tasks. These facilities will be further improved when BCT's building extension is complete and available for use at the end of 2005.

Funding for the work on monetary statistics is included in the overall budget of the BCT and is not separately identified. In general, this funding has been adequate to perform the required tasks notwithstanding the staffing issue mentioned above. The BCT's budget is prepared and executed on an annual basis. 


\subsubsection{Measures to ensure efficient use of resources are implemented}

Staff performance is reviewed once a year based on the work that they have carried out. The immediate supervisor evaluates each staff's performance and submits this evaluation to BCT's Human Resource Department. Under this merit rating system, each staff receives a rating mark, which is used to determine his/her annual bonus. Training needs of the compiling staff are always recognized and staff are provided opportunities to attend training courses whenever available. The budget of the MRD is included in and made consistent with BCT's overall annual budget. Once a year, the BCT reports to the CNS information on staffing and other resources for statistical work to be included in the CNS's annual report, which covers such information of all data producing agencies in the country. Outside expert assistance has not been sought to evaluate statistical methodology and compilation systems used by the MRD. The staff's understanding of the up-to-date statistical framework and methodology has been acquired by attending training courses and by using the IMF's Monetary and Financial Statistics Manual (MFSM) as a reference. Currently, the staff's knowledge of the new methodology is considered quite adequate for the planned migration from the current methodological practice to the one in the MFSM.

\section{$0.3 \quad$ Relevance}

\subsubsection{The relevance and practical utility of existing statistics in meeting users' needs are monitored}

The relevance of the monetary statistics produced by the BCT is ensured through consultations with other members of the CNS, which has been expanded to include various representatives from the private sector. During the meetings of the CNS's ad-hoc committees and working groups that are held several times a month, participants discuss methodological issues and share their views and experience in statistics, thus providing opportunities for the BCT to keep abreast of new data requirements. Within the BCT, the MRD consults with other departments on the types of data needed for policy purposes and other analyses. Interaction with other (outside) users is undertaken through the Office of the Governor of BCT. In most cases, data users request additional data or information about the data and such requests are used to determine user needs. To inform the data users of some specific information about the data, the BCT's Quarterly Financial Statistical Bulletin (QFSB) contains methodological pages, which are devoted to explaining the structure of the banking and financial systems that are covered in the monetary statistics, data coverage, any recent changes to the data etc. In general, the MRD is aware of the lack of some types of information needed to meet users' needs and will address these gaps when it will move to using the methodology recommended in the MFSM. In addition, MRD's staff participate in statistical meetings and seminars organized by international organizations to keep abreast of new developments in the area of monetary statistics so as to assess the compliance of their practice with the international standards. 


\subsection{Other quality management}

\subsubsection{Processes are in place to focus on quality}

The BCT fully recognizes that reliable monetary statistics are crucial for monetary policy decisions. The manager of MRD is responsible for the quality of data, is sensitive to all aspects of data quality, and promotes a shared concern for data quality throughout the department. Processes in place to ensure data quality include BSD's computerized procedures to check reported data for internal consistency as well as consistency across reporting institutions; MRD's computerized procedures to compile and analyze the data; and a commitment to ensure that monetary statistics are compiled and disseminated in a timely manner according to the advanced release calendar. The diagram of the department indicates the responsibility of each staff member for the quality of their respective work, which contributes to ensuring the data quality of the monetary statistics produced in general. The importance of data quality is explained during new staff training. In addition, new staff receive the statistical manual, guidelines, and notes on methodology, and have to pass a test period before being allowed to get fully involved in the statistical work. Such an approach is aimed at ensuring the quality of the produced data. These practices are adequate to ensure that quality is a cornerstone of the MRD's statistical work although it has not implemented externally recognized processes that focus on quality.

\subsubsection{Processes are in place to monitor the quality of the statistical program}

The performance of the entire statistical work, starting from data collection to the dissemination of the monetary statistics to the public is closely monitored and assessed. The result of the assessment is reported to the manager of MRD on a regular basis. So far, MRD has relied on internal expertise, which is updated through the participation of MRD staff in the training courses organized by the IMF and the sharing of experience with other data producing agencies in the country. As mentioned earlier, MRD is aware of the departure of its compilation practices from the framework and methodology recommended in the MFSM and is taking steps that will lead to using the MFSM.

\subsubsection{Processes are in place to deal with quality considerations in planning the statistical program}

As noted in Section 0.3.1 above, MRD regularly participates in the meetings of the working groups of the CNS and reviews the needs of data users within and outside the BCT in order to gauge the relevance of the monetary statistics produced. This interaction provides opportunities for MRD to obtain feedback on issues relating to data quality and new data requirements. Developments in the financial markets, such as creation of new financial instruments and changes to the structure of the financial system are monitored closely and reflected in the reporting system, where relevant, to maintain the completeness of the coverage of monetary statistics. The BCT is in the process of migrating from the 1984 Guide to the MFSM and the concern about data quality is the driving force behind this process. 


\section{Assurances of integrity}

\subsection{Professionalism}

\subsubsection{Statistics are produced on an impartial basis}

Law 58-90 of 9/19/1958 on the creation and organization of the Central Bank of Tunisia provides for the independence of the BCT in performing its functions. Under this Law, the $\mathrm{BCT}$ is a national public institution which is a legal entity, has financial autonomy (Article 2 ), and is not subject to the laws and regulations governing the public accounts of the state (Article 3). The BCT's governor is appointed and removed from office by a decree; the appointment is for six years and may be renewed one or several times (Articles 8 and 9). As regards data dissemination, Article 71 (new) of the Law states that "The Central Bank shall be permitted to publish any documents, periodicals, reports, or papers having an economic, monetary, or banking focus." In practice, these provisions appear to be sufficient to support the statistical work of the BCT, which is found to follow strict technical criteria and to be free of interference from other agencies.

Professionalism of the compiling staff is underpinned by the BCT's recruitment process. The recruitment is announced in newspapers and the selection is based exclusively on merit, especially on the qualifications and aptitude of the job seekers in the fields of accounting and statistics. Recently, young qualified college graduates were recruited through competitive exams. Once selected, recruits are subject to hands-on internal training in the methodology and framework for the compilation of monetary statistics. Staff promotion is based on professional competence that is determined in the context of the annual staff performance review mentioned earlier. The compiling staff have opportunities to participate in training seminars, courses, and workshops on monetary statistics and other related topics held in the country and abroad to advance their understanding of the methodology and to share experience with their counterparts. As mentioned earlier, the BCT's staff members are subject to rules contained in the staff's statute, which contribute to safeguarding and strengthening the staff's professionalism. Research in the area of statistics has been conducted by staff for internal use only, not for publication.

\subsubsection{Choices of sources and statistical techniques as well as decisions about dissemination are informed solely by statistical considerations}

The choice of source data and statistical techniques, as well as decisions about data dissemination, are based solely on statistical considerations, particularly the meeting of international statistical requirements. MRD's work on monetary statistics is free of intervention from other agencies and the current data dissemination is based on the SDDS specifications. 


\subsubsection{The appropriate statistical entity is entitled to comment on erroneous interpretation and misuse of statistics}

The BCT's Office of the Governor monitors, as standard practice, the relevant information published by the press. If misuse of statistics is found, the BCT will request the press to publish the correction. However, so far there have been very few occasions where the BCT has had to comment on erroneous interpretations of its statistics. The methodological pages in the BCT's $Q F S B$ contain some information about the structure of the banking and financial systems and about the data, which is useful to data users, thus contributing to preventing erroneous interpretations.

\subsection{Transparency}

\subsubsection{The terms and conditions under which statistics are collected, processed, and disseminated are available to the public}

Some of the laws and circulars that set the terms and conditions for the data collection, compilation, and dissemination of monetary statistics are available to the public in the BCT's publications and website. In addition, these general terms and conditions are shared with participants during meetings with reporting institutions. Other relevant laws and circulars as well as additional information about the statistics are available upon request.

\subsubsection{Internal governmental access to statistics prior to their release is publicly identified}

No officials outside the BCT have access to monetary data prior to their release to the public.

\subsubsection{Products of statistical agencies/units are clearly identified as such}

All BCT publications clearly identify the BCT as the only source of monetary data. For example, the first paragraph on the methodological pages in BCT's QFSB indicates that the major part of the published financial statistics is produced by BCT's departments. Data obtained from other data producing agencies also clearly identify their sources. The BCT requires attribution when its statistics are used or reproduced.

\subsubsection{Advanced notice is given of major changes in methodology, source data, and statistical techniques}

Information about changes in the methodology is provided by the BCT in particular during the meetings of the CNS's working groups, as well as during other meetings and seminars on the relevant topics. As mentioned earlier, the BCT's QFSB contains methodological pages, which provide some information about the structure of the banking and financial systems and about changes to the data, which is useful to data users. The QFSB is also posted on the BCT's website. When provisional data are published, footnotes are provided to inform the users. However, while no advanced notice of major changes in methodology is provided to 
the public, information on changes to the structure of the financial system as well as changes to data series is provided when the data are released.

\subsection{Ethical standards}

\subsubsection{Guidelines for staff behavior are in place and are well known to the staff}

As mentioned in Section 1.1.1 above, the BCT's staff members are subject to rules contained in the staff's statute, which provides guidelines for staff behavior. Ethical standards for staff behavior are specified in their employment contract. The background of new staff is checked and they are made aware of the standards when they join the BCT. The standards are reinforced through briefing and training courses, which provide guidance on staff behavior and the ethical standards expected of the BCT staff. Staff are reminded of these ethical standards when there are incidents of behavior departing from these standards.

\section{Methodological soundness}

Methodological soundness is assessed against the principles stated in the MFSM.

\subsection{Concepts and definitions}

\subsubsection{The overall structure in terms of concepts and definitions follows internationally accepted standards, guidelines, or good practices}

The analytical framework used by the BCT in the compilation of monetary statistics reflects concepts and principles that are based on the IMF's Draft Guide to Money and Banking Statistics in International Financial Statistics, December 1984 (1984 Guide). This framework is not in line with the recommendations of the MFSM. The BCT has initiated a plan to migrate from the current practice to the guidelines recommended in the MFSM. As the first step in this migration process, BCT staff has began to review and improve the source data on the BCT to permit appropriate classification of assets and liabilities as well as sectorization of institutional units as recommended in the MFSM.

The BCT compiles and disseminates the monetary statistics including (i) the BCT's monthly statement, (ii) monthly statement of the deposit money banks, (iii) the monetary system's monthly statement, (iv) monthly statements of other financial corporations, (v) the resident financial system's monthly statement, (vi) the offshore banks' monthly statement, and (vii) the overall financial system's monthly statement. The monetary system's monthly statement is similar to the monetary survey, which is a consolidation of the accounts of the BCT and the deposit money banks (DMBs), as defined in the 1984 Guide, and the Postal Check Center. The monthly statement of the overall financial system is similar in scope to the depository corporations (DCs) survey as recommended in the MFSM. It consolidates the accounts of the monetary system, the development banks, the Postal Savings Center (CEP), 
the leasing companies, and the offshore banks. ${ }^{27}$ However, the sectorization of transactors and classification of assets and liabilities used in the compilation of the monthly statement of the overall financial system do not conform to the methodology recommended in the MFSM. For the purpose of this assessment, the main focus is on the monetary system's monthly statement because the money aggregates reported in this monthly statement are used for policy purposes in Tunisia.

In the monetary system's monthly statement, four measures of money (M1, M2, M3, M4) are provided. M1, a narrow measure of money, consists of currency outside banks (banknotes and coins in circulation, less cash held by the Treasury and banks) and demand deposits of resident nonfinancial sectors (other than government) as well as deposits of nonmonetary financial institutions with the monetary system. M2 equals M1 plus quasi-money, which consists of time and savings deposits, certificates of deposit, and other accounts payable to customers. M3 equals M2 plus tied and contractual savings and bonds issued by the monetary system. M4, the broadest measure of money, is the sum of M3 and securities issued by the government and nonfinancial economic agents on the money market and subscribed to by the public through banks. Other key aggregates shown in the monetary system's monthly statement include (a) net foreign assets, (b) net claims on government, (c) financing of the economy, (d) other items (net), and (e) capital. In addition, the BCT also compiles the four money aggregates and other aggregates noted above on the basis of the resident financial system and the overall financial system. However, money supply growth calculated using data from the monetary system's monthly statement is used as an intermediate target of monetary policy.

\section{$2.2 \quad$ Scope}

\subsubsection{The scope is broadly consistent with internationally accepted standards, guidelines, or good practices}

The financial system in Tunisia comprises the BCT, 17 commercial banks, CCP, 8 offshore banks, 2 development banks, CEP, 11 leasing companies, 2 merchant banks, and 2 factoring companies. The BCT is the central bank of the country. Commercial banks fall in the category of credit corporations, which are defined in Law No. 2001-65 of July 10, 2001 as any legal entities undertaking banking transactions as their main profession. According to this Law, banking transactions include, among other things, accepting deposits, granting loans, providing currency exchange, and payment services. The CCP is a government-owned financial institution, which accepts deposits from the public. The deposits collected by the CCP (2.5 percent of M2 as of August 2004) are used by the government. Development banks are specialized banks, which give medium- and long-term loans, participate in other companies' capital, and also collect all types of deposits ( 0.1 percent of M2). All development banks will be transformed into universal banks by the end of 2005 . The

${ }^{27}$ Activities of these financial institutions are discussed later in Section 2.2. 
activities of the offshore banks are defined in the Law No.85-108 of December 6, 1985 and BCT's circular No. 86-13 of May 6, 1986 as specialized banks that may also provide banking services to residents, including collecting deposits from residents ( 0.7 percent of M2) with certain limitations and provide other financial services to nonresidents. The CEP accepts savings deposits from the public and these deposits (6.6 percent of $\mathrm{M} 2$ ) are used by the government. The leasing companies provide financing of equipment acquisitions and make it available for lease. However, in practice they also accept deposits (3.6 percent of M2). Merchant banks are financial institutions that provide, among other things, advice and assistance services in the field of patrimony management, financial management and financial engineering, but do not accept deposits. Factoring companies do not accept deposits. Based on the activities of the financial institutions described above, commercial banks, CCP, offshore banks, development banks, CEP, and leasing companies fall into the category of ODCs as defined in the MFSM, while merchant banks and factoring companies fall into the category of other financial corporations.

For the compilation of monetary statistics, data for ODCs and the BCT, covering their headquarters and all domestic branches are collected. As mentioned earlier, the monetary system's monthly statement is the consolidation of the accounts of the BCT, commercial banks, and the CCP, which is not equivalent in scope to the depository corporations survey as defined in the MFSM. The monthly statement of the overall financial system, which is also compiled by the BCT, consolidates the accounts of the BCT and all ODCs, as described above, and, therefore, it is similar in scope to the depository corporations survey.

\subsection{Classification/sectorization}

\subsubsection{Classification/sectorization systems used are broadly consistent with internationally accepted standards, guidelines, or good practices}

The residency criterion used to distinguish between claims on and liabilities to residents and nonresidents is that used by the BCT in the compilation of balance of payments statistics, which is currently based on the Balance of Payments Statistics Manual, fifth edition, and is consistent with the concept of residence recommended in the MFSM. Article 18 of the BCT's Circular 93-08 of July 30, 1993 states that "the definitions of residents and nonresidents to be adopted for establishing the monthly statements are those used for the balance of payments records." However, in the current compilation of monetary statistics, the sectorization of the offshore banks is ambiguous as data on some of their transactions with the monetary system are classified under domestic assets, while data on some other transactions are under foreign assets. Furthermore, in practice, procedures are not in place to ensure that, when distinction between residents and nonresidents is made, banks and other financial institutions apply appropriately and consistently the concept of residence to all transactions. The BSD and the MRD basically rely on the BCT's Balance of Payments Department, which is responsible for collecting balance of payments data to check banks' application of this concept. 
The principles underlying the sectorization of institutional units and classification of assets and liabilities used by the BCT in the current compilation of monetary statistics are largely based on the 1984 Guide, but not consistent with the guidelines of the MFSM. The economic sectors identified in the monetary statistics compiled by the BCT include (1) the central bank (BCT), (2) DMBs, (3) other financial institutions, (4) the central government (state), (5) the rest of the domestic sector (economy), and (6) nonresidents (abroad). As discussed earlier, the financial subsector included in the compilation of the monetary system's monthly statement-which covers only commercial banks and the CCP, but not the development banks, CEP, leasing companies, and offshore banks - does not correspond to the other depository corporations subsector as defined in the MFSM. Under the current practice, the classification of the offshore banks partly as nonresidents and partly as residents, and social security funds as public enterprises is not in line with the MFSM. According to the MFSM, offshore banks should be classified as resident banks based on the recommended concept of residence. The MFSM recommends the social security funds be classified as a separate subsector under general government or part of other subsectors of general government at which they are organized.

Another deviation from the MFSM is that the rest of the domestic sector (other than central government and financial corporations) is not disaggregated into (i) public nonfinancial corporations, (ii) other nonfinancial corporations, (iii) households, and (iv) local governments as recommended in the MFSM. Furthermore, insurance corporations and pension funds exist in Tunisia, but they are not identified and included in the appropriate financial corporations subsectors as recommended in the MFSM.

In the monetary statistics published by the BCT, assets and liabilities are classified into the following groups: monetary gold and SDRs, currency and deposits, loans, securities other than shares, shares and other equity, and other assets/liabilities. This classification of assets and liabilities is broadly in line with the guidelines of the MFSM. However, financial derivatives are not separately identified and reported in monetary statistics as a separate instrument. Such treatment of financial derivatives is not in line with the MFSM, which recommends that all financial derivatives with market value or fair value, which are subject to on-balance-sheet recording, should be presented as a separate category in the sectoral balance sheets.

While the classification of assets and liabilities is broadly consistent with the MFSM, some items are published at a highly aggregated level or have descriptions that do not correspond to any of the identified categories of assets and liabilities or any of the identified sectors of the transactors. For example, in the BCT's monthly statement, "foreign currency assets," which are the major component of foreign assets are reported as such and not broken down by type of financial instrument. The titles "special resources" (reported as a liability item in the banks' monthly statements and the monetary system) and "claims purchased firm" (reported as an asset in the BCT's statement) and some other nomenclatures in the monthly statements of the BCT and of the banks do not convey adequate information on the type of financial instrument and the sector of the involved creditor or debtor. 
Consistent with the MFSM, repo transactions are treated as collateralized loans. Under the current practice in Tunisia, accrued interest on loans is incorporated into the outstanding amount of these loans, while accrued interest on deposits is not included in the outstanding amount of these deposits. Accrued interest on deposits is recorded in a pending account, which is classified under "other liabilities" in the banks' monthly statement. The current treatment of accrued interest on loans is consistent with the guidelines of the MFSM, while the treatment of accrued interest on deposits is not. The MFSM recommends that accrued interest be included in the outstanding value of the underlying instruments.

\subsection{Basis for recording}

\subsubsection{Market prices are used to value flows and stocks}

The BCT's circular 93-08 of July 30, 1993 lays out the requirements for banks and other financial corporations to prepare and report their account statements to the BCT. According to this circular (article 1), banks and other financial corporations operating in Tunisia must design their accounting systems in accordance with the general Tunisian chart of accounts and the specific rules set out in that Circular.

The current practice of valuing "securities other than shares" and "shares and other equity" is broadly consistent with the MFSM. The approaches used by banks to record the value of "securities other than shares" and "shares and other equity" in their monthly statement are stipulated in the circular 93-08. Under the current practice, securities other than shares listed on the stock exchange are valued at market price; unlisted securities are valued using fair value. The same valuation approach applies to holdings of shares and other equity. For securities held for liquidity and investment purposes, the market value excludes any interest accrued on these instruments before they are acquired by banks and any fees associated with this acquisition. Shares and other equity issued by banks are valued at book value. The general recommendation of the MFSM is that the valuation of financial assets and liabilities should be done on the basis of market prices or market-price equivalents. Valuation according to market-price equivalent (or fair value) is needed for valuing financial instruments that are not traded in financial markets.

Also consistent with the MFSM is the conversion of accounts denominated in foreign currency into local currency equivalents. Under the current practice, accounts in foreign currency are converted to national currency values using the mid-point between the buying and selling exchange rates at the time they are entered in the accounts. The mid-point of the rates prevailing on the last working day of the month is used for such conversion in the preparation of the monthly statement. This requirement is set out in article 5 of circular 9308, which states that "the assets and liabilities in foreign currency must be converted into dinar at an average rate between the buying and selling rates on the closing date of the statement." The MFSM recommends that financial instruments (flows and stocks) denominated in foreign currency must be converted into national currency equivalents for balance sheet purposes at the relevant (market) exchange rates prevailing on the balance 
sheet date. In addition, the MFSM specifies that the midpoint between the buying and selling rate of exchange should be used.

Monetary gold held by the BCT is valued at a fixed price, which is inconsistent with the MFSM. The last revision to the price used to value the holdings of monetary gold took place in 1986 based on Decree No. 685 of 08/19/1986. As mentioned in Section 2.3.1. above, accrued interest on deposits is not incorporated into the outstanding amount of these deposits, but recorded under "other liabilities." Such treatment of accrued interest is not in line with the MFSM.

The MFSM recommends that data be compiled not only on stocks but also on each of the three flow components: transactions, revaluations, and other changes in the volume of assets. In Tunisia, the BCT does not collect and compile monetary flow data statistics.

\subsubsection{Recording is done on an accrual basis}

The monthly statements of the BCT and the DMBs, which are used to compile the monetary system's monthly statement, are derived from accounting records that follow accrual accounting. Under this accrual accounting, accrued interest on loans and deposits is calculated and reported in the accounting records. The use of accrual accounting is recommended by the MFSM. In this regard, the current practice is considered consistent with internationally accepted good practices.

As accrued interest on loans is currently incorporated into the outstanding amount of loans, interest arrears on loans do not require separate recording as they continue to be included in the outstanding amount of loans after the interest becomes overdue. Like the application of accrual accounting, the recording of interest arrears on loans conforms to internationally accepted practices.

Article 3 of the Circular 93-08 states that "accounting operations must be recorded on the day in which they take place. In case it is materially impossible to record all the entries on the day relating to a periodical statement in time, the reporting institution must reestablish its true positions by means of additional accounting days in order to be able to provide the periodical statement on the date determined by the Central Bank of Tunisia." In this regard, transactions are in general recorded at the time the transaction occurs (real time settlement), which is consistent with the MFSM.

\subsubsection{Grossing/netting procedures are broadly consistent with internationally accepted standards, guidelines, or good practices}

In line with the general principle of the MFSM, assets and liabilities of the BCT and the deposit money banks are collected and compiled on a gross basis. In the compilation of monetary statistics, claims on particular transactors are not netted against liabilities to those transactors. Such grossing approach is set out in Article 6 of the Circular 93-08. The presentation of some data on a net basis (e.g., "Net claims on nonresidents (abroad)" and 
"Net claims on government (state)") with their underlying gross data in the monetary system's monthly statement is for analytical purposes and in line with the analytical framework recommended in the MFSM. Moreover, the practice of canceling out all outstanding claims and liabilities between the BCT and the banks to produce the monetary system's monthly statement is consistent with the methodology recommended in the MFSM.

\section{Accuracy and reliability}

\subsection{Source data}

\subsubsection{Source data are obtained from comprehensive data collection programs that take into account country-specific conditions}

The MF is responsible for issuing licenses to banks and other financial corporations operating in Tunisia based on the information about these institutions prepared and submitted by the BCT. The BCT's BSD is in charge of collecting, preparing, and reporting the information about new bank applicants to the MF and, therefore, it has a comprehensive and up-to-date financial sector institutional units register available as part of core data sources for bank supervision and monetary statistics compilation. This up-to-date register reflects all changes that affect the reporting population, including adding new units, deleting units that have been closed, mergers, and other changes. The institutional and geographical coverage of the data collected by the BCT is complete.

The source data for compiling the monthly statement of the BCT are derived directly from the database, which is updated on a daily basis by the BCT's Accounting Department. The source data for compiling the data on the rest of the banking and financial systems are the monthly statements of banks and other financial institutions that are prepared and reported to the BCT in accordance with the BCT's Circular 93-08 of July 30, 1993. No other sources of information are used for the compilation of monetary statistics.

According to the Circular 93-08, the accounting system used by banks and other financial institutions should be in accordance with the general Tunisian chart of accounts and the rules specified in this circular. While data on the monthly statements reported by banks and other financial institutions are sufficient for compiling monetary statistics under the current practice, they do not contain sufficient details for classification of assets and liabilities by type of financial instruments and by economic sectors as defined in the MFSM. The BCT's accounting system may provide sufficient details for account classification as recommended in the MFSM, but the banks' accounting system may not have these details.

Data sources are kept under review in relation to changes in the financial sector. New financial instruments have been developed after the adoption of the Circular 93-08 in 1993 and, therefore, are not reflected in the structure of the banks' monthly statement. The BCT works with representatives of the financial markets to understand these developments and any report forms that will be developed by the BCT will include these changes, where relevant. 
As noted above, the BCT is working on the migration from the current practice to the methodology recommended in the MFSM. As a first step in this process, the BCT has started to work on completion of the standardized report forms (SRFs) for the central bank, which was circulated recently together with other SRFs by the IMF's Statistics Department to member countries to be used to report data to the IMF for publication in International Financial Statistics. This process will help the MRD to develop a new report form to be used to collect data on the BCT for compiling the sectoral balance sheet of the central bank as defined in the MFSM. The MRD will consult with the BSD and the reporting entities when it develops a new report form to collect data on the ODCs for compiling the monetary statistics based on the MFSM.

\subsubsection{Source data reasonably approximate the definitions, scope, classifications, valuation, and time of recording required}

Source data are not fully in line with the classifications and valuation as recommended in the MFSM. As mentioned earlier, source data from banks and other financial institutions are prepared in accordance with Circular 93-08. Under this framework, source data do not have all the breakdowns by sector and by financial instrument that would permit classification of assets and liabilities as recommended in the MFSM. Some data are reported at a highly aggregated level with descriptions that make them inconsistent with the recommended categories of assets and liabilities or sectors. In addition, some data are not valued or revalued according to internationally accepted practice (see Section 2). For example, monetary gold is valued at a fixed price; deposits are reported at book value excluding accrued interest. Notwithstanding the inconsistency with the required classification and valuation, the current source data are not adjusted and no supplementary data sources are used as they are sufficient for compiling the monetary statistics under the current practice.

\subsubsection{Source data are timely}

The monthly provisional data on the BCT are available to the MRD by the $10^{\text {th }}$ day, whereas the final data are available by the $25^{\text {th }}$ after the end of the reference month. According to Article 17 of Circular 93-08, the monthly statements of banks and other financial institutions must be reported to the BCT at the latest on the $25^{\text {th }}$ of the month following the closure of the statement. In addition, by the $10^{\text {th }}$ after the end of the reference month, banks and other financial institutions must report to the BCT provisional data with less detail than the final data. Any delays in reporting are immediately followed up by the BCT with the entities that have not reported. As mentioned in Section 0.1.4 above, Article 49 of the Law No. 2001-65 of July 10, 2001 governing credit institutions sets out, among other things, penalties for any delays in submitting information required by the BCT.

All reporting by banks to the BCT is in hard copy and the data are entered into the BCT's computerized system by the BSD. Data obtained from the BSD for compiling monetary statistics are in electronic format. In general, the MRD receives all the required data on a timely basis and is able to compile and disseminate the monetary statistics a few days after 
all data have been received. The BCT's data dissemination meets the standards of timeliness and periodicity as specified by the SDDS.

\subsection{Assessment of source data}

\subsubsection{Source data-including censuses, sample surveys and administrative records-are routinely assessed, e.g., for coverage, sample error, response error, and nonsampling error; the results of the assessments are monitored and made available to guide statistical processes}

No census or sample surveys are used in collecting data for compiling monetary statistics. Data on the BCT are obtained electronically from the database of the BCT's Accounting Department. Data on the rest of the financial sector are reported in hard copy by banks and other financial institutions to the BSD, which is responsible for checking them and entering them into the computerized system. Findings of missing data, inconsistencies, out-of-trend values etc. are immediately followed up with the respondents. High value transactions are also confirmed with the reporting institutions. All corrections and clarifications received from reporting entities are appropriately filed for future reference. Information on operations in the money market, the bond market, and foreign exchange markets available from other departments within the $\mathrm{BCT}$ is used to check for underreporting or misreporting. Once the reported source data have passed the validation procedures, they are made available for statistical compilation. This practice is adequate to ensure the accuracy of the source data for compiling monetary statistics.

\subsection{Statistical techniques}

\subsubsection{Data compilation employs sound statistical techniques to deal with data sources}

The data processing is automated, thereby reducing the number of processing errors that can occur in coding, revising, and tabulating the source data. With respect to the source data on the $\mathrm{BCT}$, there are reviewing procedures in the BSD and MRD that help minimize errors. The banks' monthly statements are in hard copy, but uniform across reporters (except the CCP and CEP). The final data for the BCT as well as the rest of the financial system are reported in full detail as required by the Circular 93-08, and, in general, the compilation of monetary statistics from these final data does not require estimation, imputation, or adjustment to the source data. However, the provisional data that are reported to the BCT by the $10^{\text {th }}$ after the end of the reference month are less detailed than the final data. As a result, some data are estimated when the provisional data are processed for publication. For example, provisional data on loans and deposits lack breakdown by sector and type needed for classifying them into the appropriate categories of assets and liabilities. Under the current practice, the historical trends as well as percent share of total are used for such estimation. However, according to the current schedule, the provisional data are published for only a few days, and are subsequently replaced by the final data. In general, the statistical techniques employed by the MRD are adequate. 


\subsubsection{Other statistical procedures (e.g., data adjustments and transformations, and statistical analysis) employ sound statistical techniques}

Except for the estimation associated with the provisional data mentioned above, in general, source data are not adjusted for the compilation of monetary statistics. Data reported by banks and other financial institutions are not subject to coverage or other statistical adjustments. In general, data are reported in time. Circular 93-08 sets out what exchange rate should be used to convert accounts in foreign currency to local currency equivalents; this requirement is used to ensure the appropriate practice of conversion used by reporting entities. The BCT does not calculate seasonally adjusted monetary data.

\subsection{Assessment and validation of intermediate data and statistical outputs}

\subsubsection{Intermediate results are validated against other information where applicable}

Cross-checks are carried out against data available from other departments of the BCT. For instance, data on transactions in financial markets and data on government bonds and bills from the General Department of Credit and Capital Markets are used to verify data on the deposit money banks' holdings of such instruments. Data on foreign currency transactions from the General Department of External Finance are also used for cross-checking. In general, most queries concerning monetary statistics are resolved by the MRD with reporting entities through the BSD or directly with reporting entities. Comprehensive secondary data sources that could be used for regular verification of monetary statistics do not exist.

\subsubsection{Statistical discrepancies in intermediate data are assessed and investigated}

Where reasonable doubt exists as to the correctness, completeness, or changes in data (e.g., exceptionally large fluctuations) the $\mathrm{BCT}$ contacts the reporting agents to investigate the sources of such behavior. The relevant reporting banks are then required to provide the BCT with supporting materials and explanations. In addition, as noted in Section 3.4.1, reported data are cross-checked with information obtained from other databases, such as data on claims on and deposits of government, positions with nonresidents, etc. Procedures are in place to cross-check data on interbank transactions and the causes of discrepancies are investigated. Data on reserve assets in balance of payments statistics are compiled based on data provided by the MRD and, therefore are always reconciled. As regards data on government accounts, the BCT sends a statement of accounts to the MF on a daily basis for cross-checking.

\subsubsection{Statistical discrepancies and other potential indicators of problems in statistical outputs are investigated}

As noted earlier, most queries concerning monetary statistics are resolved by the MRD with individual reporting entities through the BSD or directly with reporting entities. For example, large fluctuations in major categories of assets and liabilities in monetary statistics are 
routinely investigated for their causes, including classification or sectorization errors. The $\mathrm{BCT}$ does not collect and compile monetary flow data statistics.

\subsection{Revision studies}

\subsubsection{Studies and analyses of revisions are carried out routinely and used internally to inform statistical processes (see also 4.3.3)}

In practice, revisions are undertaken whenever the need arises, or when there is a change in the accounting system or in methodology, which affects the compilation system. Unless the latter occurs, revisions to monthly monetary statistics tend to be rare, of small magnitude, and not substantial for the major aggregates.

As mentioned earlier, the monthly provisional data on the BCT, the deposit money banks, and the monetary system are compiled and published on the BCT's website until they are replaced with the final data. Under this practice, any differences between the provisional and final data are noted by staff for the subsequent provisional data processing. However, no explicit revision studies are undertaken.

\section{Serviceability}

\subsection{Periodicity and timeliness}

\subsubsection{Periodicity follows dissemination standards}

The monthly statements of the BCT and the deposit money banks as well as the analytical accounts of the BCT and the banking sector, having coverage as required under the SDDS, are disseminated on a monthly basis in line with SDDS requirements.

\subsubsection{Timeliness follows dissemination standards}

The analytical accounts of the BCT are disseminated within two weeks following the end of the reference month and the analytical accounts of the banking sector are disseminated within one month after the end of the reference month. The timeliness of the dissemination for both analytical accounts meets SDDS requirements.

\subsection{Consistency}

\subsubsection{Statistics are consistent within the dataset}

The records of the BCT and banks regarding claims on, and liabilities to, each other show discrepancies. As regards banks' liabilities to the BCT, a discrepancy arises as data on "Other advances" reported under "Advances from the Central Bank" in the banks' monthly statement are not capture in the data on "Claims on banks" in the BCT's monthly statement. The magnitude of these items is small, accounting for about two percent of the BCT's total 
claims on banks as of August 2004. As regards banks' claims on the BCT, data on "Deposits at the Central Bank" reported in the banks' monthly statement are not consistent with the corresponding data (Claims of banks) reported in the BCT's monthly statement. These data in the banks' monthly statement equal 75 percent of the corresponding data in the BCT's monthly statement. A factor contributing to these discrepancies is the time difference in recording the same transactions by the BCT and banks (due to the time spent on check clearing).

Data on interbank positions reported on both sides of the banks' monthly statement also show discrepancies. Data on "Bank correspondents in Tunisia" reported under "Other items of assets" are larger (by 30 percent as of August 2004) than their corresponding data reported under "Other items of liabilities". This inconsistency is largely due to the fact that the asset data cover all financial institutions, while the liability data cover only commercial banks. If the breakdown of the published data by sector is provided, these data will be reconcilable. The BCT's plan to adopt the methodology, including on the sectorization of institutional units, recommended in the MFSM will provide an appropriate breakdown of these data by sector, thus contributing to resolving this discrepancy. Another action that will be taken is to review and improve the report forms so as to fully and accurately capture data on interbank positions; this will allow the BCT to effectively check the internal consistency of the data.

\subsubsection{Statistics are consistent or reconcilable over a reasonable period of time}

The monetary statistics database is maintained by the MRD. The consistent data series for money and other major aggregates are available from 1980. When major changes in source data, methodology, and statistical techniques are introduced, historical data are reconstructed as far back as the available detailed information permits (normally back to 1980). In case the historical data are not revised, the break in time series is explained in the methodological pages of the BCT's QFSB. These methodological pages also contain other information about the data and are updated on a regular basis.

\subsubsection{Statistics are consistent or reconcilable with those obtained through other data sources and/or statistical frameworks}

Data on gross international reserves reported in the BCT's monthly statement and the deposit money banks' holdings of foreign currency are reconciled with data on reserve assets reported in the international investment position of Tunisia. Also, data on the monetary system's foreign liabilities in the monetary statistics are consistent with the same data in the international investment position. Transactions in net foreign assets in monetary statistics are also consistent with the corresponding data in balance of payments statistics. This full consistency between the two data sets is due to the fact that data prepared by the MRD are used by the BCT's Balance of Payments to compile the international investment position and balance of payments statistics. However, the data on net claims on central government and their components reported in the monetary system's monthly statement on the one hand and the fiscal data on the other hand are not reconcilable on the basis of published information due to the lack of detailed breakdown of central government's domestic debt by sector in the 
data published by the MF. However, the data can be reconciled on the basis of supplementary data with the needed breakdowns provided to the mission.

\subsection{Revision policy and practice}

\subsubsection{Revisions follow a regular and transparent schedule}

As mentioned earlier, provisional data on both the BCT and ODCs are available to the MRD by the $10^{\text {th }}$ day after the end of the reference month. They are less detailed than the final data, which are available by the $25^{\text {th }}$ day after the end of the reference month. These provisional data are published on the BCT's website and subsequently replaced by the final data. The provisional data are disseminated on the website of the BCT with appropriate footnotes to inform the users and this dissemination is based on a predetermined schedule. The monetary statistics published in the BCT's QFSB are final; once the final data are published in this bulletin, in principle they are not revised. Any significant change made in the procedures for calculating monetary aggregates is announced in the methodological pages of the BCT's QFSB.

\subsubsection{Preliminary and/or revised data are clearly identified}

The BCT disseminates the provisional data on its website with footnotes to inform the users. When these provisional data are replaced with the final data, the footnotes on the provisional status of data are deleted. This practice takes place on a regular basis.

\subsubsection{Studies and analyses of revisions are made public (see also 3.5.1)}

As mentioned in Section 3.5.1 above, the BCT does not undertake any explicit studies and analyses of revisions. The differences between the published provisional data and final data on the BCT's website are analyzed by staff for internal use, but this practice is not publicized. Apart from the updating of the provisional data with the final data as mentioned earlier, revisions in monetary statistics are said to be rare and, if they take place, they are small. Methodological pages in the BCT's $Q F S B$ are used to explain any significant changes to the data series.

\section{Accessibility}

\subsection{Data accessibility}

\subsubsection{Statistics are presented in a way that facilitates proper interpretation and meaningful comparisons (layout and clarity of text, tables, and charts)}

Monetary statistics published in the BCT's $Q F S B$, which is also posted on the BCT's website, are generally presented in a clear manner. The BCT's QFSB is published in Arabic, French, and English. It is subdivided into two major sections: (1) Money, loan, foreign exchange, and stock market and (2) General economic statistics. The coverage period varies 
from topic to topic, and for some data series it goes back to the early 1980s. In the $Q F S B$, the monetary statistics are published in the form of the monthly statement by sector with data series available from December 2002 and in the form of statements by sector with the data series available as far back as 1980. In addition, tables showing the detailed components of the major data categories are provided to support the analysis of monetary statistics. The $Q F S B$ also covers the monthly statements of other financial corporations and a wide range of other economic and financial statistics, such as stock market, exchange rate, foreign trade, national accounts, and balance of payments. The BCT also publishes the monthly Supplement to Financial Statistics Bulletin and the Economic Situation Periodical that cover data pertaining to the banking sector and the balance of payments. The BCT's annual report covers, among other things, data on the banking system with commentaries and charts, highlighting the important developments in the banking sector.

\subsubsection{Dissemination media and format are adequate}

The media and formats used in the dissemination of data are in general adequate. Monetary statistics are disseminated in hardcopy and on the website of the BCT to meet the needs of data users. The entire $Q F S B$, which contains both recent and historical data on the banking sector as well as a wide range of economic and financial statistics are also posted on the BCT's website. The QFSB posted on the website is available both in French and English.

\subsubsection{Statistics are released on a preannounced schedule}

Monetary statistics are released according to an advance release calendar providing for exact release dates at least three months in advance. This calendar is posted on the BCT's website, and is also available on the IMF's Dissemination Standards Bulletin Board (DSBB). Notification of the location of the posted calendar is also made in the QFSB.

\subsubsection{Statistics are made available to all users at the same time}

Data are disseminated simultaneously to all interested parties, first on the BCT's website (http://www.bct.gov.tn), then in the BCT's monthly Supplement to Financial Statistics Bulletin and in its $Q F S B$. Data users are informed of the data release and how to access the data through a notice published in the $Q F S B$.

\subsubsection{Statistics not routinely disseminated are made available upon request}

Some additional information is available upon request. Customized tabulations may be provided depending on the details requested and the available resources in the MRD. Users can request additional information in two ways - by communicating their queries to the $\mathrm{BCT}$ using the e-mail address provided on the BCT's website or by contacting the BCT's press officials (the Office of the Governor). The queries are forwarded to the relevant department for response. 


\subsection{Metadata accessibility}

5.2.1 Documentation on concepts, scope, classifications, basis of recording, data sources, and statistical techniques is available, and differences from internationally accepted standards, guidelines, or good practices are annotated

The summary methodology for the analytical accounts of the banking sector and the central bank, including the concepts, classifications, data sources, characteristics, and definitions are also available in the SDDS framework posted on the IMF's DSBB. These metadata pages are scrutinized and updated on a regular basis. The BCT's QFSB contains methodological pages, in which information on the structure of the financial system and its recent developments as well as notes on data and changes to data coverage are provided. These methodological notes are useful to assess in the case where some definitions, scope, and account classifications used in the compilation of monetary statistics deviate from the internally accepted standards. However, information on the compilation method, statistical techniques, and source data as well as information on the departures of the current compilation from good practices is not available.

\subsubsection{Levels of detail are adapted to the needs of the intended audience}

As mentioned earlier, the methodological pages in the $Q F S B$ provide some information about the structure of the financial system in Tunisia and notes on the data series (including any changes in the latter). Circular 93-08, which lays out standards for banks and other financial institutions to prepare and report data to the $\mathrm{BCT}$ is available to the public upon request. However, there is no detailed documentation available to the public specifically describing the methods and sources used to compile the monetary statistics.

\section{$5.3 \quad$ Assistance to users}

\subsubsection{Contact points for each subject field are publicized}

Data users can easily reach the contact persons for the monetary statistics identified in the SDDS metadata through the website of the BCT or the IMF's DSBB. The users can also address queries on monetary data to the BCT through e-mail bct@bct.gov.tn, which is provided under each table of statistics published on the BCT's website. In addition, the BCT's press officials in the Office of the Governor can be contacted for such assistance. The Office directs any queries to the appropriate departments.

\subsubsection{Catalogs of publications, documents, and other services, including information on any changes, are widely available}

Catalogs of BCT's publications are not available. However, lists of the data published by the $\mathrm{BCT}$ and the BCT's publications, as well as a list of the last updates of the data are posted on the BCT's website. In addition, the BCT has a subscription form, which contains a list of $B C T$ 's publications and their prices. 


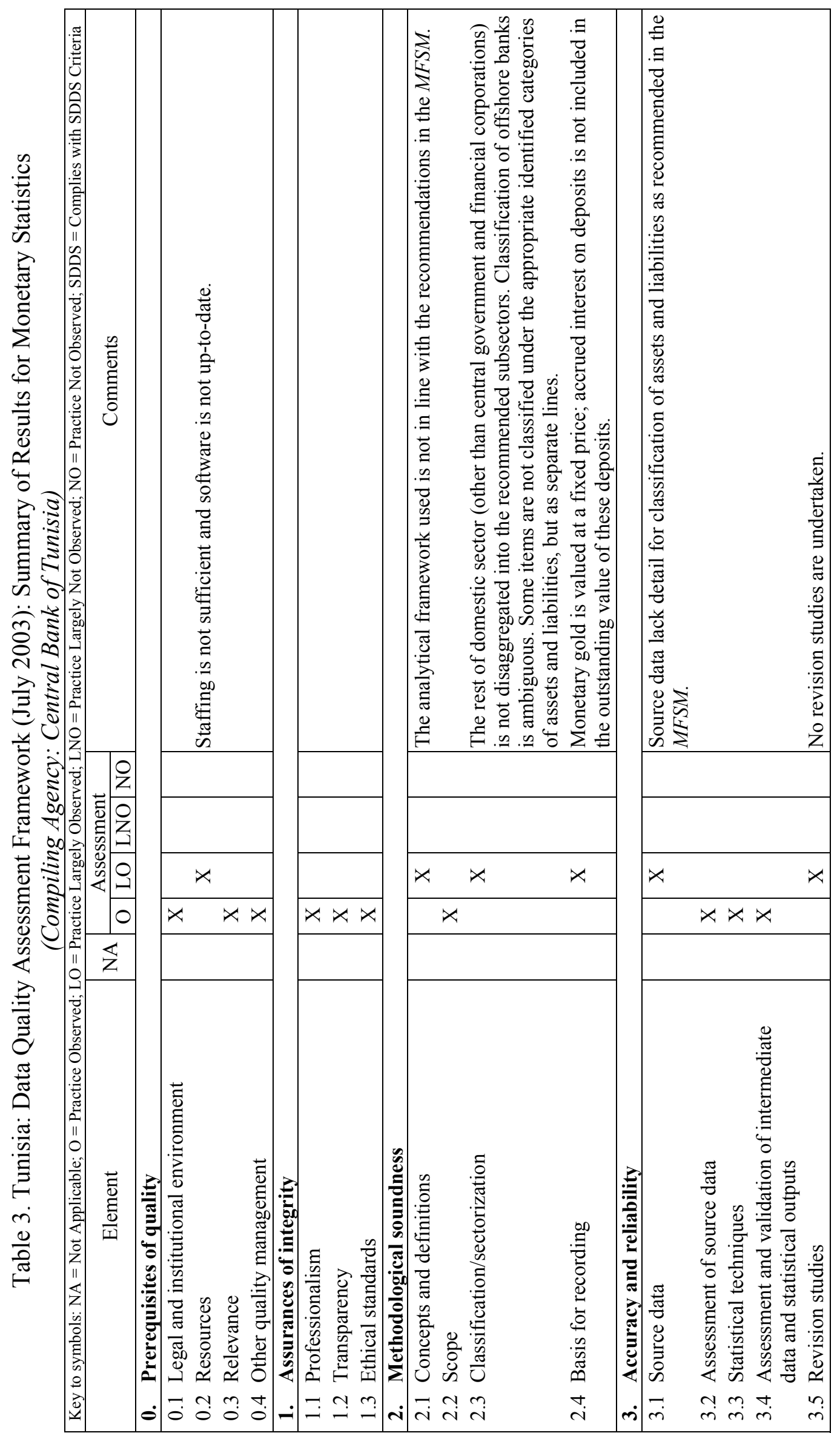




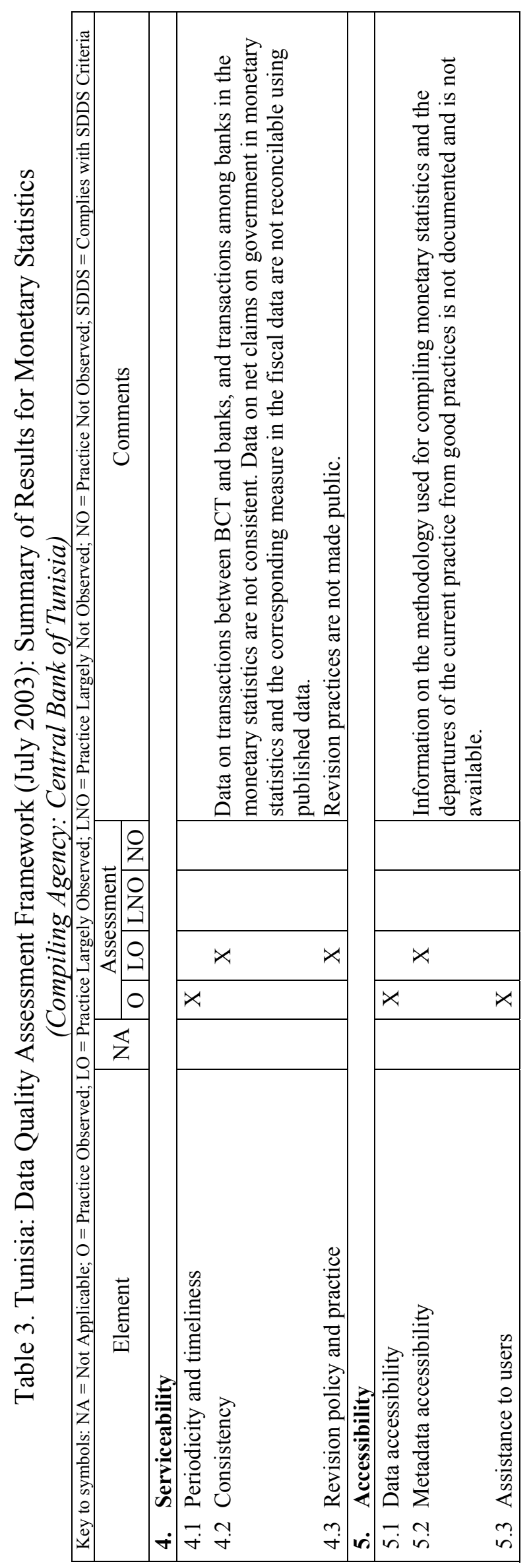




\section{Balance of Payment Statistics}

\section{Prerequisites of Quality}

\subsection{Legal and institutional environment}

0.1.1 The responsibility for collecting, processing and disseminating the statistics is clearly specified.

As part of its responsibilities in monitoring exchange regulations, the BCT has prepared Tunisia's balance of payments statistics since its creation in 1958. Since 1996, it has also prepared statistics on the international investment position of Tunisia. The BCT prepares the external debt statistics together with the DGGD of the MF, the responsibilities of which in this regard are set out in decree 2005-492 of March 1, 2005. The BCT prepares the statistics for the private sector and certain lines of credit delegated to it by the Ministry of Finance, while the Ministry itself prepares the rest of the data on public sector external debt.

The role of the BCT as regards external sector statistics is governed by Law 58-90 on the creation and organization of the Central Bank of Tunisia and by the legally binding circulars it issues as necessary, and especially when there are changes to the provisions of the exchange regulations, the implementation of which it is responsible for monitoring.

Law 58-90 (amended by Laws 88-119 and 2000-37) provides an effective basis for collecting, processing, and disseminating the balance of payments statistics, even though it does not explicitly mention the role of the $\mathrm{BCT}$ in this respect.

A number of circulars have been issued by the BCT either on the balance of payments statistics directly, or on exchange regulation and indirectly on the balance of payments statistics. The circulars that pertain to balance of payments statistics, either directly or indirectly, are the following:

- $\quad$ Circular 2 of 01/12/1960;

- Circular BCT 85-40 of 11/26/1985, on the transmission of monthly documents to the $\mathrm{BCT}$ for the balance of payments;

- Circular BCT 86-02 of 01/22/1986, on individual reports of the purchase and sale of foreign exchange;

- Circular BCT 87-02 of 01/09/1987, on withdrawals and deposits of foreign banknotes by nonresidents holding convertible foreign exchange accounts;

- Circular BCT 89-21 of 06/02/1989, on identifying payments to and from the rest of the world; 
- Circular BCT 96-11 of 09/24/1996, on the revision of the outward payment codes by type of operation;

- $\quad$ Circular BCT 98-13 of 12/01/1998, on the modification of data structures in preparation for the year 2000; and

- $\quad$ Circulars 2 of 01/12/1960, BCT 85-40, 8602, and 9611 specifically on balance of payments statistics.

Besides, Law 99-32 of April 13, 1999 on the national statistics system "defines the basic principles of statistical activity, the structure of the National Statistics System, its mission, and the role of each of its components." Article 12 of the law states, "The National Statistics System is made up of the units and agencies in charge of collecting, processing, storing, analyzing, and disseminating the official statistics, and of coordinating statistical activity. The National Statistics System comprises:

- $\quad$ the National Council on Statistics (CNS);

- $\quad$ the National Statistics Institute (INS);

- $\quad$ other specialized public statistics units; and

- $\quad$ statistical training institutions."

The Director General of Research of the BCT is an ex officio member of the National Council on Statistics.

Article 71 of Law 58-90 states that "The Central Bank may publish all documents or periodicals, reports or studies of an economic, monetary, or banking nature."

Overall, the legal and institutional environment in which the BCT carries out its statistical activities lacks an explicit reference assigning it responsibility for collecting and preparing statistics on the external sector, along with the relevant authority. The undisputed authority enjoyed by the BCT in the country easily compensates for this legal lacuna, and the practice in force since its inception is well-established and has never been called into question. This is all the more true in that, at the present time, all the BCT's requests are addressed exclusively to authorized intermediaries (AI), which are under its supervision.

The de facto division of labor among data producing agencies is clear, and agencies have well-established practices of cooperation and mutual consultation. For example, the BCT publishes the external debt statistics, including the public external debt, before the Ministry of Finance (MF). Prior to publication, the BCT ensures that its data are consistent with the data to be published by the MF.

The BCT can collect data from the authorized intermediaries unhindered, since its status takes precedence over banking secrecy. 


\subsubsection{Data sharing and coordination among data-producing agencies are adequate.}

Data flow and coordination between the agencies concerned are adequate. This is especially true for the external trade data sent monthly by the Customs Administration to the INS, which adjusts them and sends them to the BCT in electronic form.

The creation of the CNS has served to formalize the active cooperation among the producing agencies mentioned above. The Council, which originally had 28 members, now has 36 members. It is composed of ex officio members (producers and users of statistics in the central government, the INS, and the BCT, in the person of the Director General of Research), and members selected to represent all of civil society. The Council meets four times a year in plenary, and establishes ad hoc working groups and committees as needed. The Balance of Payments Subdirectorate (SDBP) of the BCT is currently drafting a brief for CNS members on the methodology and practices adopted for compiling balance of payments statistics.

\subsubsection{Individual reporters' data are to be kept confidential and used for statistical purposes only.}

The BCT firmly upholds the principle of professional confidentiality. The principle is mentioned in its Staff Statute (Article 3), a copy of which is given to each new recruit, and is stressed in the course of the orientation sessions for new staff members.

Articles 4 and 5 of Decree 99-2797, on the creation and organization of the CNS, clearly stipulate that individual data are to be kept confidential and used for statistical purposes only. Moreover, data of a personal nature (i.e., concerning individuals) are protected by the provisions of Law 2004-63 of July 27, 2004, on the protection of data of a personal nature.

The disclosure of confidential data by a BCT employee is grounds for action by the disciplinary board of the Bank, and penalties may include dismissal. Access to individual data stored in the databases is protected with passwords and restricted to staff in charge of balance of payments statistics.

Entry to the BCT is restricted to authorized persons, and all discarded documents are destroyed inside the Bank.

No individual data are disclosed to anyone, even for research purposes. The general rule is that nothing may be divulged that is not published. The risk of indirect disclosure in publication is also taken into account in procedures. The BCT does not publish a data category unless it contains at least three different items. 


\subsubsection{Statistical reporting is ensured through legal mandate and/or measures to encourage response.}

The BCT is authorized by its circulars to collect the information it needs to prepare the balance of payments of Tunisia.

In general, the reporting banks carry out their obligations satisfactorily. A standing balance of payments committee established at the initiative of the BCT meets every month to review the reporting problems noted by the $\mathrm{BCT}$, to inform $\mathrm{BCT}$ correspondents of current developments, and to enlist their assistance in drafting circulars.

The development of information systems both in the BCT and in the banks facilitates the transmission and processing of data and allows the BCT to absorb an average daily volume of approximately 4,000 transaction reports. To maintain and strengthen bank cooperation, the BCT systematically provides the banks with aggregated feedback information, which is found to be very useful.

The penalties for withholding or willfully misreporting data, as set out in Article 49 of Banking Law 2001-65, apply to the balance of payments statistics reports, which are the same as those required for monitoring the implementation of the exchange regulations (Article 32).

\section{$0.2 \quad$ Resources}

\subsubsection{Staff, facilities, computing resources and financing are commensurate with statistical programs.}

The Balance of Payments Subdirectorate comprises two divisions, one in charge of methodology and analysis, and another in charge of database updating and monitoring. There are a total of eight employees in the Subdirectorate, which does not appear to be enough in view of the workload. The problem has not only to do with overall staffing levels but also with the rapid turnover of certain staff. A core of staff is retained, however, which generally helps preserve institutional memory. However, generally in the BCT, and specifically in the SDBP, the academic attainment of new recruits is higher than in the past. The competitive recruitment examination for BCT professionals has been specially adapted to recruit statisticians. Subdirectorate employees also have periodic opportunities for refresher training.

The salaries of SDBP employees are determined in accordance with the latter's position and seniority, as is the case for all BCT staff. The pay is considered to be competitive as compared with the public sector.

The computer equipment is found to be adequate, insofar as almost all employees have a computer. The Information Systems Directorate has a special team for the SDBP, which has developed the applications for the processing and return of data from the Subdirectorate. Overall, the SDBP information system is believed to be very good. The computer resources 
are properly secured. The databases are backed up by the Information Technology Directorate, which is able to put the series on line on request. In addition, the information is backed up every day and stored several miles away from the BCT.

A building extension, currently under construction, will give the BCT the office space it needs. Furthermore, the office equipment is sufficient for the needs of the employees.

The costs of preparing statistics are included in the general budget of the BCT, and are not monitored separately. The annual budget allocates the necessary resources for the work of the SDBP. As regards the balance of payments statistics, currently there is not, nor has there ever been, an investment plan covering several budget years. In any case, the costs of collecting data for the purposes of the balance of payments statistics are inseparable from the costs of data collection for purposes of monitoring exchange regulations implementation.

\subsubsection{Measures to ensure efficient use of resources are implemented.}

Subdirectorate employees are assessed by their immediate supervisor once a year, on the basis of their work performance. The assessments are sent to the Human Resources Directorate, which gives each employee a score. The score is used to calculate the annual bonus.

The SDBP seeks efficiency gains by finding the best information sources, for example ministries that centralize the information needed, rather than the primary reporters.

As the collection of balance of payments statistics is intrinsically linked with the monitoring of exchange regulations implementation, there is no possibility of measuring separately the resources used for preparing balance of payments statistics. However, the BCT informs the CNS each year of the number of employees assigned to statistical work, as well as the number of computers used, so that the CNS may produce an overall estimate of the resources used for statistical output in the country.

\subsection{Relevance}

\subsubsection{The relevance and practical utility of existing statistics in meeting users' needs are monitored.}

The BCT publication homepage gives an e-mail address for users to request additional information. Requests for additional information show that the statistics meet users' needs. The requests are, in particular, from rating agencies, which Tunisia has been using for several years (results on the BCT website).

The composition of the CNS has been modified to involve all of civil society in its work. It is here that new data needs can be expressed and discussed. 
The SDBP takes part in all statistical meetings and seminars to which it is invited, thus keeping abreast of on-going developments in the area of external statistics.

Moreover, the SDBP seeks to anticipate future developments and plan appropriately, as seen in recent working visits by Subdirectorate managers and staff to the Bank of France to study financial derivatives transactions and positions and their processing, in preparation for the possible introduction of this kind of activity in Tunisia. Likewise, the SDBP is already thinking over implementing surveys, should developments in the exchange regulations prevent it from ensuring sufficient coverage of balance of payments transactions in the international transactions reporting system (ITRS), which it has always used so far.

\section{$0.4 \quad$ Other quality management}

\subsubsection{Processes are in place to focus on quality.}

Notwithstanding the absence of written documentation, data quality concerns are at the heart of existing procedures for data collection, processing, and control. All SDBP professionals are aware of the importance of the quality of data output, especially in light of the high degree of public credibility enjoyed by the BCT, which must be preserved. This concern is borne out in the aforementioned monthly meetings with banks, and is impressed on all new Subdirectorate staff in the course of their training by colleagues and supervisors.

The migration from BPM4 to BPM5, which mainly involved preparing the international investment position, was accomplished in close cooperation with the other key departments in the BCT (accounting, monetary statistics), banks, and government agencies.

\subsubsection{Processes are in place to monitor the quality of the statistical program.}

The SDBP does not survey operators directly, but goes through the centralizing agencies for data on both tourism and foreign direct investment (FDI). Nonetheless, it does not incorporate the data directly, but performs cross checks, in particular for FDI data, with bank settlements and customs data (for contributions in kind).

The work with IMF staff when Tunisia was under an IMF program and, subsequently, when it subscribed to SDDS, as well as work with the rating agencies, has helped to develop and maintain an interest in data quality over the years.

\subsubsection{Processes are in place to deal with quality considerations in planning the statistical program.}

Although the Subdirectorate does not have a specific program for statistical work, there are ongoing efforts to improve statistical coverage of Tunisia' cross-border transactions and positions. In this respect, SDBP's participation in the meetings of the CNS and/or of its subgroups provides opportunities to review quality issues with data users. 


\section{Assurances of integrity}

\subsection{Professionalism}

\subsubsection{Statistics are produced on an impartial basis.}

Articles 2 and 3 of Law 5890 on the BCT state that the BCT is a national public institution with legal personality and financial autonomy, and that it is not bound by government accounting laws and regulations. According to (new) Articles 8 and 9 of the law, the Governor is appointed by decree for a term of six years, renewable one or more times. The Governor may only be removed from office by decree. The Auditor (Censeur) responsible for supervising the Bank attends the meetings of the Board in a consultative capacity. The data on the balance of payments and international investment position are collected by the BCT pursuant to circulars issued under its own authority and as needed. Under Article 71 of Law 5890, the BCT may publish all documents or periodicals, reports or studies of an economic, monetary, or banking nature. This appears to provide a sufficient basis for the $\mathrm{BCT}$ to conduct its balance of payments statistics work with full professional independence, as practice confirms.

As indicated above, BCT tradition and culture foster professionalism throughout the institution and lend credibility to its statistical output.

Aside from the Governor and Deputy Governor, who are appointed by decree, the senior managers of the BCT are appointed through internal promotion. Entry-level recruitment to the $\mathrm{BCT}$ is exclusively through competitive examination open only to persons under 30 years of age. Thereafter, professionalism plays a key role in promotion decisions.

The young professionals thus recruited are given theoretical and hands-on training by their seniors. They are encouraged to participate in courses, seminars, and workshops offered by regional and international organizations. The Directorate General for Research, to which the SDBP reports, has a library available to staff wishing to expand their knowledge.

Staff members must observe the rules contained in the Staff Statute, which contribute to enhance their professionalism.

\subsubsection{Choices of sources and statistical techniques as well as decisions about dissemination are informed solely by statistical considerations.}

The choice of sources and statistical techniques used by the BCT and decisions about dissemination are informed by statistical and practical considerations. Law 58-90 requires the BCT to monitor the implementation of the exchange regulations. The bank settlement reports it receives for that purpose also cover most balance of payments needs. 
The appropriate statistical entity is entitled to comment on erroneous interpretation and misuse of statistics.

The statistics are published in the $Q S F B$ together with a number of methodological notes, which reduces the risk of misinterpretation. If the statistics are misinterpreted, though, the BCT asks the press office concerned to publish a correction. The Office of the Governor closely monitors coverage by the Tunisian press.

\subsection{Transparency}

\subsubsection{Terms and conditions under which statistics are collected, processed and disseminated are available to the public.}

Most of the (most recent) texts governing data collection are available to the public on the $\mathrm{BCT}$ website. The BCT provides all regulatory texts free of charge.

Senior managers of the Bank are often invited to conferences, where they have the opportunity to inform the public about how the BCT conducts its business, in particular with regard to statistics.

\subsubsection{Internal governmental access to statistics prior to their release is publicly identified.}

No government employee has access to the balance of payments data prior to their release.

\subsubsection{Products of statistical agencies/units are clearly identified as such.}

The QFSB clearly identifies the BCT as the producer of published data (see first paragraph in the methodology notes). The products of other agencies used by the BCT are clearly identified as such. No such indication appears in the annual publication, Balance of Payments of Tunisia. The Bank stamp on the publication identifies it as the source of the data.

The BCT authorizes the reproduction of its data provided the source is mentioned.

\subsubsection{Advance notice is given of major changes in methodology, sources data and statistical techniques}

Major changes such as the migration to BPM5 and the compilation of the IIP are announced in BCT internal briefings and in meetings with banks, and were mentioned in a number of issues of the $Q F S B$ when introduced, and for several quarters following their introduction. The changes are also mentioned in the BCT Annual Report and in the annual brochure on the balance of payments. However, users have not been notified of major changes in advance. 


\section{Ethical standards}

\subsubsection{Guidelines for staff behavior are in place and are well known to the staff.}

All candidates for positions in the BCT are subject to a background check prior to hiring. The professional code of ethics of the BCT is contained in the Staff Rules and Regulations, and its importance is emphasized to new staff. Staff are also reminded of the code in rare cases where penalties are imposed on a staff member in violation.

There has been no political interference with the BCT since its creation.

\section{Methodological soundness}

Methodological soundness is assessed against the standards set out in BPM 5.

\subsection{Concepts and definitions}

\subsubsection{The overall structure in terms of concepts and definitions follows internationally accepted standards, guidelines, or good practices.}

Since 1996, the BCT has compiled the balance of payments of Tunisia in accordance with the concepts and definitions of BPM5, and in addition, prepares the country's IIP statistics. The basic convention for preparing the balance of payments is the double entry recording system. The current account differentiates the components: goods, services, income, and current transfers. The capital and financial account records asset and liability operations separately. In terms of stocks, the IIP shows the assets and liabilities for the headings of the balance of payments financial operations account separately.

The changes brought by BPM5 mainly consisted of a reclassification of merchanting from goods to services, separation of services income, a distinction between current and capital transfers, and a reclassification of central bank liabilities under "Other Investment," so as to show reserve assets in gross terms.

The concept of residence is applied to institutions in keeping with the principles set out in BPM5. However, the fact that transfers of savings on salaries by Tunisian workers residing abroad are shown under the income heading rather than under current transfers in the national publications suggests that the workers are considered as resident, border, or seasonal workers (i.e., remaining abroad for less than one year).

Foreign construction and public works enterprises that are not incorporated in Tunisia and that carry out work in the country remain nonresident, regardless of the length of their stay. This is the case, for example, of the Spanish firm that built Radès Stadium over the course of more than one year. 
The private sector external debt statistics compiled by the BCT are prepared according to the recommendations of BPM5 and the IMF's External Debt Statistics: Guide for Compilers and Users.

The data on international reserves are also prepared and reported in keeping with SDDS requirements, except for the foreign currency deposits of resident banks in the central bank, which, when they are included as stocks in the reserve assets, as is the case in Tunisia, under heading I.A(1)(a) or (b), should also appear in Section II(1) of the report form as "predetermined short-term net drains," or in Section III.(1) as "contingent liabilities in foreign currency", depending on the circumstances. (See paragraphs 161 and 197 of the IMF brochure, "International Reserves and Foreign Currency Liquidity - Guidelines for a Data Template.") On the other hand, items on the debt service of public enterprises do not have to be included systematically under "predetermined short-term drains." If, however, they are included, which is the case in Tunisia, the notes accompanying the country data should mention the fact. (ibid., paragraph 20).

Prepared in keeping with the concepts and definitions of international standards, all of the aforementioned statistics comply with the requirements of the SDDS, with the exception of those differences already cited. The same is true for both spot and forward exchange rate data.

\section{$2.2 \quad$ Scope}

2.2.l The scope is broadly consistent with internationally accepted standards, guidelines, or good practices.

In principle, all transactions between residents and nonresidents, as defined in BPM5, are covered in the balance of payments statistics, and no major component is intentionally excluded. However, without a real survey of FDI stocks (stocks are estimated as the accumulation of balance of payments flows, adjusted by the gross fixed capital formation (GFCF) deflator), reinvested earnings are not covered (or estimated), which is not in keeping with the BPM5 recommendations.

Similarly, all resident institutional entities engaged in transactions with nonresidents are covered, in particular, the affiliates of nonresident firms, Tunisian embassies and consulates, and free zones (Bizerte and Zarzis). However, the assets of embassy offices in banks in the host country are not covered in the international investment position statistics (the amounts involved are small). 


\subsection{Classification/sectorization}

\subsubsection{Classification/sectorization systems used are broadly consistent with internationally accepted standards, guidelines or good practices.}

Overall, the transactions are recorded in the balance of payments in keeping with the classification indicated in BPM5. One notable exception is "Savings on Salaries" (to use the $\mathrm{BCT}$ term) that Tunisian workers residing abroad send to Tunisia, and that are recorded as income, and not as current transfers ("Workers' Remittances") as required by BPM5. This treatment is used by the $\mathrm{BCT}$ to enhance the visibility of this major component of foreign exchange income in the country, in the belief that if it were classified as income it would be more readily comprehensible to the uninformed public. This treatment does not, however, comply with the international standards set out in the BPM5, and does not allow for valid comparisons with data from partner countries. Furthermore, a certain number of lesser reclassifications should be carried out: social security and pension contributions should be moved from income to current transfers (see BPM5, paragraph 299). In addition, the current practice of recording transfers of funds between Tunisia and another country, carried out by providers of technical assistance posted in the country, under the government services heading (debit) is not in accordance with standards. They should be recorded either under "Workers' Remittances," or under "Other Investment - Other Sectors" of the financial account, depending on the beneficiary.

In the financial account loans are distinct from deposits, as per BPM5.

Data transmitted to the IMF are presented using the BPM5 standard presentation. To facilitate international comparisons, the BCT should also adopt this format for national publications.

\subsection{Basis for recording}

\subsubsection{Market prices are used to value flows and stocks.}

All transactions reported by the banks (including the BCT itself) in the ITRS are valued at market prices and at the exchange rate in effect on the date of transaction, in keeping with the recommendations of BPM5. Exports and imports are recorded at f.o.b. value (based on a c.i.f./f.o.b. coefficient of 5.5 percent on imports, of which 90 percent is for freight and ten percent is for insurance).

Current transfer figures provided yearly by foreign embassies in Tunisia and by the ministries (grants, scholarships and internships, and technical assistance) are converted into dinars at the average annual exchange rates of the currencies in question.

Stocks of medium- and long-term trade credits, BCT and bank assets and liabilities, external debt, and reserve assets, are valued at nominal value (except for assets in the form of securities among the reserve assets, which are valued at market prices, and monetary gold, 
which is valued at a price in dinars that was fixed in 1986), and converted into dinars at the end-of-period exchange rate.

Changes in these stocks from one period to another are used to calculate the flows to be posted to the relevant balance of payments headings, without adjustments for exchange rate variation (contrary to the BPM5 recommendations). The exception is public external debt flows, which are taken directly by the BCT from the activity it records in the Treasury account on its books (the BCT is the sole banker of the Treasury) at the exchange rate on the date of the transaction.

The calculation method for the FDI stock in Tunisia indicated in 2.2.1. is similar to an assessment based on an updated historical value. The same is true of portfolio investment stocks derived from the accumulation of flows, without the update. Beginning with the stock at end-December 2004, the Financial Markets Board (CMF), which has authority over the Tunis Stock Exchange, will report to the BCT the stock, at market value, of Tunisian securities held by nonresidents, which will be in accordance with the recommendations of BPM5 regarding the compilation of the portfolio investment stocks of the international investment position.

The medium- and long-term stock of trade credits is determined by means of a quarterly BCT survey of the main operators, who are selected using repayments reported by authorized intermediaries under the ITRS.

As for the compilation of the FDI stock, after having used a method that served to rapidly address the necessity of assessing stocks for purposes of the international investment position, the BCT should now endeavor to compile the data by collecting information on stocks, consistently with BPM5 methodology. This collection can be conducted using the data from the balance sheets of direct investment enterprises that are already available, such as the annual reports of the main enterprises (which usually show the capital of the enterprise: equity capital, reserves, carryover), or, for the banking sector, the data collected by the BCT as part of the prudential supervision of banks. The balance sheet database to be introduced by the BCT will provide an alternative source of corporate accounting data.

\subsubsection{Recording is done on an accrual basis}

Most transactions are recorded in the balance of payments on a settlement basis, except for transactions in goods, which are taken from customs data (reprocessed by the INS). Services are thus recorded when settled, and not when provided. Likewise, investment earnings are recorded when paid. Current transfers obtained from the annual survey of foreign embassies and the ministries are evenly distributed over the four quarters of the year under review.

By reviewing the annual reports of enterprises to compile statistics on FDI stocks, the BCT will also be able to collect information on reinvested earnings (change in reserves and carryover, if there is no capital increase through incorporation of reserves), which are currently not recorded in the balance of payments of Tunisia. 
The BCT should also find a way to apply the principle of recording on an accrual basis the interest that is presently recorded at the time of payment, in the ITRS context.

\subsubsection{Grossing/netting procedures are broadly consistent with internationally accepted standards, guidelines or good practices.}

Grossing/netting procedures are consistent with BPM5 recommendations. Operations recorded in the current account and in the capital account are recorded on a gross basis, while financial account transactions are recorded on a net basis, separately for assets and liabilities.

\section{Accuracy and reliability}

\subsection{Source data}

\section{3.l.1 Source data are obtained from comprehensive data collection programs that take into account country specific conditions.}

Under the exchange regulations currently in effect in Tunisia, neither individuals nor enterprises may hold accounts abroad. Only authorized intermediaries, i.e. banks, may hold accounts abroad. They may hold minimal working balances in their foreign correspondent banks. Foreign exchange receipts of residents must be repatriated and sold on the foreign exchange market or deposited in a resident bank in so-called 'Foreign Exchange Professional Accounts' that allow operators with foreign exchange receipts and expenditures to hedge against exchange risk. The foreign exchange must be deposited by the authorized intermediaries in the BCT. Nonresidents may hold foreign exchange assets in resident banks, which may freely redeposit the assets abroad.

These regulations are the basis for the ITRS, which the BCT uses to gather the information it needs to compile the balance of payments statistics. The authorized intermediaries report to the $\mathrm{BCT}$ on all transactions between residents and nonresidents, operation by operation and with no threshold, recorded in the foreign correspondent bank accounts on their books (nostri accounts on the asset side and lori accounts on the liability side), with the detail they need both to monitor implementation of the exchange regulations and to produce the balance of payments. All imports and exports of goods and services involving payments must be registered with, and cleared by, authorized intermediaries. These reports show, in particular, a "customs code" identifier that is permanently assigned to all residents engaged in transactions with nonresidents (whatever the nature of the transaction). If there is no customs code, as may be the case for a newly established enterprise for example, the authorized intermediaries use the Trade Register number.

This identifier serves to establish the link between the different databases used for execution, monitoring, and clearing of cross-border transactions. As banker to the Treasury, the BCT can readily collect all international transfers issued or received by the Treasury, in the ITRS, as well as the information needed to record them in the balance of payments. 
For all transactions in excess of the equivalent of TND 200,000, the reporting bank is systematically asked to provide further information and confirmation. When an operation is found to be irregular in the course of the automatic control procedures, the other reports for the day cannot be validated, which forces the employees in charge to remedy the situation the same day.

No netting between debits and credits is permitted in the ITRS (except for transactions with IATA, which are replaced by the information obtained from Tunis Air showing debits and credits separately).

The reports of the authorized intermediaries are taken from their accounting system. Because of the close cooperation between the BCT and the authorized intermediaries, only a few transactions are not precisely coded. The reports have been issued in electronic form since 1986 and will shortly be transmitted on-line.

An ITRS, however, does not allow for the capture of all the transactions to be recorded in the balance of payments, and does not necessarily allow for the correct concepts to be used. To compensate for these shortcomings in the ITRS, the BCT uses complementary or alternative data sources:

For transactions in goods, the data recorded in the balance of payments are customs administration data reprocessed by the INS. Bank reports of transactions in goods submitted to the BCT are therefore not included in the balance of payments, but in addition to being used to monitor implementation of the exchange regulations, they are used to perform checks (annually, according to the activity sector of the operator), and to calculate short-term trade credits. These are calculated as a residual, by taking the difference between the customs data-diminished by the magnitude of transactions without payment, such as grants, FDI contributions in kind, imports by Tunisians working abroad - and medium- and long-term trade credits compiled by means of the BCT quarterly survey mentioned hereafter).

The counter entries for goods imports 'without payment' from the customs statistics are recorded under FDI (see above) or, alternatively, under public or private sector current transfers. In some cases, they are misrecorded under income, as it happens sometimes with vehicles that Tunisian workers living abroad import annually duty free. Information on technical assistance and in-kind grants is collected from foreign embassies in Tunisia and from the relevant ministries (Finance, Social Affairs, Higher Education, and Development) in an annual survey, the findings of which are evenly distributed over each month of the year retrospectively. The response rate for these requests, which are signed by the Governor, is excellent.

For FDI, information on bank settlements is complemented by information from other sources, namely the Investment Promotion Agency (API) and its branch in charge of activities targeted at nonresidents: the Foreign Investment Promotion Agency (FIPA). Every year, the different parties concerned reach an agreement on the yearly data to be issued, to avoid any differences. 
The data needed to monitor external debt, especially in the SDDS context, which are also used to prepare the balance of payments and the international investment position, are taken from a database managed jointly by the BCT and the MF, called the "National Database." The BCT is responsible for the data on (nonguaranteed) private sector external debt, certain credit lines that it manages on behalf of the MF (those that are onlent to the banking sector) or upon the instructions of the donors, and debts to the IMF and the Arab Monetary Fund (AMF). The MF is responsible for data on the rest of the public external debt, as well as on the external debt of public enterprises guaranteed by the government (with no effect on sectorization of the debt).

As regards the public debt, the database is functional and not purely statistical; that is, it is used to manage activity. The information in the database (stocks and flows) can be used to obtain the public external debt service schedule as well as a breakdown by type of maturity (initial or residual), type and level of rate (fixed or variable), by currency, by creditor, by country, etc., or any combination thereof. Daily cooperation between the relevant departments of the MF and the BCT allows for full consistency of the information in the database.

The data for private sector external debt come from a BCT survey of borrowers, which used to be annual, but which is now conducted on a quarterly basis since Tunisia subscribed to the SDDS. The survey population comprises economic agents who were already listed as borrowers under the provisions of previous regulations, and potential borrowers (i.e., economic agents whose activity makes them likely to become borrowers). Gradual liberalization of external loans has, since January 2005, enabled banks to borrow unlimited amounts on external markets on condition that they are officially rated by a rating agency (in the absence of such rating, the maximum amount they can borrow annually without prior authorization is TND 30 million), and has enabled enterprises to borrow up to TND 30 million per year with no authorization required, subject to the same condition of an official rating (failing which, a TND 3 million annual ceiling applies). This has not prevented monitoring of the loans on a quasi-accounting basis. The loans of enterprises continue to be domiciled in a resident bank, and all repayments by a bank or an enterprise give rise to a foreign exchange operation in the BCT, for which the National Database identifier is required.

The BCT quarterly survey also has a section on medium- and long-term trade credits. The survey is conducted on operators identified through repayment transactions reported in the ITRS.

Data from the banks and the BCT collected for monetary statistics purposes are used in exactly the same way for balance of payments statistics, except for certain minor differences, the identification of which allows for perfect reconciliation of the two series.

The SDBP is closely monitoring possible developments in international standards, particularly on the basis of the information disseminated by the IMF. The SDBP is 
represented in the Direct Investment Technical Expert Group (DITEG) of the IMF, which is in charge of FDI matters in the BPM5 revision. ${ }^{28}$

IIP stocks are determined as follows:

- For FDI in Tunisia, in 1996, the SDBP estimated a stock at end-December 1959 using the average FDI earnings recorded over a period of three years around that year and the reference interest rate average. Added to the stock thus obtained were the annual FDI flows, adjusted by the GFCF deflator. This calculation method is still in use. The BCT agreed that it would be necessary in the future to conduct an annual census of the stocks of the main enterprises, on the basis of the real data in their annual reports, which would also allow for an assessment of reinvested earnings.

- For portfolio investments, the SDBP added up the flows recorded in the balance of payments since they started developing. Each year, the flows for the year are added to the existing stock. Starting at the reference date of end-December 2004, the SDBP will use the stock data provided by the Financial Markets Board, which oversees Tunisian financial markets. All Tunisian securities should be kept with a resident custodian, including those held by nonresidents.

- For other investment, the medium- and long-term debt stock comes from the National Database and the BCT balance sheet (liabilities to the IMF and the AMF). The brochure on the balance of payments and the IIP for 2003 shows that government liabilities under 'Other Investment' includes bonds issued by the government with the help of the BCT, which should come under 'Portfolio Investment' (bonds and notes).

The stock of short-term trade credits results from the sum of balance of payment flows. Because the flows are calculated on a residual basis as indicated above (by comparison with the customs data, less operations not involving payment), it is likely that they partially reflect errors in one or another component of the equation. However, efforts by the SDBP to render the data more reliable are likely to keep such errors at a rather limited level. The other headings of the financial account contain data collected for the monetary statistics, on the assets and liabilities of monetary institutions.

\subsubsection{Source data reasonably approximate the definitions, scope, classifications, valuation, and time of recording required.}

The source data are reasonably consistent with the definitions, scope, classifications, valuation, and time of recording required by BPM5, insofar as the BCT compensates for the inherent flaws in collection systems based on bank settlements by using additional reliable

${ }^{28}$ DITEG is one of the three technical expert groups set up by the IMF in the context of the updating of BPM5. 
sources: the INS for adjusted customs statistics, which are used in the same way as for the national accounts, and which allow for recording in the balance of payments on the basis of transactions rather than settlement; and the ministries and foreign embassies for technical assistance and grants: annual data are provided in the transaction currency and converted into dinars at average annual rates. In the financing received under the so-called "upgrade program" with the European Union, a distinction is easily made between capital transfers and current transfers, based on the amounts involved.

Information on the external debt obtained as indicated in 3.1.1. is consistent with the recommendations in BPM5 and the External Debt Guide.

\subsubsection{Source data are timely.}

In the ITRS, transactions are to be reported by authorized intermediaries the day after execution (on the same day in the case of the BCT). Foreign banknote transactions must be reported no more than ten days after the end of the month. In the event of repeated or lengthy reporting delays, authorized intermediaries are reminded of this obligation in the monthly meetings with the SDBP. If necessary, the governor discusses the problem with the president of the institution in question, before his/her peers, at the quarterly meeting with the presidents of local banks. Such action is rarely necessary, due to the close cooperation between the BCT and the banks, as well as among the banks themselves. The monthly meetings held by the BCT provide an opportunity for its statistical correspondents in the commercial banks to get to know and help one another.

The information on the external debt is also available within the SDDS required timeliness.

The annual data provided by the ministries and foreign embassies are available in the first quarter following the year under review.

\subsection{Assessment of source data}

\subsubsection{Source data-including censuses, sample surveys, and administrative records-are} routinely assessed, e.g., for coverage, sample error, response error, and nonsampling error; the results of the assessments are monitored and made available to guide statistical processes.

The provisions of the exchange regulations allow the BCT to ensure that each exchange operation is reported for balance of payments purposes by an authorized payment intermediary through the "Exchange Titles" database that it manages, in which the exchange titles should be paired with a statistical report. Without a simplification or exemption threshold, the BCT ITRS is likely to record exhaustively all cross-border transactions settled. Transfers of workers' remittances are captured easily as there are no informal "Hawalah" type channels in Tunisia. Western Union and Moneygram - two institutions specialized in money transfers - are not authorized intermediaries (hence not subject to reporting 
obligations) and are associated with the Post Office and the commercial banks, which take care of reporting.

Tunisia has an open ITRS, except for foreign banknotes and nonresident accounts in convertible dinars, the reported activity of which is reconciled with the change in balances from the beginning to the end of the period (closed system).

The SDBP tries to obtain any information that allows it to check or complete ITRS information. For example, it regularly receives information from Tunis Air and Compagnie Tunisienne de Navigation.

\subsection{Statistical techniques}

\subsubsection{Data compilation employs sound statistical techniques to deal with data sources.}

Only foreign banknote transaction reports are still processed partly on a manual basis; they are checked to avoid errors. Ongoing efforts to improve data quality have helped prevent the recording of statistical incongruities.

As indicated above, the exchange regulations and the ITRS provide full coverage of settled transactions. The only estimates incorporated in the balance of payments by the SDBP are for transactions not involving payment, for which only annual data are obtained (technical assistance, grants, scholarships, etc.). The amounts recorded over the previous year are evenly distributed over the months or quarters of the current year.

Careful checks are performed on the annual data obtained from various sources (ministries and embassies) that may pertain to the same transactions, to avoid the risk of double counting in the balance of payments.

\subsubsection{Other statistical procedures (e.g., data adjustments and transformations, and statistical analysis) employ sound statistical techniques.}

The c.i.f./f.o.b. coefficient for adjusting imports is revised every two to three years. It is determined by the BCT on the basis of a sample of customers representative of products traded and partner countries, with the help of itemized invoices provided by the three largest local banks. The data collected from the National Tourism Office of Tunisia are used to improve the geographical breakdown of the "Travel" transactions collected from the ITRS and the reports on foreign banknotes operations.

The SDBP believes that the customs statistics faithfully reflect all of the transactions, especially imports insofar as - besides oversight by the Customs Administration - the favorable customs arrangement for Tunisian expatriates returning for vacation or to reside permanently in the country provides no incentives for fraud. Cross-border trade by the informal sector does not appear to be an issue in Tunisia. 
The statistics compiled and published are based on raw data with no seasonal adjustment.

\subsection{Assessment and validation of intermediate data and statistical outputs}

\subsubsection{Intermediate results are validated against other information where applicable.}

As indicated, the SDBP constantly strives to guarantee the validity of the source data reported in the ITRS or from other sources. It also guarantees the validity of aggregated data insofar as possible by comparing the results obtained with information from other sources. This is especially the case for portfolio investment validated with a representative of the $\mathrm{CMF}$, and for FDI for which annual data are determined by the BCT together with FIPA for investments in the manufacturing sector, with the BCT bank supervision departments for investments in the banking sector, and with the relevant ministries for investments in the hotels and insurance sectors.

\subsubsection{Statistical discrepancies in intermediate data are assessed and investigated.}

Because of the current method of calculating the stocks of FDI and portfolio investments of the international investment position, their use to assess whether the data reported under investment income show a realistic rate of return, is not likely to produce conclusive results. On the contrary, interest flows on the external debt are fully consistent with the corresponding stocks.

The difference between the data reported in the ITRS for transactions on goods and the customs data is used to determine short-term trade credit, using the methodology described above.

\subsubsection{Statistical discrepancies and other potential indicators or problems in statistical outputs are investigated.}

Year after year, the "Errors and Omissions" remain fairly stable at a level not exceeding TND 50 million. As they are always negative, there is a slight statistical bias representing either an underestimate of outflows or an overestimate of inflows.

\subsection{Revision studies}

\subsubsection{Studies and analyses of revisions are carried out routinely and used internally to inform statistical processes (see also 4.3.3).}

In the ITRS, most reports by authorized intermediaries are checked and validated almost in real time, and within a few days at the latest. The many cross checks performed by the SDBP may give rise to changes, or even the inclusion of reports previously omitted, over several months following the end of the month in question. There is no specific revision study carried out, since such revisions are entirely random. Moreover, the SDBP information 
system does not keep the history of each transaction recorded, and all new information replaces the previous information.

\section{Serviceability}

\subsection{Periodicity and timeliness}

\subsubsection{Periodicity follows dissemination standards.}

Tunisia's balance of payments is published monthly by the BCT in the Financial Statistics Bulletin Supplement, expressed in cumulative data from the beginning of the year. It is also published in the economic bulletin Business Conditions Periodical, which gives the cumulative statistics, as well as the last month of the series, which does not appear in the Supplement. A quarterly balance of payments is prepared for SDDS purposes and is published on the BCT website. A more detailed annual balance of payments and the international investment position are published in June in the BCT Annual Report, and in September in the brochure The Balance of Payments in (year). In addition to dissemination in the IMF's DSBB, the external debt statistics are published in a detailed annual brochure, which comes out in September. The main components of the external debt are also presented in the publications already mentioned.

\subsubsection{Timeliness follows dissemination standards.}

All of the statistics mentioned are disseminated with the timeliness required by the SDDS.

The monthly balance of payments is published within three weeks following the end of the reference month.

\subsection{Consistency}

\subsubsection{Statistics are consistent within the dataset.}

The concepts, definitions, and classifications used are identical for monthly, quarterly, and annual statistics. Annual statistics, however, are more detailed. The sum of the quarterly statistics equals the annual statistics.

\subsubsection{Statistics are consistent or reconcilable over a reasonable period of time.}

Balance of payments data compiled in accordance with the BPM5 methodology have been calculated backwards to 1993 by the SDBP. The international investment position data are also available starting from 1993. An explanatory note was inserted into the brochure the first three times that the annual balance of payments was published in accordance with the new methodology. 


\subsubsection{Statistics are consistent or reconcilable with those obtained through other data sources and/or statistical frameworks.}

Because of the sources used and the ongoing cooperation among the different producing agencies, the balance of payments statistics are consistent with national accounts, monetary statistics, government finance, and external debt statistics.

\subsection{Revision policy and practice}

\subsubsection{Revisions follow a regular and transparent schedule.}

Revisions are introduced as the SDBP becomes aware of them, except for the period following the first publication of a full year as the sum of twelve months, and up to the compilation of the annual figures for the Annual Report, during which time the data are provisionally frozen. Pending revisions are incorporated into the Annual Report data. The data are then considered final, and the asterisk indicating that they are provisional is deleted. Upon publication of the annual balance of payments brochure, however, new revisions may be introduced as needed. To ensure consistency between the statistical series, any subsequent adjustments (to the external trade data, for example, indicated by the INS) may be introduced at any time. This practice is not made known to the public.

\subsubsection{Preliminary and/or revised data are clearly identified.}

An asterisk identifies provisional data.

\subsubsection{Studies and analyses of revisions are made public (see also 3.5.1).}

Given the source data collection system and storage method, the SDBP does not conduct any specific revision studies (see 4.3.3).

\section{Accessibility}

\subsection{Data accessibility}

\subsubsection{Statistics are presented in a way that facilitates proper interpretation and meaningful comparisons (layout and clarity of text, tables, and charts).}

The statistics are presented clearly in BCT publications. The annual data are published in the Annual Report and then in the balance of payments brochure together with graphs and detailed descriptions of developments over the year in question. The same is true for external debt statistics. However, the comparability of the balance of payments and international investment position statistics would be facilitated if the BCT adopted a presentation format in its publications that was more consistent with the BPM5 standard presentation. 
In its annual publications, the BCT provides numerous additional useful details in almost all headings such as trade balance trends by product group, or trends in the main indicators in the tourism sector.

\subsubsection{Dissemination media and format are adequate.}

All balance of payments statistics are published on the BCT website and in print.

\subsubsection{Statistics are released on a preannounced schedule.}

The quarterly statistics release calendar for the coming year is published on the BCT website in November. The calendar is strictly adhered to.

\subsubsection{Statistics are made available to all users at the same time.}

The statistics are made available to all users simultaneously on the BCT website or in print.

\subsubsection{Statistics not routinely disseminated are made available upon request.}

Under BCT policy, nothing is made available that is not published. The BCT does, however, release additional information that is available, if it is part of a published aggregate. For example, the BCT provides the INS with the breakdown by mode of transport (sea, air, etc.) of the general "Transportation" heading of the balance of payments.

The SDBP considers additional requests for information from users on a case-by-case basis. Due to its small staff, the SDBP only responds to those requests that it can meet promptly. The SDBP usually offers to make the information requested available in its offices, if such information exists.

\subsection{Metadata accessibility}

5.2.1 Documentation on concepts, scope, classifications, basis of recording, data sources, and statistical techniques is available, and differences from internationally accepted standards, guidelines, or good practices are annotated.

The metadata prepared by the SDBP in preparation for Tunisia's accession to the SDDS are the most accessible source of information as regards concepts, definitions, sources, and methods used to compile statistics on the external sector. They are only accessible through the IMF's DSBB. Printed documentation is also available for consultation in BCT offices. This documentation was assembled during the seminar organized in Tunisia in 1996 with the cooperation of the IMF, in preparation for the migration to the BPM5 methodology. 


\subsubsection{Levels of detail are adapted to the needs of the intended audience.}

The 'Statistics' section of the BCT website gives the list of external sector statistical series and their links. The CNS publishes an annual report that lists the statistical agencies and the statistics that they produce, the BCT and its statistics included.

\subsection{Assistance to users}

\subsubsection{Contact points for each subject field are publicized.}

No mention is made in the national publications of a contact person for questions about balance of payments statistics. The BCT website gives a single e-mail for all requests. The Press and Public Relations Office channels the requests to the relevant department. The SDBP tries to respond to the requests in good time, within the aforementioned constraints.

\subsubsection{Catalogs of publications, documents, and other services, including information on any changes, are widely available.}

The list of BCT publications with the prices and subscription form are available on the BCT website. Users may contact the Publications Department for assistance. 


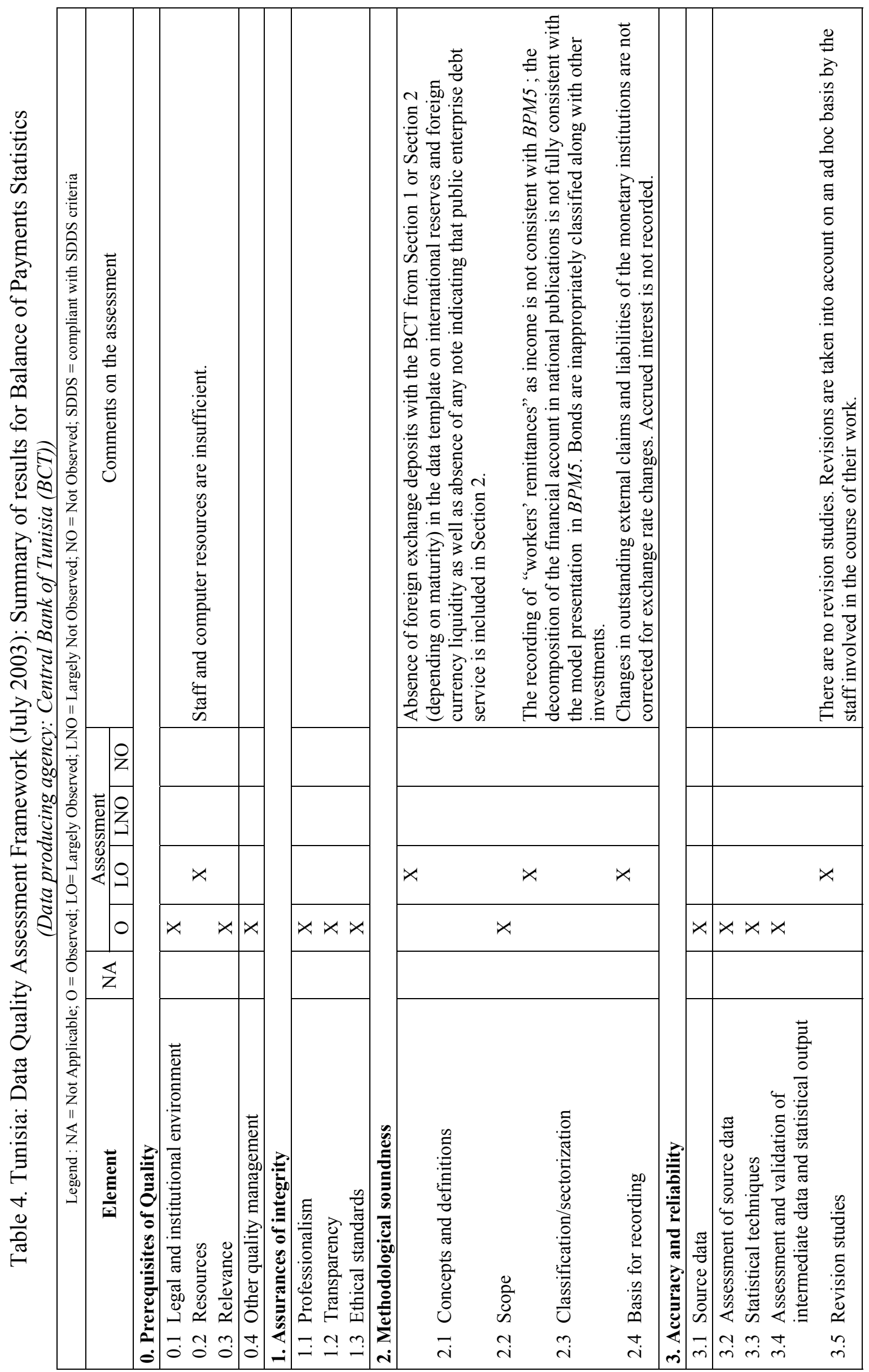




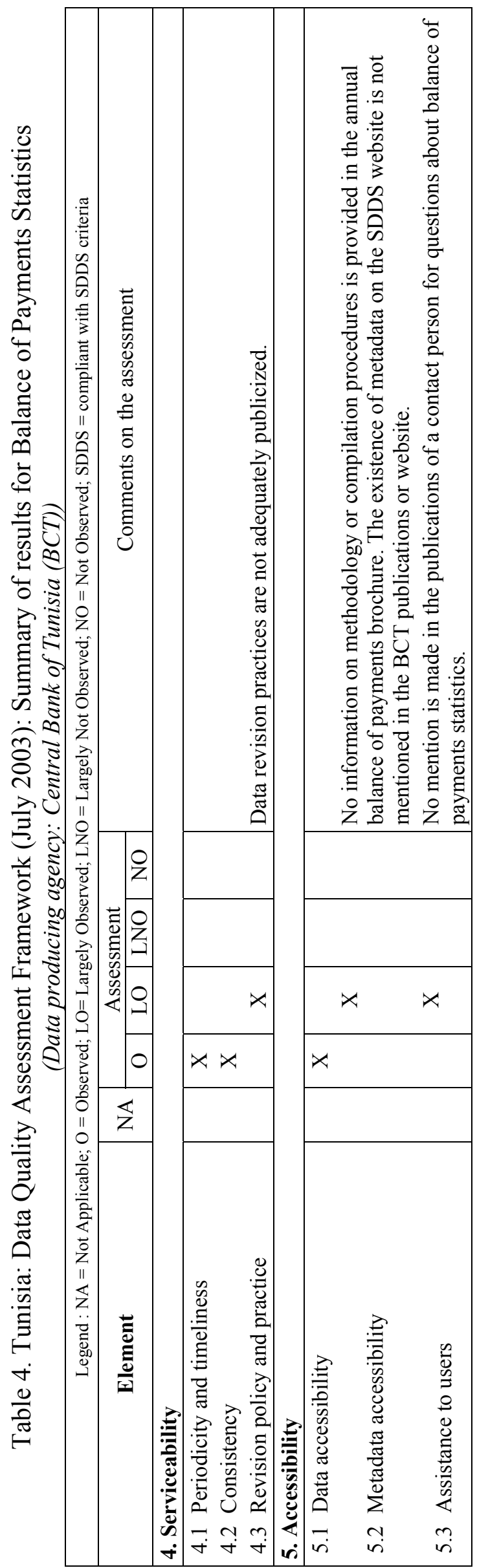




\section{Summary of the Special Data Dissemination Standard (SDDS)}

The SDDS prescribes the following practices under each of the identified dimensions:

Data dimension (coverage, periodicity, and timeliness)

- $\quad$ the dissemination of 18 data categories, including component detail, covering the four main sectors (real, fiscal, financial, and external) of the economy, with prescribed periodicity and timeliness.

\section{Access dimension}

- the dissemination of advance release calendars providing at least one-quarter advance notice of approximate release dates, and at least a one-week advance notice of the precise release dates; and

- $\quad$ the simultaneous release of data to all users.

\section{Integrity dimension}

- the dissemination of the terms and conditions under which official statistics are produced and disseminated;

- $\quad$ the identification of internal government access to data before release;

- the identification of ministerial commentary on the occasion of statistical release; and

- the provision of information about revision and advance notice of major changes in methodology.

\section{Quality dimension}

- the dissemination of documentation on statistical methodology and sources used in preparing statistics; and

- dissemination of component detail and/or additional data series that make possible cross-checks and checks of reasonableness.

SDDS subscribers are required to:

- $\quad$ post descriptions of their data dissemination practices (metadata) on the IMF's Dissemination Standards Bulletin Board (DSBB). Summary methodologies, which describe data compilation practices in some detail, are also disseminated on the DSBB; and 
- $\quad$ maintain an Internet website, referred to as the National Summary Data Page (NSDP), which contains the actual data described in the metadata and to which the DSBB is electronically linked.

The IMF staff is monitoring observance of the standard through NSDPs maintained on the Internet. Monitoring is limited to the coverage, periodicity, and timeliness of the data and to the dissemination of advance release calendars.

Source: http://dsbb.imf.org 


\section{DATA QUALITY ASSESSMENT FRAMEWORK-GENERIC FRAMEWORK (JULY 2003 FRAMEWORK)}

\begin{tabular}{|c|c|c|}
\hline Quality Dimensions & Elements & Indicators \\
\hline \multirow[t]{4}{*}{$\begin{array}{l}\text { 0. Prerequisites of } \\
\text { quality }\end{array}$} & $\begin{array}{l}\text { 0.1 Legal and institutional } \\
\text { environment-The environment } \\
\text { is supportive of statistics }\end{array}$ & $\begin{array}{l}\text { 0.1.1 The responsibility for collecting, processing, } \\
\text { and disseminating the statistics is clearly specified. } \\
\text { 0.1.2 Data sharing and coordination among data- } \\
\text { producing agencies are adequate. } \\
\text { 0.1.3 Individual reporters' data are to be kept } \\
\text { confidential and used for statistical purposes only. } \\
\text { 0.1.4 Statistical reporting is ensured through legal } \\
\text { mandate and/or measures to encourage response. }\end{array}$ \\
\hline & $\begin{array}{l}\mathbf{0 . 2} \text { Resources-Resources are } \\
\text { commensurate with needs of } \\
\text { statistical programs. }\end{array}$ & $\begin{array}{l}\text { 0.2.1 Staff, facilities, computing resources, and } \\
\text { financing are commensurate with statistical } \\
\text { programs. } \\
0.2 .2 \text { Measures to ensure efficient use of resources } \\
\text { are implemented. }\end{array}$ \\
\hline & $\begin{array}{l}\mathbf{0 . 3} \text { Relevance }- \text { Statistics cover } \\
\text { relevant information on the } \\
\text { subject field. }\end{array}$ & $\begin{array}{l}\text { 0.3.1 The relevance and practical utility of existing } \\
\text { statistics in meeting users' needs are monitored. }\end{array}$ \\
\hline & $\begin{array}{l}\text { 0.4 Other quality } \\
\text { management-Quality is a } \\
\text { cornerstone of statistical work. }\end{array}$ & $\begin{array}{l}\text { 0.4.1 Processes are in place to focus on quality. } \\
0.4 .2 \text { Processes are in place to monitor the quality of } \\
\text { the statistical program. } \\
\text { 0.4.3 Processes are in place to deal with quality } \\
\text { considerations in planning the statistical program. }\end{array}$ \\
\hline \multirow{3}{*}{$\begin{array}{l}\text { 1. Assurances of } \\
\text { integrity } \\
\text { The principle of } \\
\text { objectivity in the } \\
\text { collection, } \\
\text { processing, and } \\
\text { dissemination of } \\
\text { statistics is firmly } \\
\text { adhered to. }\end{array}$} & $\begin{array}{l}\text { 1.1 Professionalism—Statistical } \\
\text { policies and practices are } \\
\text { guided by professional } \\
\text { principles. }\end{array}$ & $\begin{array}{l}\text { 1.1.1 Statistics are produced on an impartial basis. } \\
\text { 1.1.2 Choices of sources and statistical techniques } \\
\text { as well as decisions about dissemination are } \\
\text { informed solely by statistical considerations. } \\
\text { 1.1.3 The appropriate statistical entity is entitled to } \\
\text { comment on erroneous interpretation and misuse of } \\
\text { statistics. }\end{array}$ \\
\hline & $\begin{array}{l}\text { 1.2 Transparency_-Statistical } \\
\text { policies and practices are } \\
\text { transparent. }\end{array}$ & $\begin{array}{l}\text { 1.2.1 The terms and conditions under which } \\
\text { statistics are collected, processed, and disseminated } \\
\text { are available to the public. } \\
\text { 1.2.2 Internal governmental access to statistics prior } \\
\text { to their release is publicly identified. } \\
\text { 1.2.3 Products of statistical agencies/units are } \\
\text { clearly identified as such. } \\
\text { 1.2.4 Advance notice is given of major changes in } \\
\text { methodology, source data, and statistical techniques. }\end{array}$ \\
\hline & $\begin{array}{l}1.3 \text { Ethical standards-Policies } \\
\text { and practices are guided by } \\
\text { ethical standards. }\end{array}$ & $\begin{array}{l}\text { 1.3.1 Guidelines for staff behavior are in place and } \\
\text { are well known to the staff. }\end{array}$ \\
\hline
\end{tabular}




\begin{tabular}{|c|c|c|}
\hline Quality Dimensions & Elements & Indicators \\
\hline $\begin{array}{l}\text { 2. Methodological } \\
\text { soundness } \\
\text { The methodological } \\
\text { basis for the } \\
\text { statistics follows } \\
\text { internationally } \\
\text { accepted standards, } \\
\text { guidelines, or good } \\
\text { practices. }\end{array}$ & $\begin{array}{l}\text { 2.1 Concepts and definitions- } \\
\text { Concepts and definitions used } \\
\text { are in accord with } \\
\text { internationally accepted } \\
\text { statistical frameworks. } \\
2.2 \text { Scope-The scope is in } \\
\text { accord with internationally } \\
\text { accepted standards, guidelines, } \\
\text { or good practices. } \\
\mathbf{2 . 3} \text { Classification/ } \\
\text { sectorization-Classification } \\
\text { and sectorization systems are in } \\
\text { accord with internationally } \\
\text { accepted standards, guidelines, } \\
\text { or good practices. } \\
\mathbf{2 . 4} \text { Basis for recording-Flows } \\
\text { and stocks are valued and } \\
\text { recorded according to } \\
\text { internationally accepted } \\
\text { standards, guidelines, or good } \\
\text { practices }\end{array}$ & $\begin{array}{l}\text { 2.2.1 The scope is broadly consistent with } \\
\text { internationally accepted standards, guidelines, or } \\
\text { good practices. } \\
\text { 2.3.1 Classification/sectorization systems used are } \\
\text { broadly consistent with internationally accepted } \\
\text { standards, guidelines, or good practices. }\end{array}$ \\
\hline $\begin{array}{l}\text { 3. Accuracy and } \\
\text { reliability } \\
\text { Source data and } \\
\text { statistical techniques } \\
\text { are sound and } \\
\text { statistical outputs } \\
\text { sufficiently portray } \\
\text { reality }\end{array}$ & $\begin{array}{l}\text { 3.2 Assessment of source } \\
\text { data-Source data are regularly } \\
\text { assessed. } \\
\text { 3.3 Statistical techniques- } \\
\text { Statistical techniques employed } \\
\text { conform to sound statistical } \\
\text { procedures } \\
\text { 3.4 Assessment and validation } \\
\text { of intermediate data and } \\
\text { statistical outputs- } \\
\text { Intermediate results and } \\
\text { statistical outputs are regularly } \\
\text { assessed and validated. } \\
\text { 3.5 Revision studies- } \\
\text { Revisions, as a gauge of } \\
\text { reliability, are tracked and } \\
\text { mined for the information they } \\
\text { may provide. }\end{array}$ & $\begin{array}{l}\text { 3.1.1 Source data are obtained from comprehensive } \\
\text { data collection programs that take into account } \\
\text { country-specific conditions. } \\
\text { 3.1.2 Source data reasonably approximate the } \\
\text { definitions, scope, classifications, valuation, and } \\
\text { time of recording required. } \\
\text { 3.1.3 Source data are timely. } \\
\text { 3.2.1 Source data-including censuses, sample } \\
\text { surveys, and administrative records-are routinely } \\
\text { assessed, e.g., for coverage, sample error, response } \\
\text { error, and nonsampling error; the results of the } \\
\text { assessments are monitored and made available to } \\
\text { guide statistical processes. } \\
\text { 3.3.1 Data compilation employs sound statistical } \\
\text { techniques to deal with data sources. } \\
\text { 3.3.2 Other statistical procedures (e.g., data } \\
\text { adjustments and transformations, and statistical } \\
\text { analysis) employ sound statistical techniques. } \\
\text { 3.4.1 Intermediate results are validated against other } \\
\text { information where applicable. } \\
\text { 3.4.2 Statistical discrepancies in intermediate data } \\
\text { are assessed and investigated. } \\
\text { 3.4.3 Statistical discrepancies and other potential } \\
\text { indicators or problems in statistical outputs are } \\
\text { investigated. } \\
\text { 3.5.1 Studies and analyses of revisions are carried } \\
\text { out routinely and used internally to inform statistical } \\
\text { processes (see also } 4.3 .3 \text { ). }\end{array}$ \\
\hline
\end{tabular}




\begin{tabular}{|c|c|c|}
\hline Quality Dimensions & Elements & Indicators \\
\hline $\begin{array}{l}\text { 4. Serviceability } \\
\text { Statistics, with } \\
\text { adequate periodicity } \\
\text { and timeliness, are } \\
\text { consistent and } \\
\text { follow a predictable } \\
\text { revisions policy. }\end{array}$ & $\begin{array}{l}\text { 4.1 Periodicity and } \\
\text { timeliness-Periodicity and } \\
\text { timeliness follow internationally } \\
\text { accepted dissemination } \\
\text { standards. } \\
4.2 \text { Consistency_-Statistics are } \\
\text { consistent within the dataset, } \\
\text { over time, and with major } \\
\text { datasets. } \\
\text { 4.3 Revision policy and } \\
\text { practice-Data revisions follow } \\
\text { a regular and publicized } \\
\text { procedure. }\end{array}$ & $\begin{array}{l}\text { 4.2.1 Statistics are consistent within the dataset. } \\
\text { 4.2.2 Statistics are consistent or reconcilable over a } \\
\text { reasonable period of time. } \\
\text { 4.2.3 Statistics are consistent or reconcilable with } \\
\text { those obtained through other data sources and/or } \\
\text { statistical frameworks. } \\
\text { 4.3.1 Revisions follow a regular and transparent } \\
\text { schedule. } \\
\text { 4.3.2 Preliminary and/or revised data are clearly } \\
\text { identified. } \\
\text { 4.3.3 Studies and analyses of revisions are made } \\
\text { public (see also 3.5.1). }\end{array}$ \\
\hline $\begin{array}{l}\text { 5. Accessibility } \\
\text { Data and metadata } \\
\text { are easily available } \\
\text { and assistance to } \\
\text { users is adequate. }\end{array}$ & $\begin{array}{l}\text { 5.1 Data accessibility- } \\
\text { Statistics are presented in a } \\
\text { clear and understandable } \\
\text { manner, forms of dissemination } \\
\text { are adequate, and statistics are } \\
\text { made available on an impartial } \\
\text { basis. } \\
\\
\text { 5.2 Metadata accessibility- } \\
\text { Up-to-date and pertinent } \\
\text { metadata are made available. }\end{array}$ & $\begin{array}{l}\text { 5.1.1 Statistics are presented in a way that facilitates } \\
\text { proper interpretation and meaningful comparisons } \\
\text { (layout and clarity of text, tables, and charts). } \\
\text { 5.1.2 Dissemination media and format are adequate. } \\
\text { 5.1.3 Statistics are released on a preannounced } \\
\text { schedule. } \\
\text { 5.1.4 Statistics are made available to all users at the } \\
\text { same time. } \\
\text { 5.1.5 Statistics not routinely disseminated are made } \\
\text { available upon request. } \\
\text { 5.2.1 Documentation on concepts, scope, } \\
\text { classifications, basis of recording, data sources, and } \\
\text { statistical techniques is available, and differences } \\
\text { from internationally accepted standards, guidelines, } \\
\text { or good practices are annotated. } \\
\text { 5.2.2 Levels of detail are adapted to the needs of the } \\
\text { intended audience. } \\
\text { 5.3.1 Contact points for each subject field are } \\
\text { publicized. } \\
\text { 5.3.2 Catalogs of publications, documents, and other } \\
\text { services, including information on any charges, are } \\
\text { widely available. }\end{array}$ \\
\hline
\end{tabular}




\section{Detailed Results of Tunisia's User Survey}

\section{Summary of results of survey of data users}

To complement the Fund staff's assessment of the quality of macroeconomic statistics produced in Tunisia, an informal survey of key users of such statistics was conducted. The authorities sent questionnaires to 14 users; responses were received from 12 of them. Respondents included international and domestic banks, international and regional organizations, the financial media, employers and producers associations, think tanks, the trade unions, and some users of data in the public administration (see Table 5 below). Users were asked to evaluate the coverage, periodicity, timeliness, dissemination practices, accessibility, and overall quality of the official statistics assessed in this report.

Users overall expressed satisfaction with the quality of the statistics produced in Tunisia (see Table 6 below). The results of the survey indicated that a majority of users are satisfied with the coverage, periodicity, level of detail, soundness of the underlying methodology of the official statistics, and their timeliness. On a five point scale ( 1 meaning poor and 5 excellent), respondents' average rating for the overall quality of the official statistics for all assessed sectors was a 3.8, with the lowest score (3.5) given to GFS and the highest (4.1) to monetary statistics. Most users regarded Tunisia's official macroeconomic statistics to be of better quality than the statistics of countries at similar levels of development in the region.

The main uses of official statistics are, in order of importance, for general economic background, analysis of current developments, analysis of trends, comparisons with developments in other countries, and economic research. The macroeconomic statistics most frequently used are the monetary and balance of payments statistics, closely followed by national accounts statistics. Government Finance Statistics (GFS) are used less frequently. The main source of official statistics is, according to most users, official publications and press releases. However, similar numbers of users indicated use of publications of international organizations about Tunisia. Over 40 percent of users do not consult official descriptions of the sources and methods used to compile the official statistics.

Several comments and suggestions for improving official statistics were provided in the responses to the questionnaires. These concern mostly the national accounts (diversification of dissemination means for quarterly national accounts; dissemination of data with greater level of detail, including information on the informal sector). Some respondents also commented that the timeliness of some statistics (national accounts, GFS, and balance of payments) could be improved. 


\section{Questionnaire Results Analyzed by Type of User}

April 19, 2005

\begin{tabular}{lccc}
\hline \multicolumn{1}{c}{ Type of Respondent } & Total & $\begin{array}{c}\text { In \% } \\
\text { Received }\end{array}$ \\
\hline Banks & Total Sent & Received & Reci \\
Media & 3 & 3 & $100 \%$ \\
International organizations & 2 & 1 & $50 \%$ \\
Employers' associations & 3 & 2 & $67 \%$ \\
Labor unions & 1 & 1 & $100 \%$ \\
Think tanks & 1 & 1 & $100 \%$ \\
Government & 3 & 3 & $100 \%$ \\
Total & $\mathbf{1 4}$ & $\mathbf{1 2}$ & $\mathbf{8 6 \%}$ \\
\hline
\end{tabular}

Source: Central Bank of Tunisia

Table 6. Detailed Results of Tunisia's User Survey

April 19, 2005

General Information about Uses of Official Macroeconomic Statistics of Tunisia

\begin{tabular}{|c|c|c|}
\hline & & $\begin{array}{c}\text { Total } \\
\text { Number of } \\
\text { Responses }\end{array}$ \\
\hline & Which official statistics do you use regularly? & \\
\hline & $\begin{array}{l}\text { a. National accounts (NA) } \\
\text { b. Prices } \\
\text { c. Government finance statistics (GFS) } \\
\text { d. Monetary statistics (Monetary) } \\
\text { e. Balance of payments (BOP) } \\
\text { f. Other: } \\
\text { - Production indices } \\
\text { - Labor market } \\
\text { - Merchandise trade } \\
\text { - International reserves and foreign currency liquidity } \\
\text { - External debt } \\
\text { - International investment position } \\
\text { - Other }\end{array}$ & $\begin{array}{l}9 \\
8 \\
6 \\
10 \\
10 \\
6 \\
6 \\
9 \\
9 \\
9 \\
10 \\
2\end{array}$ \\
\hline \multicolumn{3}{|c|}{$20 . \quad$ Where do you obtain the official statistics? } \\
\hline & $\begin{array}{l}\text { a. Official press releases and publications on macroeconomic statistics } \\
\text { b. Private sector summaries and analyses } \\
\text { c. Official policy papers } \\
\text { d. Publications from international organizations about the country } \\
\text { e. Other sources }\end{array}$ & $\begin{array}{c}10 \\
5 \\
10 \\
10 \\
1\end{array}$ \\
\hline \multicolumn{3}{|c|}{$\begin{array}{l}21 . \\
\text { compile the official statistics? }\end{array}$} \\
\hline & $\begin{array}{ll} & \text { Yes } \\
- & \text { No } \\
\end{array}$ & $\begin{array}{l}7 \\
5\end{array}$ \\
\hline \multicolumn{3}{|c|}{ 4. $\quad$ For what purposes do you use the official statistics? } \\
\hline & $\begin{array}{l}\text { a. Analysis of current developments for short-term decision making } \\
\text { b. Analysis of trends for longer-term policy formulation? } \\
\text { c. Econometric model building and forecasting } \\
\text { d. Economic research } \\
\text { e. Comparison with economic developments in other countries } \\
\text { f. General economic background } \\
\text { g. Other }\end{array}$ & $\begin{array}{c}10 \\
10 \\
3 \\
6 \\
7 \\
11 \\
1\end{array}$ \\
\hline
\end{tabular}




\section{General Information about Uses of Official Macroeconomic Statistics of Tunisia}

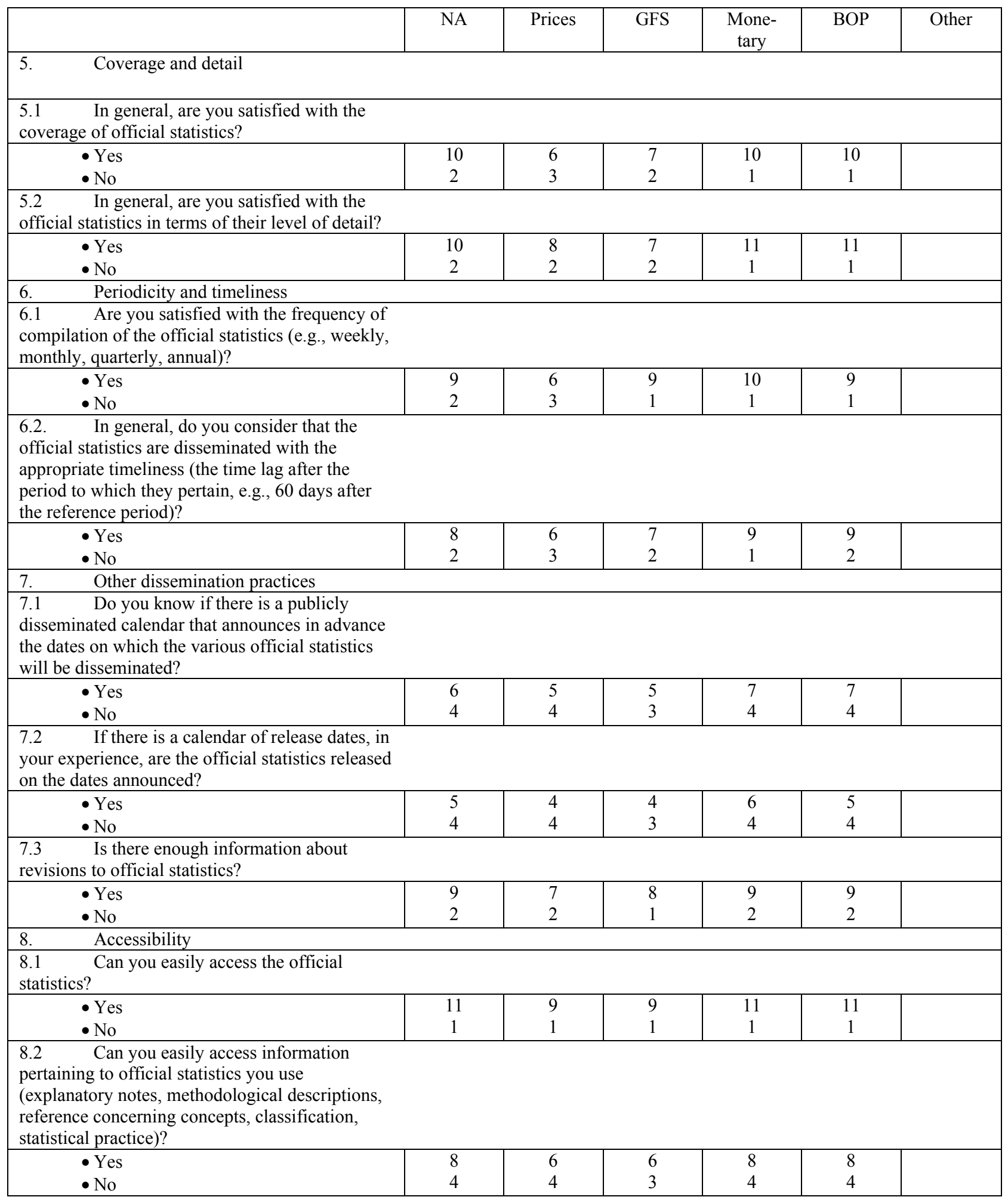




\section{General Information about Uses of Official Macroeconomic Statistics of Tunisia}

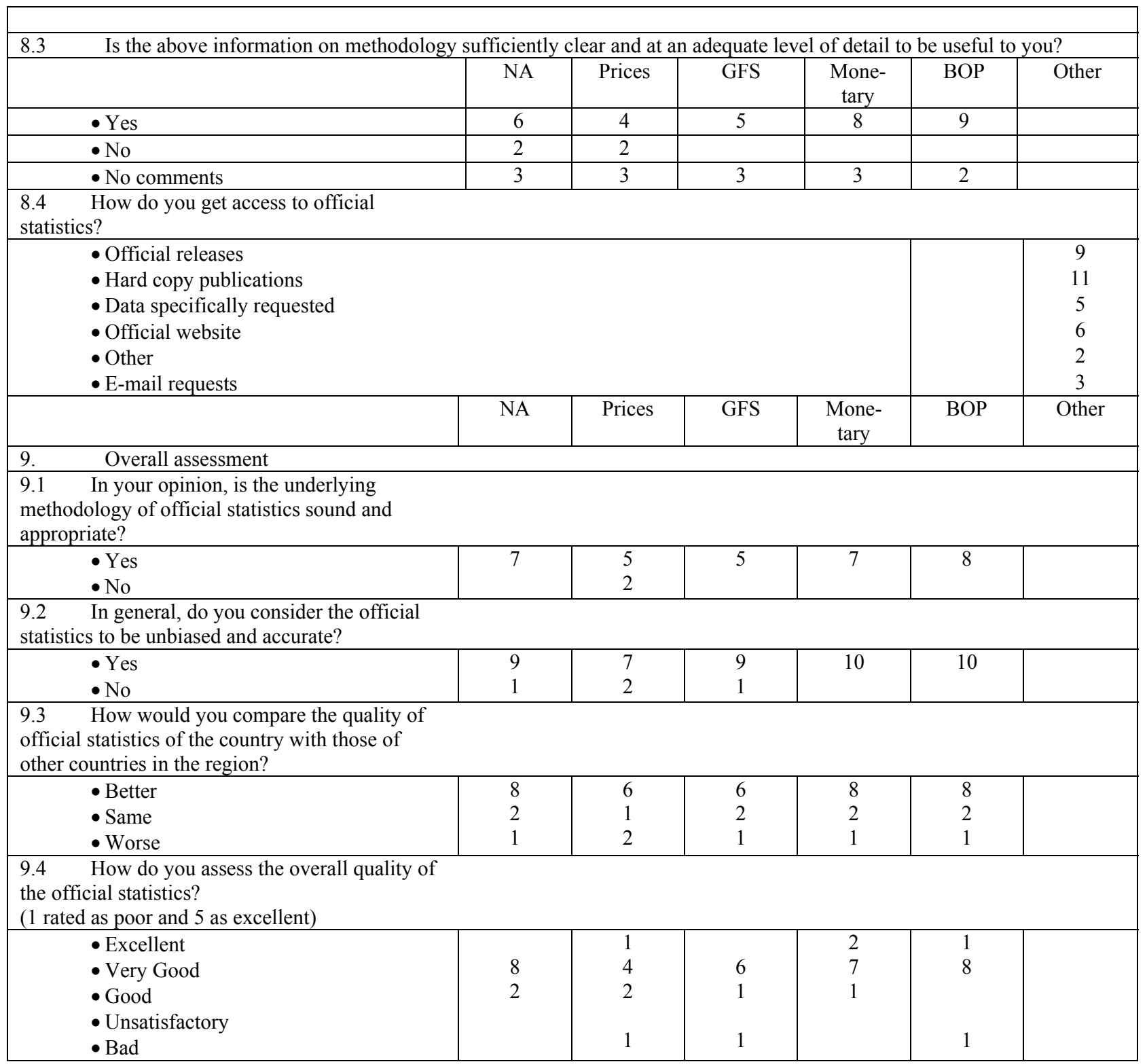

$\mathrm{NA}=$ National Accounts; Prices refers to: CPI (Consumer Price Index) and PPI (Producer Price Index);

GFS $=$ Government Finance Statistics; Monetary = Monetary Statistics; and BOP = Balance of Payments Statistics 